\title{
New South Wales \\ Child Health Survey 2001
}


Copyright (C) NSW Department of Health, September 2002

This work is copyright. It may be reproduced in whole or in part, subject to the inclusion of an acknowledgment of the source and no commercial usage or sale.

State Health Publication No: PH020105

ISSN 10347674

suggested citation:

Centre for Epidemiology and Research, NSW Department of Health. New South Wales

Child Health Survey 2001. N S W Public Health Bull 2002; 13(S-4).

produced by:

Centre for Epidemiology and Research

Public Health Division

NSW Department of Health

Locked Mail Bag 961

North Sydney NSW 2059 Australia

Tel: 61294245759

Fax: 61294245755

further copies of this publication can be obtained by contacting:

Better Health Centre Publication Warehouse

Locked Bag 5003

Gladesville NSW 2111 Australia

Tel: $\quad 61298160452$

Fax: 61298160492

or from the Public Health Division Web site at:

www.health.nsw.gov.au/public-health/phb/phb.html

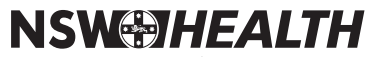

Working as a Team

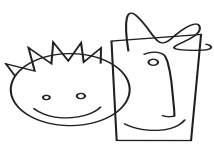

nsw commission for children \& young people 


\section{CONTENTS}

$\begin{array}{lr}\text { 1. FOREWORD } & 4\end{array}$

2. ACKNOWLEDGEMENTS

3. EXECUTIVE SUMMARY $\quad 6$

4. SNAPSHOT OF CHILD HEALTH, NSW, $2001 \quad 8$

$\begin{array}{ll}\text { 5. METHODS } & 9\end{array}$

Table 1: Outcomes of telephone numbers 9

Table 2: Completed interviews and response rate by area health service $\quad 10$

Table 3: Completed interviews by language $\quad 10$

Table 4: Completed interviews by proxy respondent 10

Table 5: Survey sample size and NSW population by age group and sex 11

Table 6: Socioeconomic distribution of survey sample using the SEIFA index of disadvantage 11

Map of NSW area health services 12

6. SOCIAL DETERMINANTS OF HEALTH 13

Family functioning $\quad 13$

Social support $\quad 13$

$\begin{array}{ll}\text { Social capital } & 14\end{array}$

Figure 1: Reciprocity and neighbourhood connections by urban-rural area health service of residence, parents or carers with children aged 0-12 years, NSW, 2001

Figure 2: Strongly agree or agree that the local area is safe, by urban-rural area health service of residence, parents or carers with children aged 0-12 years, NSW, 2001

Figure 3: Participation in the local community-very or somewhat active, by age group, parents or carers with children aged 0-12 years, NSW, 2001

$\begin{array}{ll}\text { Childhood activities } & 16\end{array}$

Attendance at childcare, preschool, or school 17

\begin{tabular}{ll}
7. & HEALTH BEHAVIOURS \\
\hline
\end{tabular}

$\begin{array}{ll}\text { Smoking in pregnancy } & 18\end{array}$

$\begin{array}{ll}\text { Smoking in the home } & 18\end{array}$

Parental views of child smoking $\quad 18$

$\begin{array}{lr}\text { Infant sleeping position } & 19\end{array}$

Figure 4: Position infant placed to sleep from birth by urban-rural area health service of residence, babies aged less than 12 months, NSW, 2001

Folate intake during pregnancy $\quad 20$

Figure 5: Folate tablets or capsules taken before or during pregnancy, mothers with babies less than 12 months of age, NSW, $2001 \quad 20$

Breastfeeding $\quad 21$

Figure 6: Duration of breastfeeding children aged less than two years, NSW, 2001 


\section{Food intake}

Figure 7: Usual daily consumption of fruit and vegetables by age group, children aged $2-12$ years, NSW, 2001

Table 7: Minimum recommended daily serves of fruit and vegetables needed to achieve a healthy diet for children

Figure 8: Usual consumption of milk, by age group, children aged 2-12 years, NSW, 2001

Figure 9: Consumption of selected foods by age group, children aged 2-12 years, NSW, 200125

\section{Food security and hunger}

Figure 10: Ever ran out of food in the last 12 months by area health service of residence, households with children aged $0-12$ years, NSW, 2001

Table 8: Ever ran out of food in the last 12 months by area health service of residence, households with children aged $0-12$ years, NSW, 2001

\section{Sun protection}

Figure 11: Use of hats, sunscreen and protective clothing last summer by age group, children aged $1-12$ years, NSW, 2001

\section{Water safety: drowning}

Figure 12: Places where child was rescued, children aged 0-12 years, who had ever been rescued from drowning, NSW, 2001

Physical activity and inactivity

Figure 13: Sports and activities played in the last 12 months by sex, children aged 5-12 years, NSW, 2001

Figure 14: Time spent playing computer games or watching television or videos, children aged 5-12 years, NSW, 2001

\section{HEALTH STATUS}

\section{Asthma}

Figure 15: Current asthma and written asthma management plan by area health service of residence, children aged 2-12 years, NSW, 2001

Table 9: Current asthma and written asthma management plan by area health service of residence, children aged 2-12 years, NSW, 2001

Oral health

Figure 16: Place of last dental visit, children aged 1-12 years, NSW, 2001

Figure 17: Type of dental treatment in the past 12 months, by age group, children aged 1-12 years, NSW, 2001

\section{Disability}

Figure 18: Prevalence and severity of speech difficulties by sex, children aged 2-12 years, NSW, 2001

\section{General health status-The Child Health Questionnaire}

Table 10: Child Health Questionnaire concepts and mean rating scores

\section{Emotional and behavioural problems}

Figure 19: Had emotional or behavioural problems in the last six months, by age and sex, children aged 4-12 years, NSW, 2001

Figure 20: Severity of emotional or behavioural problems in the last six months, by sex, children aged 4-12 years, who had emotional and behavioural problems, NSW, 2001 
Figure 21: Reason for not being able to get more help for emotional or behavioural problems, children aged 4-12 years, who needed professional help but did not get it, NSW, 2001

Infant feeding and behavioural problems

Physical health of toddlers

9. HEALTH SERVICES

Use of health services

Figure 22: Health services used in the last 12 months, by age group, children aged 1-12 years, NSW, 2001

Immunisation (vaccination)

Figure 23: Strongly or generally support immunisation program by area health service of residence, parents or carers with children aged two months to four years, NSW, 2001

Table 11: Strongly or generally support immunisation program by area health service of residence, parents or carers with children aged two months to four years, NSW, 2001

Visits to general practitioners

Personal health records: The 'blue book'

Figure 24: Current use of personal health record (the 'blue book') by age group, parents or carers with children aged $0-12$ years, NSW, 2001

Child and family health services (baby health centres or early childhood health services)

Figure 25: Ever used and current use of child and family health services, by area health service of residence, children aged 0-4 years, NSW, 2001

Table 12: Ever used and current use of child and family health services, by area health service of residence, children aged 0-4 years, NSW, 2001

Figure 26: Reason never or no longer attended child and family health services, children aged 0-4 years, NSW, 2001

Parental support services

Figure 27: Types of parental support services, parents or carers with children aged 1-12 years who used a support service, NSW, 2001

Figure 28: Reason did not access parental support service, parents or carers with children aged 1-12 years who had not used a support service when needed, NSW, 2001

Home visiting (health services received in the home)

10. CONCLUSION

11. APPENDIX : NEW SOUTH WALES CHILD HEALTH SURVEY 2001 


\section{FOREWORD}

The NSW health system and health workers play a key role in assisting children and families in their pursuit of healthy, well-adjusted lives. A range of health policies, services, and programs are aimed at promoting child health, addressing preventable child health problems, and achieving the best health outcomes for children in NSW.

I am pleased to present this report on the New South Wales Child Health Survey 2001, which provides the first ever snapshot of the health and wellbeing of children aged 0-12 years in NSW. It provides a wealth of appropriate and timely information to support planning, implementation, and evaluation of health services and programs targeting children and their families in NSW.

The Centre for Epidemiology and Research of the NSW Department of Health, in partnership with the 17 area health services and the NSW Commission for Children and Young People, conducted the New South Wales Child Health Survey 2001 using computer-assisted telephone interviewing (CATI). Parents and carers provided information about almost 9500 randomly-selected children aged from birth to 12 years of age. The survey was conducted between March 2001 and September 2001.

After describing the survey methods, this report presents information on the social determinants of health, including family functioning, social support, social capital, childhood activities and childcare, and preschool or school attendance. This is followed by a chapter on health behaviours, including smoking in pregnancy, smoking in the home, parental smoking messages, infant sleeping position, maternal folate, breastfeeding, nutrition, food security and hunger, sun protection, water safety, and physical activity and inactivity. Next there is a chapter on health status, including asthma, oral health, disability, general health status, emotional and behavioural problems, infant feeding and behavioural problems, and the physical health of toddlers. The final chapter covers health services, including services used, immunisation, visits to general practitioners, personal health records, child and family health services, parental support services, and home visiting (health services received in the home).

In developing the report, data were analysed by area health service, age, and sex, and only included in the final report if the sample size was large enough, the estimates were reliable, and the issue was of topical interest. This is a descriptive report, and there is a wealth of other information in the survey dataset that may be of specific interest. For these reasons, we encourage as many people as possible to access the dataset through the Health Outcomes Information Statistical Toolkit (HOIST), or by request, and produce more specific reports on topics of interest.

Parts of the New South Wales Child Health Survey 2001 have been incorporated into the ongoing NSW Health Survey Program. Interviewing is now conducted year-round in all NSW area health services. Further information can be obtained from the NSW Department of Health's Centre for Epidemiology and Research. Comments on the NSW Health Survey Program, and on this report, are welcome.

I thank all the individuals and organisations who contributed their time and expertise to assist in the development and conduct of the New South Wales Child Health Survey 2001, and to the preparation of this report.

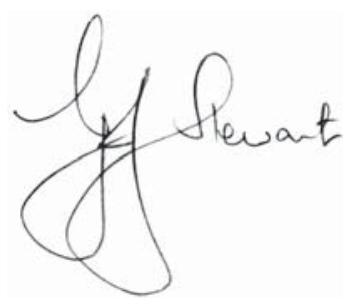

Greg Stewart

Deputy Director-General Public Health and Chief Health Officer

August 2002 


\section{ACKNOWLEDGEMENTS}

\section{Questionnaire development and coordination}

Julianne Quaine and the Child Health Survey Technical Expert Group

\section{Survey development and data collection}

Louisa Jorm, Margaret Williamson, Julianne Quaine, Deborah Baker, Kim Lim, Margo Eyeson-Annan, Matthew Gorringe, Lindy Latham, and the NSW Health Survey Program interviewers

\section{Report development and coordination}

Sharyn Lymer and Belinda O’Sullivan

\section{Data analysis and biostatistical advice}

Sharyn Lymer

\section{Programming infrastructure}

Jill Kaldor

\section{Text contributors}

Louisa Jorm, Margo Eyeson-Annan, Belinda O’Sullivan, Sharyn Lymer, Lindy Latham, and Matthew Gorringe

\section{Review of text}

Garth Alperstein, Mark Ferson, Tim Gill, Guy Marks, Rebecca Mitchell, Victor Nossar, Julianne Quaine, Chris Rissel, Peter Sainsbury, Shanti Sivaneswaren, Liz Story, Graham Vimpani, Margaret Williamson, and Karen Webb

\section{Editors}

Margo Eyeson-Annan, Louisa Jorm, Belinda O’Sullivan, and Michael Giffin

\section{Child Health Survey Technical Expert Group}

Louisa Jorm

Garth Alperstein

Guncha Ansari

Amanda Cook

Mark Ferson

Simon Fung

Julianne Quaine

Ruth Lawrence

Jason Grossman

Carol Kee

Jeannine Liddle

David Lillystone

Veena Macarty

Peter McIntyre

Victor Nossar

Titia Sprague

Janine Stennet

Lee Taylor

Graham Vimpani

Margaret Williamson

Caroline Wraith
NSW Department of Health (Chair)

Central Sydney Area Health Service

NSW Department of Health

Department of Community Services

South Eastern Sydney Area Health Service

NSW Department of Health

NSW Department of Health (Secretariat)

NSW Commission for Children and Young People

NSW Department of Health

Department of Health and Community Care (ACT)

Mid Western Area Health Service

Northern Sydney Area Health Service

Child and Family Health Nurses Association

New Children's Hospital

South Western Sydney Area Health Service

NSW Department of Health

Association for Welfare of Child Health

NSW Department of Health

Hunter Area Health Service

NSW Department of Health

NSW Department of Health 


\section{EXECUTIVE SUMMARY}

In 2001, the NSW Department of Health, in conjunction with the NSW area health services and the NSW Commission for Children and Young People, conducted a survey of the health of children, using computer-assisted telephone interviewing (CATI). The aim of the survey was to provide baseline data on the health and wellbeing of children aged $0-12$ years in NSW, to inform health policy and planning.

The survey content was developed by the Child Health Survey Technical Expert Group (CHSTEG) in consultation with area health services, other government departments, and a range of experts. The questionnaire was translated into Arabic, Chinese, and Vietnamese.

Interviews were carried out between March and September 2001. The target sample for the survey comprised 500 children from each of the 17 area health services. Households were sampled using list-assisted random digit dialling. One eligible child was randomly selected from each household and that child's main carer was interviewed. The overall response rate was 84.1 per cent. Most survey respondents ( 84.3 per cent) were mothers. Information was collected on a total of 9425 children.

\section{Social determinants of health}

The health and wellbeing of children is strongly influenced by social and family circumstances. To explore these determinants of health, the New South Wales Child Health Survey 2001 included measures of family functioning, social support, and social capital; and childhood activities and attendance at childcare, preschool, and school.

The survey showed that NSW families with children aged 0-12 years have high levels of healthy family functioning. Most parents reported that they had friends who make them feel safe, secure and happy; had people they could count on in an emergency; could get help from a neighbour to care for a child; and had attended a local community event in the past year.

Children aged 4-12 years were reported to participate in a wide range of activities including organised sport, bike riding, playing video games, and playing with toys. Approximately half of all children aged 0-5 years were reported to have attended childcare and most children over three years of age were currently attending preschool, other regular early childhood programs, or school.

\section{Health behaviours}

Health behaviours of parents and children are important not only because they shape health behaviours in later life but also because the beginnings of many chronic diseases occur before birth and in childhood. Health behaviours measured in the New South Wales Child
Health Survey 2001 included smoking during pregnancy, smoking in the home, infant sleeping position, maternal folate, breastfeeding, nutrition, food security and hunger, sun protection, water safety, and physical activity and inactivity.

One in seven mothers of babies aged less than 12 months reported smoking during pregnancy. Just under two-thirds reported placing their baby on its back to sleep, the preferred sleeping position for the prevention of Sudden Infant Death Syndrome (SIDS). Over half of all mothers were aware that taking additional folate prior to and during pregnancy reduced the risk of neural tube defects. Nearly ninety per cent of mothers of babies aged less than two years reported that their infant had been breastfed. However, almost 40 per cent of babies were breastfed for less than three months.

Almost all children aged 2-12 years were reported to consume the recommended daily minimum quantity of fruits (including fruit juice), but less than one in seven children were reported to consume the recommended daily minimum quantity of vegetables. Almost 90 per cent were reported to drink one or more cups of milk per day. Overall, six per cent of respondents reported that they had run out of food and could not afford to buy more, on at least one occasion, in the previous 12 months.

More than 90 per cent of children aged 5-12 years were reported to have participated in sports or outdoor activities in the last 12 months, and nearly 40 per cent were reported to watch an average of over two hours of television each day. When out in the sun for 15 minutes of more in the previous summer, more than 70 per cent of children aged 1-12 years were reported to have often or always used sunscreen, with similar proportions reporting wearing protective clothing.

Two-thirds of parents or carers of children aged 0-12 years reported that no one living in their household smoked and a further one-quarter reported that smokers living in the household usually or always smoked outside the house.

\section{Health status}

Although NSW children are generally healthy, physical, emotional, and behavioural problems can affect the ability of both children and their carers to participate in everyday activities and to enjoy life. The New South Wales Child Health Survey 2001 collected information about asthma, oral health, disability, emotional and behavioural problems, nutrition, and physical development.

Approximately one-quarter of parents or carers reported ever being told by a doctor or at a hospital that their child had asthma. Nearly 16 per cent of children were reported to have current asthma, and less than half of children with 
current asthma were reported to have a written asthma management plan from their doctor.

Just over half of all children aged 5-12 years were reported to have had a dental assessment at school as part of the Save Our Kids Smiles (SOKS) program in the last 12 months, and 43 per cent of children aged 1-12 years reported visiting a dental professional (excluding SOKS) in the last 12 months. More than 90 per cent of children aged 2-12 years were reported to have normal vision and more than 80 per cent were reported to have no speech difficulties, while one in 30 children was reported to have any form of hearing loss.

Overall, almost one-third of children aged 4-12 years were reported to have had any emotional or behavioural problems in the past six months. More than one-quarter of infants aged $0-1$ years were reported to have feeding problems (most commonly problems with breastfeeding and reflux) and one-third were reported to have a behavioural problem (most commonly with settling to sleep). Less than one in 10 toddlers aged $1-4$ years were reported to have problems with eating, feeding, mobility, or other aspects of physical development.

\section{Health services}

The New South Wales Child Health Survey 2001 collected information on use of health services, including immunisation, general practitioners, the use of personal health records, child and family health services, parental support services, and home visiting (health services received in the home).

More than 90 per cent of parents or carers of children aged 0-4 years reported they had attended child and family health services, but only 29 per cent were currently using these services. More than 90 per cent of parents or carers of children aged 0-12 years reported their child had a personal health record, with three-quarters of children aged 0-4 years and one-quarter of children aged 5-12 years currently using the personal health record (mainly to record immunisation and growth).

Just over two-thirds of parents or carers stated that they needed parental support services, but 19 per cent of these did not access such services. Just over one-third of parents or carers of children aged 0-4 years reported they had received a visit in their home from a nurse or volunteer to provide support or advice in caring for their child. 


\section{SNAPSHOT OF CHILD HEALTH, NSW, 2001}

\section{SNAPSHOT OF CHILD HEALTH, NSW, 2001}

\begin{tabular}{|c|c|c|c|}
\hline Topic & Issues & Indicator & Result (\%) \\
\hline \multicolumn{4}{|c|}{ Determinants of health } \\
\hline & Social support & $\begin{array}{l}\text { Parents or carers who reported having friends who make them feel } \\
\text { safe, secure and happy }\end{array}$ & 95.7 \\
\hline & Social capital & $\begin{array}{l}\text { Parents or carers who reported being able to get help from a } \\
\text { neighbour to care for a child }\end{array}$ & 68.3 \\
\hline & & Parents or carers who reported most people can be trusted & 61.6 \\
\hline & & $\begin{array}{l}\text { Parents or carers who reported they had helped out at any local } \\
\text { group or organisation }\end{array}$ & 40.4 \\
\hline & $\begin{array}{l}\text { Early childhood } \\
\text { programs }\end{array}$ & $\begin{array}{l}\text { Children aged } 4 \text { years reported to have been currently attending } \\
\text { preschool or other regular early childhood programs }\end{array}$ & 92.8 \\
\hline \multicolumn{4}{|c|}{ Health behaviours } \\
\hline & Smoking in pregnancy & Mothers who reported smoking in pregnancy & 14.2 \\
\hline & Smoking in the home & $\begin{array}{l}\text { Parents or carers who reported that no-one living in their } \\
\text { household smoked }\end{array}$ & 65.7 \\
\hline & Infant sleeping position & Parents or carers who reported placing baby on its back to sleep & 62.4 \\
\hline & Folate in pregnancy & $\begin{array}{l}\text { Mothers who reported awareness of reasons for taking folate in } \\
\text { pregnancy }\end{array}$ & 61.6 \\
\hline & Breastfeeding & Mothers who reported their infant had ever been breastfed & 89.8 \\
\hline & Food intake & $\begin{array}{l}\text { Children reported to consume the recommended quantity of fruits } \\
\text { (includes fruit juice) }\end{array}$ & 92.7 \\
\hline & & $\begin{array}{l}\text { Children reported to consume the recommended quantities of } \\
\text { vegetables }\end{array}$ & 12.9 \\
\hline & Sun exposure & $\begin{array}{l}\text { Children reported to have always used sunscreen when out in the } \\
\text { sun for fifteen minutes or more in the previous summer }\end{array}$ & 86.6 \\
\hline & & $\begin{array}{l}\text { Children reported to wear protective clothing when out in the sun } \\
\text { for fifteen minutes or more in the previous summer }\end{array}$ & 82.4 \\
\hline & Physical activity & Children reported to participate in sports or physical activities & 91.9 \\
\hline & Physical inactivity & $\begin{array}{l}\text { Children reported to watch an average of two or more hours } \\
\text { television per day }\end{array}$ & 39.5 \\
\hline \multicolumn{4}{|c|}{ Health status } \\
\hline & Asthma & Children reported to have current asthma & 15.7 \\
\hline & & $\begin{array}{l}\text { Children with current asthma who had a written asthma } \\
\text { management plan }\end{array}$ & 43.6 \\
\hline & Oral health & $\begin{array}{l}\text { Children reported to have visited a dental professional in last } 12 \\
\text { months (excluding SOKS assessment) }\end{array}$ & 43.1 \\
\hline & $\begin{array}{l}\text { Emotional or } \\
\text { behavioural problems } \\
\text { Infant feeding }\end{array}$ & $\begin{array}{l}\text { Children reported to have any emotional or behavioural problems } \\
\text { in the last six months }\end{array}$ & 31.4 \\
\hline & problems & Infants reported to have feeding problems & 28.0 \\
\hline & $\begin{array}{l}\text { Infant behavioural } \\
\text { problems }\end{array}$ & Infants reported to have behavioural problems & 35.1 \\
\hline & $\begin{array}{l}\text { Toddler eating or } \\
\text { feeding problems }\end{array}$ & Toddlers reported to have eating or feeding problems & 7.5 \\
\hline & $\begin{array}{l}\text { Toddler physical } \\
\text { developmental } \\
\text { problems }\end{array}$ & Toddlers reported to have physical developmental problems & 3.2 \\
\hline \multicolumn{4}{|c|}{ Health services } \\
\hline & $\begin{array}{l}\text { Personal health } \\
\text { record }\end{array}$ & Children reported to have a personal health record & 94.0 \\
\hline & $\begin{array}{l}\text { Attendance at child } \\
\text { and family health }\end{array}$ & $\begin{array}{l}\text { Parents or carers who reported ever attending child and family } \\
\text { health services }\end{array}$ & 92.1 \\
\hline & services & $\begin{array}{l}\text { Parents or carers who reported currently attending child and family } \\
\text { health services }\end{array}$ & 28.9 \\
\hline & $\begin{array}{l}\text { Parental support } \\
\text { services }\end{array}$ & $\begin{array}{l}\text { Parents or carers who reported they needed parental support } \\
\text { services }\end{array}$ & 68.6 \\
\hline & & $\begin{array}{l}\text { Parents or carers who reported they needed parental support } \\
\text { services but did not access them }\end{array}$ & 19.0 \\
\hline & Home visiting & Parents or carers who reported they had received a home visit & 36.3 \\
\hline
\end{tabular}




\section{METHODS}

In 2001, the NSW Department of Health, in conjunction with the 17 area health services and the NSW Commission for Children and Young People, conducted a survey of the health of children in NSW, using computer-assisted telephone interviewing (CATI). The main aim of the New South Wales Child Health Survey 2001 was to provide useful statewide and area health service (AHS) data on the health and wellbeing of children aged $0-12$ resident in NSW, for the purpose of monitoring child health and wellbeing, and for informing health policy and planning. The development of the survey and the methods used are described in detail in an accompanying report. ${ }^{1}$

\section{Survey instrument}

The survey instrument was developed by the Child Health Survey Technical Expert Group (CHSTEG), in consultation with area health services, relevant branches of the NSW Department of Health, and the NSW Health Survey Program Steering Committee (HSPSC). The CHSTEG was established in 1999, as an expert group on the technical aspects of measuring and reporting on child health and wellbeing. The CHSTEG consisted of community paediatricians, public health professionals, child and family health nurses, child health policy analysts, child mental health professionals, health promotion professionals, epidemiologists, and representatives of the NSW Department of Community Services and the Association for Welfare of Child Health (see Acknowledgements). The draft survey instrument was refined, following field-testing and piloting.

The final survey instrument included questions on:

- the social determinants of health, including family functioning, social support, and social capital; childhood activities and childcare, preschool, or school attendance;

- health behaviours, including smoking in pregnancy, smoking in the home, parental smoking messages, infant sleeping position, maternal folate, breastfeeding, nutrition, food security and hunger, sun protection, water safety, and physical activity and inactivity;
- health status, including asthma, oral health, disability, the Child Health Questionnaire (physical-emotionalbehavioural health and impact of family), ${ }^{1}$ emotional and behavioural problems, feeding and behavioural problems in infants, and physical health of toddlers;

- health services, including health services used, immunisation, visits to general practitioners, personal health records, child and family health and parental support services, and home visiting.

The survey instrument was translated into Arabic, Chinese, and Vietnamese, because of the higher proportion of Arabic, Chinese, and Vietnamese women aged 19-54 years, whose English language proficiency was categorised in the $1996 \mathrm{ABS}$ Census as poor or not able to speak English, The survey questionnaire is included as an appendix to this report.

\section{Survey sample}

The target population for the New South Wales Child Health Survey 2001 was NSW residents aged 0-12 years living in households with private telephones. The target sample comprised 500 children aged 0-12 years in each of the 17 area health services (total sample of 8500).

The sampling frame was developed as follows. Records from the Australia on Disk electronic White Pages were geo-coded using MapInfo mapping software., ${ }^{3,4}$ The geocoded telephone numbers were assigned to statistical local areas and area health services. The proportion of numbers for each telephone prefix by area health service was calculated. All prefixes were expanded with suffixes ranging from 0000 to 9999 . The resulting list was then matched back to the electronic White Pages. All numbers that matched numbers in the electronic White Pages were flagged and the number was assigned to the relevant geocoded area health service. Unlisted numbers were assigned to the area health service containing the greatest proportion of numbers with that prefix. Numbers were then filtered to eliminate contiguous unused blocks of greater than 10 numbers. The remaining numbers were then matched to the electronic Yellow Pages to eliminate business numbers. Finally, numbers were randomly sorted.

\section{TABLE 1}

\section{OUTCOMES OF TELEPHONE NUMBERS}

\begin{tabular}{|lr|}
\hline Outcome & Number \\
\hline No answer (10 call backs) or not connected & 56972 \\
Business telephone number or fax number & 21298 \\
No children aged 0-12 years in household & 42202 \\
Household not in NSW or a holiday house & 159 \\
Selected respondent away for duration of survey & 85 \\
Selected respondent confused or deaf & 87 \\
Selected respondent spoke other language not including those being translated & 463 \\
Refusal to participate & 1770 \\
Complete interview & 9425 \\
Total telephone numbers called & 132461 \\
\hline
\end{tabular}




\section{TABLE 2}

\section{COMPLETED INTERVIEWS AND RESPONSE RATE BY AREA HEALTH SERVICE}

\begin{tabular}{|lcc|}
\hline AHS & $\begin{array}{c}\text { Completed } \\
\text { interviews }\end{array}$ & $\begin{array}{c}\text { Response } \\
\text { Rate (per cent) }\end{array}$ \\
\hline Central Coast & 667 & 85.2 \\
Central Sydney & 521 & 80.5 \\
Far West & 622 & 86.1 \\
Greater Murray & 662 & 89.2 \\
Hunter & 508 & 85.8 \\
Illawarra & 509 & 84.0 \\
Macquarie & 514 & 88.5 \\
Mid North Coast & 516 & 87.0 \\
Mid Western & 513 & 86.4 \\
New England & 514 & 88.8 \\
Northern Rivers & 515 & 85.0 \\
Northern Sydney & 525 & 80.9 \\
South Eastern Sydney & 511 & 79.2 \\
Southern & 652 & 88.1 \\
South Western Sydney & 546 & 83.0 \\
Wentworth & 514 & 81.8 \\
Western Sydney & 616 & 83.8 \\
Total & 9425 & 84.2 \\
\hline Response rate $=$ completed interviews / completed \\
interviews + household refusals
\end{tabular}

\section{TABLE 3}

\section{COMPLETED INTERVIEWS BY LANGUAGE}

\begin{tabular}{|lcc|}
\hline Language of interview & Respondents & Per cent \\
\hline English & 9323 & 98.9 \\
Arabic & 27 & 0.3 \\
Chinese & 53 & 0.6 \\
Vietnamese & 22 & 0.2 \\
Total & 9425 & 100.0 \\
\hline
\end{tabular}

When households were contacted, one child aged 0-12 years was selected, using random numbers generated by the CATI system.

\section{Interviews}

Interviews were carried out between March and September 2001. Selected households that were in the electronic White Pages (giving an address for the number) were sent a letter describing the aims and methods of the survey approximately one week before initial telephone contact. A 1800 freecall contact number was provided.

Interviews were carried out by trained interviewers at the NSW Department of Health CATI facility. Up to seven calls were made to make initial contact with a household, and up to 10 calls were made in order to contact the selected respondent. The survey respondent was a parent or main carer of the selected child. Respondents were selected by requesting to speak to 'the person who knows the most about [the child's name's] health'.

\section{Call outcomes and response rates}

During the survey, a total of 132461 telephone numbers were called. The outcome for each of these telephone numbers is shown in Table 1. Only 11830 (8.9\%) of the numbers called yielded an eligible household. The majority of numbers called belonged to households that reported having no children aged $0-12$ years and households where the phone was not answered with 10 call-backs or disconnected. The overall response rate was $84.1 \%$ (completed interviews divided by completed interviews and refusals). The total sample was 9425 children.

Response rates varied by area health service (Table 2) from 79.2 per cent in South Eastern Sydney to 89.2 per cent in Greater Murray. Most respondents (98.9 per cent) were interviewed in English (Table 3). The remaining interviews were conducted in Arabic, Chinese, or Vietnamese. Most survey respondents ( 84.3 per cent) were mothers, followed by fathers (13.9 per cent) (Table 4$)$.

\section{Data analysis}

For analysis, the survey sample was weighted to adjust for differences in the probabilities of selection among subjects, according to the number of eligible children in the household, and the number of residential telephone connections for the household. Post-stratification weights were used to reduce the effect on survey estimates of differing rates of non-response among males and females and children of different ages. These weights used oneyear age groups and Australian Bureau of Statistics mid-year population estimates adjusted to exclude children resident in institutions.

Call and interview data were manipulated and analysed using SAS version 8.02. The SURVEYMEANS procedure was used to calculate standard errors that took into account the stratified sample design. This procedure uses the Taylor expansion method to estimate sampling errors of estimators based on the stratified random sample. ${ }^{5}$

\section{TABLE 4}

\section{COMPLETED INTERVIEWS BY PROXY RESPONDENT}

\begin{tabular}{|lrc|}
\hline Relationship to child & Number & Per cent \\
\hline Mother & 7909 & 84.3 \\
Father & 1321 & 13.9 \\
Stepmother & 22 & 0.2 \\
Stepfather & 17 & 0.2 \\
Grandmother & 80 & 0.7 \\
Grandfather & 9 & 0.1 \\
Legal guardian-Foster parent & 42 & 0.4 \\
Other & 25 & 0.2 \\
Total & 9425 & 100.0 \\
\hline
\end{tabular}




\section{TABLE 5}

SURVEY SAMPLE SIZE AND NSW POPULATION BY AGE GROUP AND SEX

\begin{tabular}{|c|c|c|c|c|c|c|}
\hline \multirow[t]{2}{*}{ Age group (years) } & \multicolumn{3}{|c|}{ Survey sample (unweighted) } & \multicolumn{3}{|c|}{ NSW Population, June 2000} \\
\hline & Males $n(\%)$ & Females $n(\%)$ & Persons $n(\%)$ & Males $N(\%)$ & Females $N(\%)$ & Persons $N(\%)$ \\
\hline $0-4$ & $1814(19.2)$ & $1724(18.3)$ & $3538(37.5)$ & $220936(19.3)$ & $210256(18.4)$ & $431192(37.8)$ \\
\hline $5-7$ & $976(10.4)$ & $1024(10.9)$ & $2000(21.2)$ & $136390(11.9)$ & $129881(11.4)$ & 266271 (23.3) \\
\hline $8-12$ & $1968(20.9)$ & $1919(20.4)$ & 3887 (41.2) & $227968(20.0)$ & $216525(19.0)$ & 444493 (38.9) \\
\hline Total & $4758(50.5)$ & 4667 (49.5) & $9425(100)$ & 585294 (51.3) & $556662(48.7)$ & $1141956(100)$ \\
\hline
\end{tabular}

Source: NSW Child Health Survey 2001 and ABS Estimated Resident Population 2000, excluding people resident in institutions (HOIST)

\section{TABLE 6}

\section{SOCIOECONOMIC DISTRIBUTION OF SURVEY SAMPLE (WEIGHTED) USING THE SEIFA INDEX OF DISADVANTAGE}

\begin{tabular}{|c|c|c|c|c|}
\hline SEIFA & Per cent Population & $\begin{array}{l}\text { Per cent Sample } \\
\text { (weighted) }\end{array}$ & $\begin{array}{l}\text { Lower limit } 95 \% \\
\text { confidence interval } \\
\text { for sample }\end{array}$ & $\begin{array}{c}\text { Upper limit } 95 \% \\
\text { confidence interval } \\
\text { for sample }\end{array}$ \\
\hline Least disadvantaged 1 st quintile & 19.7 & 18.1 & 17.1 & 19.1 \\
\hline 2nd quintile & 19.9 & 24.0 & 22.8 & 25.2 \\
\hline 3rd quintile & 20.4 & 18.8 & 17.8 & 19.8 \\
\hline 4th quintile & 20.1 & 18.3 & 17.4 & 19.3 \\
\hline Most disadvantaged 5th quintile & 19.9 & 20.7 & 19.7 & 21.7 \\
\hline
\end{tabular}

\section{Survival analysis}

The LIFETEST procedure in SAS version 8.02 was used to perform survival analysis on breastfeeding data. ${ }^{5}$ Survival analysis models data that specifies a time between an initial event and a terminating event. The length of time babies received any breastfeeding and full breastfeeding were modelled. The initial event was the commencement of breastfeeding.

The time babies were 'fully breastfed' was determined from the date breastfeeding started (initial event) to the introduction of either solids or a milk substitute, or the date of survey (terminating event). For 'any breastfeeding', the terminating event was the cessation of breastfeeding or the date of survey.

The survival analysis calculated non-parametric estimates of the survival distribution function using the Kaplan-Meier method. The procedure calculated proportions at time intervals, allowing for the weighting of the dataset.

\section{Representativeness of the sample}

Female children were slightly over-represented in the survey sample, comprising 49.5 per cent of the unweighted sample, compared with 48.7 per cent of the population. Conversely, males were under-represented, making up 50.5 per cent of the unweighted sample, compared with 51.3 per cent of the population. Among both sexes, children aged 5-7 years were under-represented in the sample, while children aged 8-12 years were over-represented. After weighting, the age and sex distribution of the survey sample reflected that of the population. Indigenous children comprised 3.8 per cent of the weighted survey sample, similar to their representation in the population ( 3.7 per cent). Children born in Australia were slightly over-represented in the weighted survey sample (96.3 per cent compared with 93.8 per cent in the population).

Compared with the 1996 ABS Census, using the SEIFA index of relative socioeconomic disadvantage, ${ }^{6}$ the survey sample had a slight under-representation of the first (least disadvantaged), third, and fourth quintiles. This coincided with slight over-representation of the second (least disadvantaged) quintile (Table 6).

\section{References}

1. Landgraf JM, Abetz L, Ware JE. The Child Health Questionnaire (CHQ) User's Manual. First Edition. Boston, Mass: The Health Institute, New England Medical Centre, 1996.

2. Quaine J, Eyeson-Annan M, Baker D, O'Sullivan B, Williamson $\mathrm{M}$ and Jorm L. Report on the development of the NSW Child Health Survey 2002. Sydney: Centre for Epidemiology and Research, NSW Department of Health, 2002 (unpublished).

3. Australia on Disk [software]. Sydney: Australia on Disk, November 2000.

4. MapInfo [software]. Troy, NY: MapInfo Corporation, 1997.

5. SAS Institute. The SAS system for Windows version 8.02. Cary NC: SAS Institute Inc., 2001.

6. Australian Bureau of Statistics. Information Paper: 1996 Census-Socioeconomic indices for areas. Canberra: ABS, 1998. ABS Catalogue no. 29120, 1998. 
MAP OF NSW AREA HEALTH SERVICES

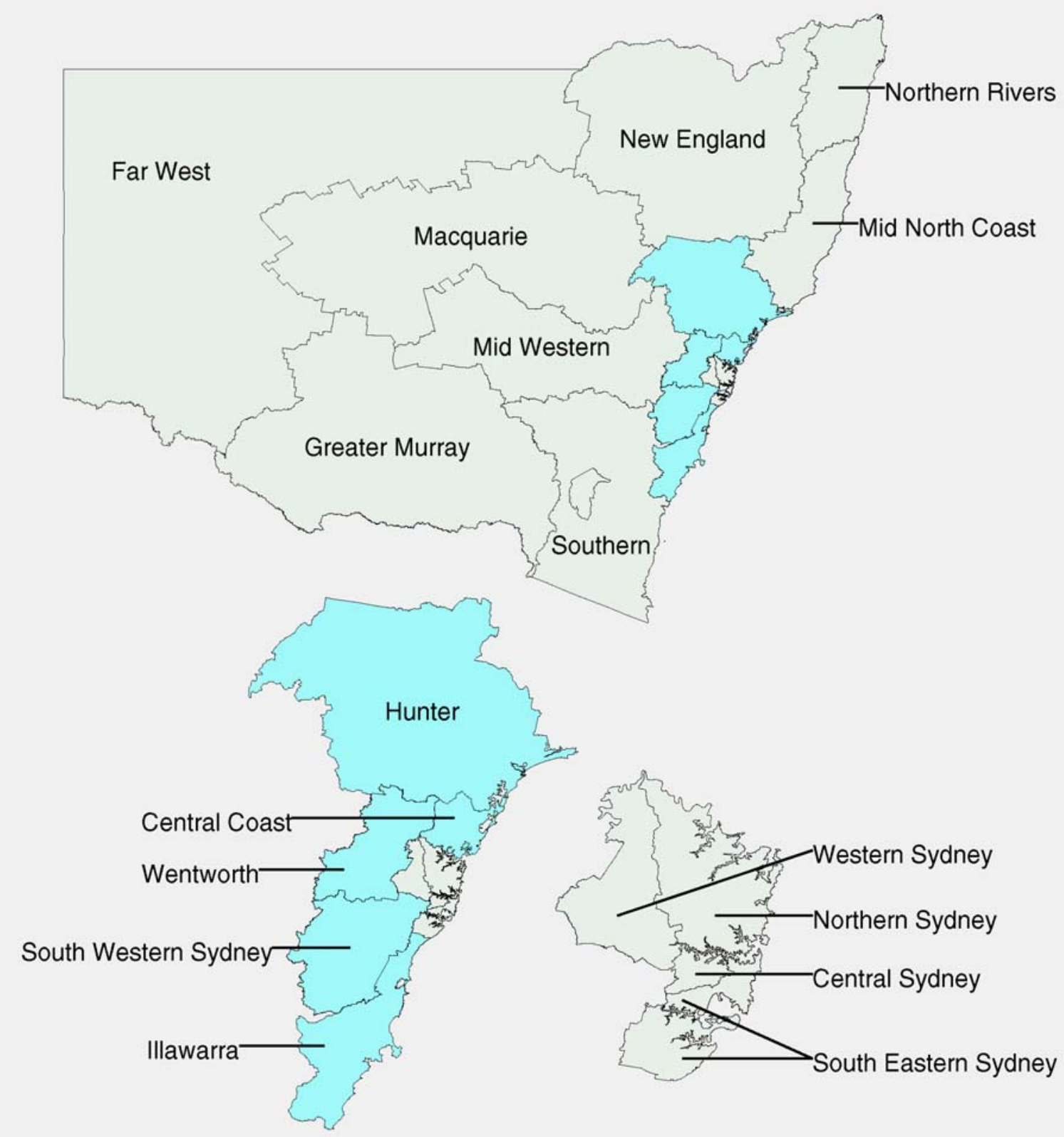




\section{SOCIAL DETERMINANTS OF HEALTH}

The context in which children live their lives, including the family, school, and community environments-and the interactions among these-is crucial to their health and wellbeing. In order to examine some of the social determinants of child health, the New South Wales Child Health Survey 2001 asked parents or carers of children to report on family functioning; access to social support; social capital; attendance at childcare, preschool, or school; and other childhood activities outside of these environments.

\section{Family Functioning}

The ability of a family to function well affects the health and wellbeing of children within the family. Family functioning affects many aspects of family life, including acceptance of individuals, degree of consensus on decisions, communication, and the ability to solve day-today problems. ${ }^{1}$ How a family functions is influenced by many factors, including quality of relationships; the health of family members; and the presence of life stresses, work, and finance. The enhancement of family and social functioning is a national and state priority for children. ${ }^{2,3}$

In the New South Wales Child Health Survey 2001, parents or carers of children aged 0-12 years were asked 14 questions from the McMaster Family Assessment Device, a questionnaire about family functioning that was used in the Western Australian Child Health Survey 1993. ${ }^{1}$ The tool generates a score between one and four, with one reflecting healthy functioning and four reflecting unhealthy functioning. ${ }^{4}$ Unhealthy family function relates to avoiding discussing concerns or fears, having lots of bad feelings within the family, not being able to turn to each other for support or to confide in each other, not being able to talk about sadness or express feelings to each other, difficulty in making decisions, not accepting family members as they are, and difficulty planning family activities. ${ }^{4}$

The median score for family functioning was 1.65, which reflects high levels of healthy family functioning overall. Families experiencing healthier family functioning than the median for the population included those where the mother had tertiary level qualifications (1.58), where all children in the family were under five years (1.58), and where the family was in the least socially-disadvantaged quintile by SEIFA index of postcode (1.59).

\section{References}

1. Zubrick SR, Silburn SR, Garton A, Burton P, Dalby R, Carlton J, et al. Western Australian Child Health Survey 1993-Developing health and wellbeing into the nineties. Perth: Western Australia Australian Bureau of Statistics and the Institute for Child Health Research, 1995.

2. Child, Adolescent and Family Health Service. Health Goals and Targets for Australian Children and Youth. Canberra: Child, Adolescent and Family Health Service and Department of Human Services and Health, 1992.
3. NSW Department of Health. The Start of Good HealthImproving the health of children in NSW. Sydney: NSW Department of Health, 1999.

4. Epstein NB, Baldwin LM, Bishop DS. The McMaster Family Assessment Device. Journal of Marital and Family Therapy1983; 9: 171-180.

\section{Social Support}

Social support includes support with parenting, feeling there are other people with which to share problems, and feeling close with another person. Social support is particularly relevant to disadvantaged parents or carers; and to those with physical problems or with mental health problems such as postnatal depression. Social support is known to affect a range of health and social outcomes for children, including rates of child injury in families with disadvantaged mothers. ${ }^{1}$ Olds et al. found that, for unmarried mothers on low income, frequent and targeted home visits (health services received in the home) by prenatal and early childhood nurses reduced the number of subsequent pregnancies; the use of welfare services; and the problems of child abuse and neglect, which are associated with the use of drugs and alcohol and criminal behaviour. ${ }^{2}$ Families First is a NSW Government policy that supports universal visiting by volunteers and health professionals, to increase social support for parents. ${ }^{3}$

In the New South Wales Child Health Survey 2001, parents or carers of children aged 0-12 years answered six questions about their relationships and support from others. These questions were previously used in the National Longitudinal Survey of Children in Canada. ${ }^{4}$

Five per cent of parents or carers reported that they would not have anyone to help them if something went wrong; 6.8 per cent reported there is no-one they feel comfortable with talking about problems; and 11.1 per cent reported they lack a feeling of closeness with another person. Parents or carers in urban areas reported higher levels of lack of social support. In urban areas, 5.2 per cent reported there was no one to help them if something went wrong compared iwth 4.5 per cent in rural areas; 7.0 per cent (urban) versus 6.1 per cent (rural) reported there was noone they feel comfortable with talking about problems; and 11.4 per cent (urban) versus 10.2 per cent (rural) reported that they lacked a feeling of closeness with another person.

Most parents or carers (95.7 per cent) reported that they had friends who make them feel safe secure and happy; 96.6 per cent reported there was someone they could trust and to whom they could turn for advice if they were having problems; and 96.9 per cent reported there were people they could count on in an emergency.

\section{References}

1. Hodnett ED, Roberts I. Home-based social support for socially disadvantaged mothers. Cochrane Database Syst Rev. 2000(2): CD000107. 


\section{FIGURE 1}

\section{RECIPROCITY AND NEIGHBOURHOOD CONNECTIONS BY URBAN-RURAL AREA HEALTH SERVICE OF RESIDENCE, PARENTS OR CARERS WITH CHILDREN AGED 0-12 YEARS, NSW, 2001}
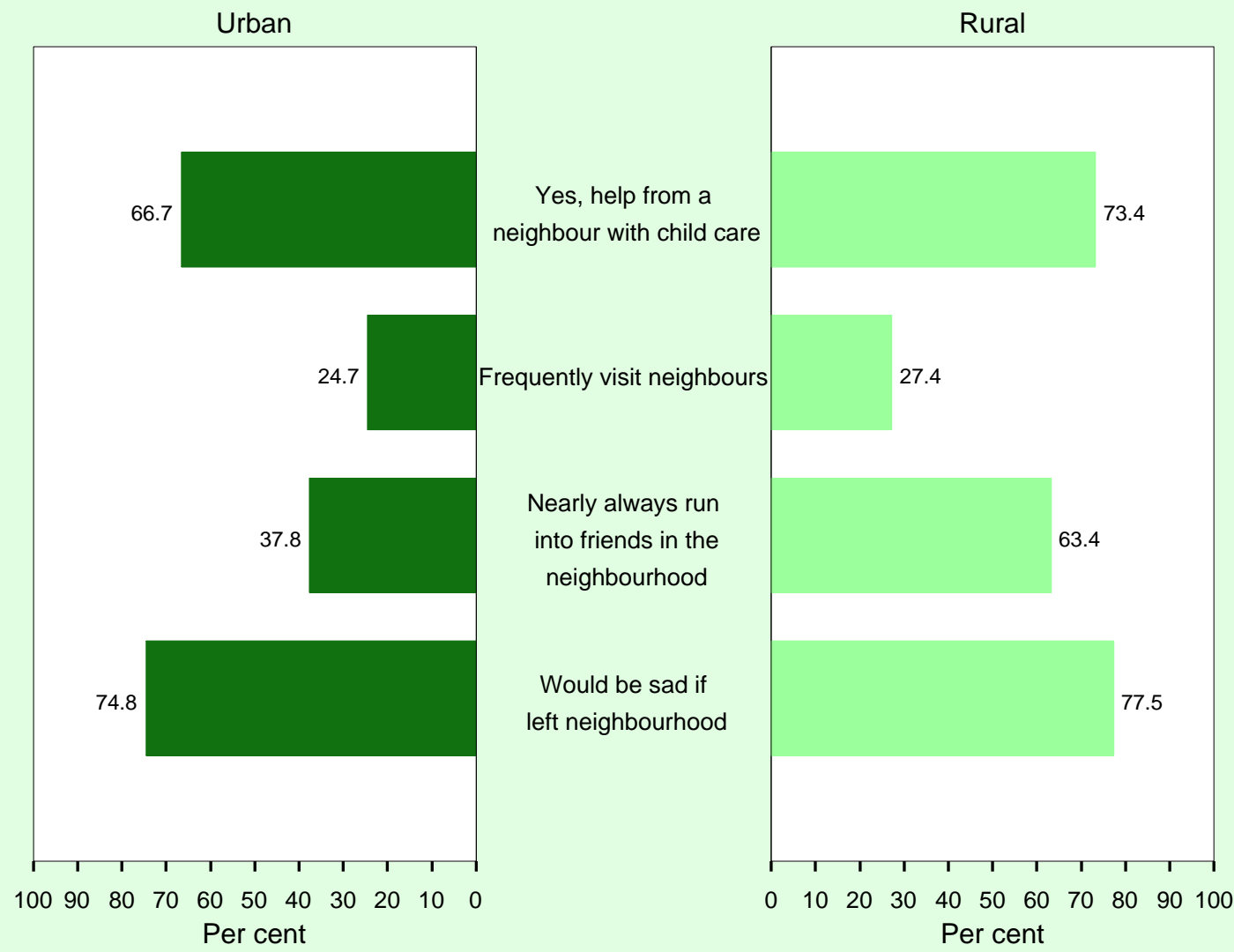

Note: Health areas in Greater Sydney, Hunter, and Illawarra were classified as urban. Estimates based on 9425 respondents.

Source: New South Wales Child Health Survey 2001 (HOIST). Centre for Epidemiology and Research, NSW Department of Health.

2. Olds DL, Eckenrode J, Henderson CR, et al. Long term effects of home visitation on life course and child abuse and neglect: Fifteen year follow up of a randomized trial. JAMA 1997; 78: 637-643.

3. The Families First Resource Kit. Sydney: NSW Cabinet Office, 2000 Web site www.parenting.nsw.gov.au, accessed 24 April 2002.

4. Child Support Team. National Longitudinal Survey of Children, Child Support. Ottawa: Canadian Department of Justice, 1993.

\section{Social Capital}

The term 'social capital' refers to the institutions, relationships, and norms, that shape social networks, foster trust, and facilitate coordination and cooperation for mutual benefit. ${ }^{1}$ A key concept of social capital is the notion of interlocking networks of relationships between individuals and groups.

In the New South Wales Child Health Survey 2001, all parents and carers were asked questions that relate to aspects of social capital. The questions were limited to the domains of reciprocity, neighbourhood connection, safety, trust, and community participation, which are consistent with those used in a recent study that compared five communities in NSW. ${ }^{2}$ One new question was included-whether the respondent would be sad if they had to leave their neighbourhood.

\section{Social reciprocity and neighbourhood connection}

Social reciprocity and neighbourhood connection are defined as a combination of short-term altruism and longterm self interest - where people help each other or act for the benefit of other people at a personal cost, with the general expectation that this help will be returned in the future when they might need help themselves. ${ }^{2}$

Parents or carers of children aged 0-12 years were asked three questions regarding reciprocity and neighbourhood connections. Approximately two-thirds (68.3 per cent) responded that they could get help from a neighbour to care for a child, approximately one-quarter ( 25.3 per cent) said they frequently visited neighbours, nearly half (43.9 per cent) responded that they nearly always run into friends in the neighbourhood, and approximately three- 


\section{FIGURE 2}

STRONGLY AGREE OR AGREE THAT THE LOCAL AREA IS SAFE, BY URBAN-RURAL AREA HEALTH SERVICE OF RESIDENCE, PARENTS OR CARERS WITH CHILDREN AGED 0-12 YEARS, NSW, 2001
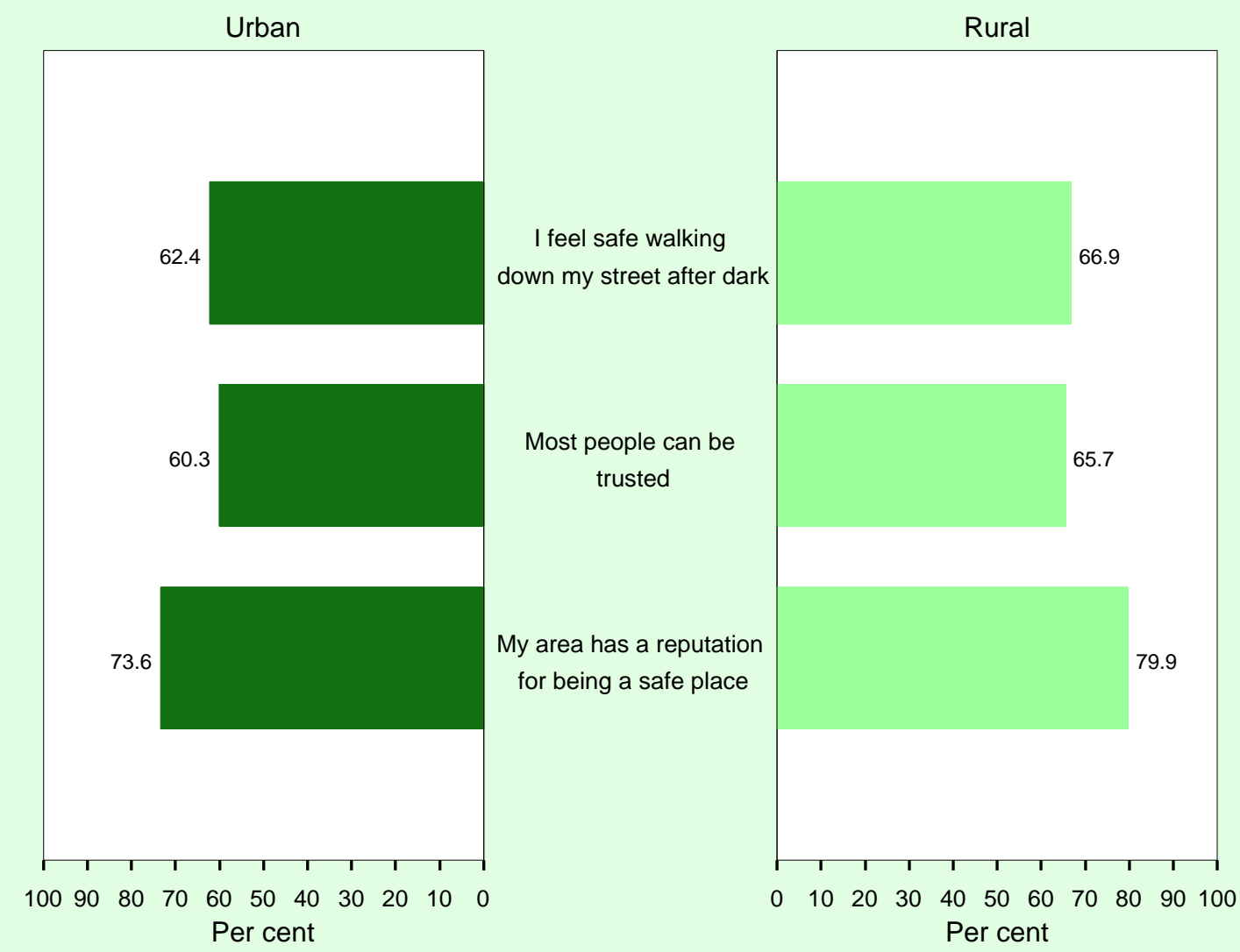

Note: Health areas in Greater Sydney, Hunter, and Illawarra were classified as urban. Estimates based on 9425 respondents.

Source: New South Wales Child Health Survey 2001 (HOIST). Centre for Epidemiology and Research, NSW Department of Health.

quarters (73.5 per cent) reported that they would be sad if they left their neighbourhood. Respondents in rural areas reported more reciprocity and neighbourhood connection, compared with urban areas; the main difference being the frequency of respondents who nearly always ran into friends in the neighbourhood-63.4 per cent in rural areas compared with 37.8 per cent in urban areas (Figure 1).

\section{Feelings of trust and safety}

Trust involves a willingness to take risks in a social context. This willingness is based on a confidence that others will respond as expected and will act in mutually supportive ways-or at least that others will not intend harm.

Parents or carers of children aged 0-12 years were asked three questions regarding trust and safety. Approximately two-thirds (63.5 per cent) of respondents reported that they felt safe walking down the street after dark, 61.6 per cent reported that most people can be trusted, and threequarters (75.1 per cent) reported that their area has a reputation for being safe. A higher proportion of respondents from rural areas, compared with urban areas, reported feeling safe and trusting of others, with the most difference shown for the response to the statement that their area has a reputation for being a safe place-79.9 per cent in rural areas compared with 73.6 per cent in urban areas (Figure 2).

\section{Participation in local community}

Social capital is not generated by individuals acting on their own; it is generated by people in communities engaging with others through a variety of associations that are both voluntary and equitable. Participation in the local community depends on a tendency among people to be social and to form new associations and networks.

Parents or carers of children aged 0-12 years were asked three questions regarding participation in the local community. Forty (40.4) per cent reported they had 'helped out' at a local group or organisation; 68.2 per cent reported they had attended a local community event; and 40.0 per 


\section{FIGURE 3}

\section{PARTICIPATION INTHE LOCAL COMMUNITY_VERY OR SOMEWHAT ACTIVE, BY AGE GROUP, PARENTS OR CARERS WITH CHILDREN AGED 0-12 YEARS, NSW, 2001}
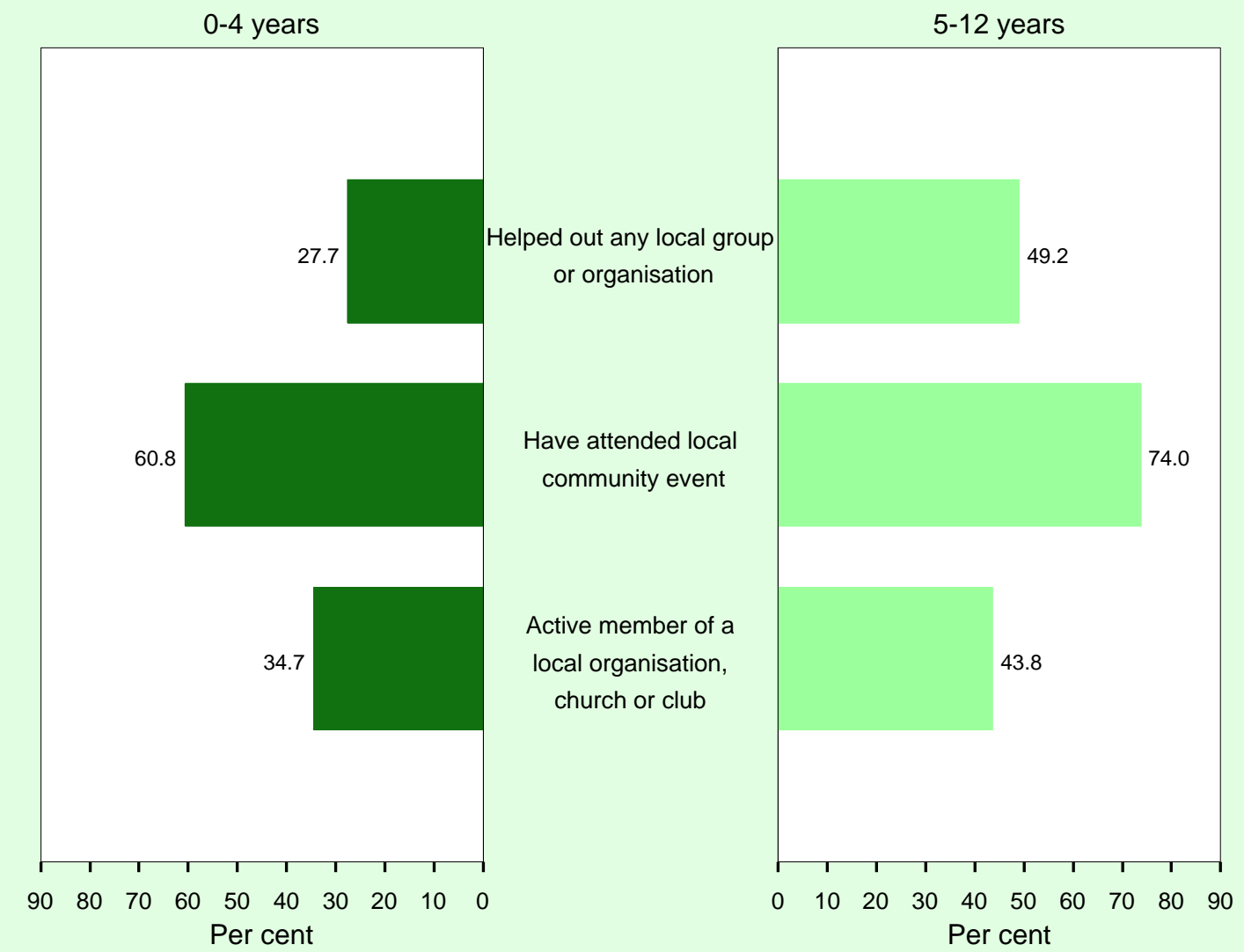

Note: Estimates based on 9425 respondents.

Source: New South Wales Child Health Survey 2001 (HOIST). Centre for Epidemiology and Research, NSW Department of Health.

cent reported they were active members of local organisations, churches, or clubs. Respondents with children aged 5-12 years, and respondents from rural areas, reported higher rates of participation in the local community. The greatest difference was in helping a local group or organisation-49.2 per cent for parents or carers of children aged 5-12 years, compared with 27.7 per cent for children aged 0-4 years (Figure 3 ); and 45.8 per cent for rural areas compared with 38.6 per cent for urban areas.

\section{References}

1. The World Bank Web Site at www.worldbank.org/poverty/ capital/whatsc.htm accessed 19 July 2002.

2. Onyx J, Bullen P. Measuring Social Capital in Five Communities in NSW: An analysis. Sydney: Centre for Australian Community Organisations and Management, 1997.

\section{Childhood activities}

On a daily basis, children are involved in different arenas that affect their physical, emotional, and social wellbeing including school, family, and extracurricular activities. Schools teach children skills such as reading, writing, and teamwork, which they need to participate in community life. Family is the first place children learn about sharing and cooperation. For children, extracurricular activities-provided through clubs, sporting teams, and informal groups of friends-are a major source of social capital. Children pursue common goals, and obtain a feeling of solidarity and commitment with their peers, through their involvement in these activities. ${ }^{1}$

In the New South Wales Child Health Survey 2001, parents or carers of children aged 4-12 years were asked two questions about children's extracurricular activities, including their child's favourite activities and places where their child plays when not at childcare, preschool, or school. 
Favourite activities when not at childcare, preschool, or school

Parents and carers reported that the most common favourite activities among children were organised sport (16.6 per cent), computer and video games (10.3 per cent), bike riding (8.8 per cent), playing with toys at home (8.7 per cent), and drawing and colouring-in (6.9 per cent). Among males, the most commonly reported favourite activities were: organised sport (22.5 per cent), computer and video games (16.3 per cent), bike riding (12.0 per cent), playing at home with toys (8.1 per cent), and informal sport (7.9 per cent). In contrast, the most frequently reported favourite activities among females were: drawing and colouring-in (11.2 per cent), organised sport (10.5 per cent), playing with toys at home ( 9.4 per cent), dancing (8.1 per cent), and reading ( 7.7 per cent). The most commonly reported favourite activities of children aged 4-7 years were: playing with toys at home (14.3 per cent), drawing and colouring-in (12.0 per cent), bike riding (11.1 per cent), playing outside (9.1 per cent) and organised sport (8.1 per cent). The most frequently reported favourite activities of children aged 8-12 years were: organised sport (22.6 per cent), computer and video games (12.8 per cent), bike riding (6.9 per cent), reading (6.7 per cent), and informal sport (6.2 per cent).

\section{Places where children play when not at childcare, preschool, or school}

The most frequently reported locations where children were reported to play were: in the back yard of their home (68.8 per cent), inside the house (57.5 per cent), in the park (29.0 per cent), at the home of a friend or relative ( 23.7 per cent), at the home of a neighbour (21.8 per cent), and in the street (10.6 per cent). Children aged 8-12 years were almost twice as likely to play in the street, compared with children aged 4-7 years (13.1 per cent versus 7.4 per cent). Females more frequently played inside the house (61.4 per cent) and at friends or relatives (25.9 per cent), compared to males who more frequently played in the backyard (68.8 per cent) and in the park (32.8 per cent).

\section{Reference}

1. Goss K. Better Together: Report of the Saguaro Seminar on Civic Engagement in America, Cambridge, Mass: John F. Kennedy School of Government, Harvard University, 2000. Web site: www.bettertogether.org, accessed 3 May 2002.

\section{Attendance at childcare, preschool, or school}

The link between health and education has been widely reported. Participation in appropriate early care and educational settings has been associated with enhanced cognitive and language development-and with emerging literacy.

Education about and awareness of health issues is also known to contribute to children's health. In addition, health status is a major determinant of educational achievement; children in good health are more likely to achieve higher educational goals. ${ }^{1}$

\section{Attendance at childcare}

In the New South Wales Child Health Survey 2001, parents and carers of children aged 0-5 years were asked about childcare attendance on a regular basis. 'Childcare' was defined as formal (that is, long day care or family day care) or informal (that is, care by relatives, friends, paid babysitters, or nannies). 'Regular basis' was considered to be childcare for at least half-a-day per week. Approximately half (52.6 per cent) of all children aged $0-5$ years were reported to have attended childcare, with 43.0 per cent currently attending childcare. Of the children currently attending childcare, 19.8 per cent had started childcare when they were less than six months of age, 46.4 per cent had started childcare by one year of age, and 73.4 per cent had started childcare by the age of two years. The main types of childcare used by families were: long day care (37.7 per cent); grandparents (30.4 per cent); family day care (15.6 per cent), and other relatives or family (9.5 per cent). Compared with mothers with no tertiary qualifications, mothers who had tertiary qualifications were more likely to report higher use of childcare in the past (62.8 per cent compared with 48.3 per cent) and higher current use of childcare (53.5 per cent compared with 38.5 per cent).

\section{Attendance at preschool and school}

Parents and carers of children aged 3-6 years reported preschool attendance and parents and carers of children aged 4-12 years reported school attendance. Preschool was defined as a place being attended between 9.00 a.m. and 3.00 p.m. at least once per week before the child starts full-time school. Overall, 53.0 per cent of children aged three years were currently attending preschool, 72.7 per cent of children aged four years and 17.0 per cent of children aged five years were currently attending preschool. The majority of children not attending preschool were either attending childcare (20.2 per cent of children aged three years, 11.7 per cent of children aged four years and 0.05 per cent of children aged five years) or attending school (8.4 per cent of children aged four years and 80.0 per cent of children aged five years). Ninety-nine per cent of children aged 6-12 years were currently attending school. Of the children currently attending school, 69.0 per cent were attending public schools, 19.9 per cent were attending Catholic schools, and 10.2 per cent were attending other private schools.

\section{Reference}

1. National Health and Medical Research Council. Effective school health promotion: Towards health promoting schools. Canberra: NHMRC, 1996. 


\section{HEALTH BEHAVIOURS}

Health behaviours represent an important range of factors that influence child health and wellbeing, from the antenatal period and beyond. Parental health behaviours - such as maternal smoking and diet-can directly influence children in the early years. Along with the school and social environments, parenting styles, parental messages, early childcare, and education in early childhood, all have an influence on child health behaviours as children grow up. Health behaviours in childhood affect health in later life, because behaviours in childhood influence behaviours in adulthood, and because the beginnings of many chronic diseases actually occur in childhood.

\section{Smoking in pregnancy}

Smoking in pregnancy is one of the most important risk factors associated with adverse perinatal outcomes. It is associated with complications such as placenta previa and abruptio placentae, spontaneous abortion, premature rupture of the membranes, pre-term birth, low birthweight, and sudden infant death syndrome (SIDS). ${ }^{1}$ Additionally, it increases the risk for the later development of childhood allergies and asthma. ${ }^{2}$

In the New South Wales Child Health Survey 2001, mothers of babies aged less than 12 months were asked about their smoking behaviour during pregnancy. One in seven mothers (14.2 per cent) reported any smoking during pregnancy, with 7.9 per cent of mothers continuing to smoke but reducing their smoking, 3.6 per cent successfully quitting, 2.1 per cent unsuccessfully trying to quit, and 0.6 per cent continuing their previous smoking behaviour during pregnancy. The remaining mothers had quit prior to pregnancy (20.5 per cent) or had never smoked more than 100 cigarettes in their lifetime (64.4 per cent). The proportion of mothers who reported any smoking in pregnancy was slightly lower than the 17.4 per cent recorded in the NSW Midwives Data Collection in $2000 .^{3}$

\section{References}

1. Walsh RA, Lowe JB, Hopkins PJ. Quitting smoking in pregnancy. Med J Aust 2001; 175: 320-323.

2. Floreani AA, Rennard SI. The role of cigarette smoke in the pathogenesis of asthma and as a trigger for acute symptoms. Curr Opin Pulmonary Med 1999; 5: 38-46.

3. Public Health Division, NSW Department of Health. NSW Mothers and Babies 2000. N S W Public Health Bull 2001; 13(S-3).

\section{Smoking in the home}

Children are particularly vulnerable to the adverse effects of passive smoking, related to exposure to environmental tobacco smoke, either at home or in other confined spaces.
Parental smoking causes lower respiratory infections, middle ear disease, asthma and sudden infant death syndrome (SIDS) in children. It also exacerbates symptoms of asthma ${ }^{1,2}$.

In the New South Wales Child Health Survey 2001, all parents or carers were asked to describe the smoking status of their household; and, where applicable, to estimate the number of cigarettes smoked inside the house each day. Two-thirds of respondents (65.7 per cent) reported that no one living in their household smoked. A further onequarter (24.1 per cent) reported that smokers living in the household usually or always smoked outside the house. The remaining respondents (10.2 per cent) reported that smokers living in the household sometimes, usually, or always smoked inside the house.

The proportion of parents or carers reporting that their household was smoke-free-that is, where no cigarettes were smoked inside the house each day-was considerably higher (85.6 per cent) than reported in a previous survey of the NSW adult population aged 16 years and over in 1998 (73.2 per cent). ${ }^{3}$ In that same survey, parents with children aged less than six years had the highest smokefree home status (78.0 per cent). ${ }^{4}$

\section{References}

1. Cook DG, Strachan DP. Health effects of passive smoking 10: Summary of effects of parental smoking on the respiratory health of children and implications for research. Thorax 1999; 54: 357-366.

2. Wahlgren DR, Hovell MF, Meltzer EO, Meltzer SB. Involuntary smoking and asthma. Curr Opin Pulm Med 2000; 6: $31-36$

3. Public Health Division 2001. 1997 and 1998 NSW Adult Health Surveys. Electronic Report. Web site: http:// internal.health.nsw.gov.au/public-health/nswhs/index.htm, accessed 11 January 2002.

4. Merom D, Rissel C. Factors associated with smoke-free homes in NSW: Results from the 1998 NSW Health Survey. Aust N Z J Public Health 2001; 25(4): 339-345.

\section{Parental views of child smoking}

Parenting practices that may reduce adolescent smoking include parent-child discussion of smoking, punishment of smoking, restrictive home smoking policies, and rules against smoking. ${ }^{1,2}$

In the New South Wales Child Health Survey 2001, parents or carers of children aged 8-12 years were asked whether they had ever clearly told their child not to smoke, or forbidden their child from smoking. Overall, 62.7 per cent of respondents reported that they had delivered such an anti-smoking message to their child. Parents or carers living in households that included smokers (68.8 per cent) were more likely to report telling their child not to smoke than those from non-smoking households (59.3 per cent). 


\section{FIGURE 4}

\section{POSITION INFANT PLACEDTO SLEEP FROM BIRTH BY URBAN-RURAL AREA HEALTH SERVICE OF}

RESIDENCE, BABIES AGED LESS THAN 12 MONTHS, NSW, 2001
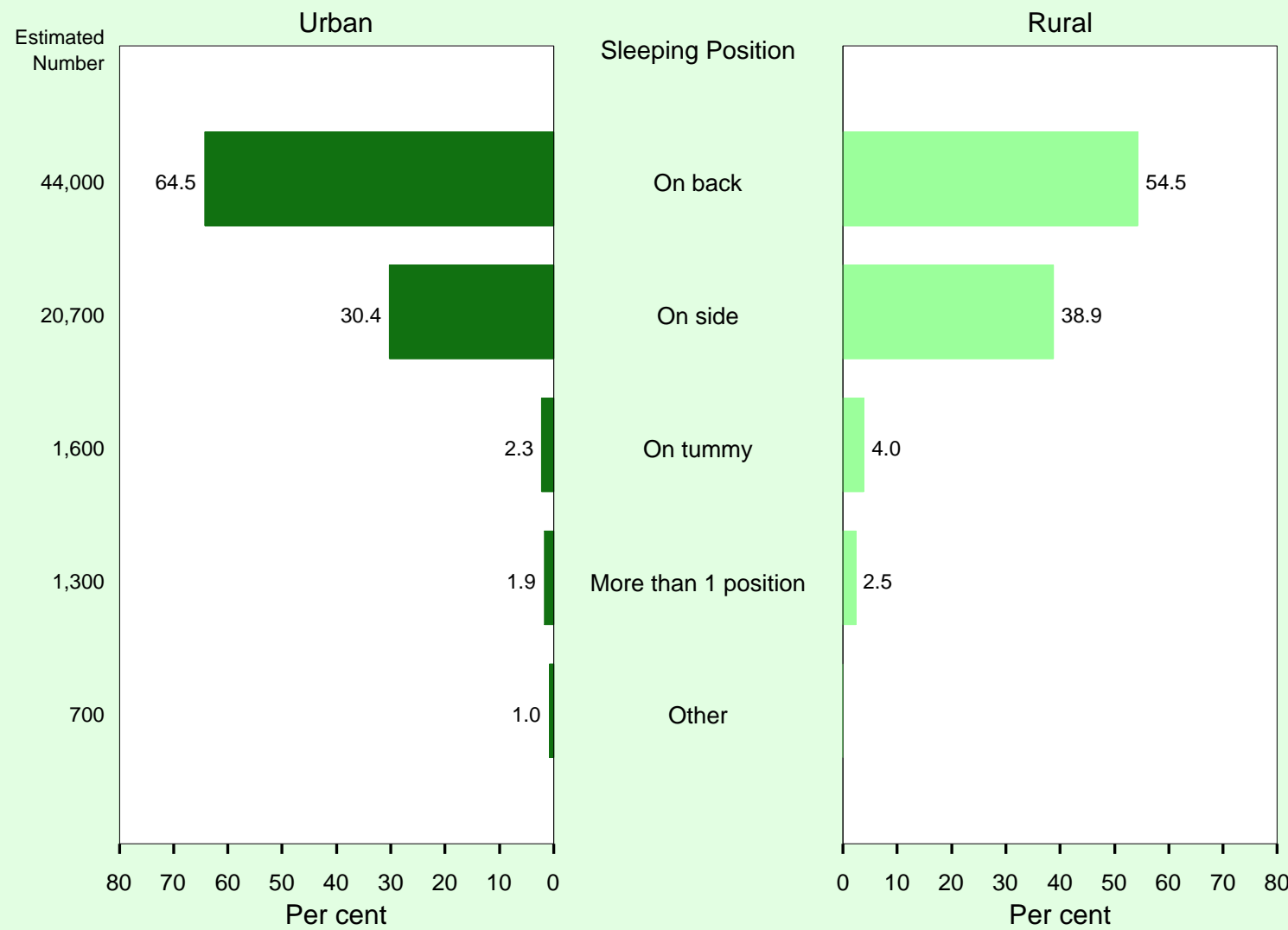

Note: Health areas in Greater Sydney, Hunter, and Illawarra were classified as urban. Estimates based on 736 respondents. Source: New South Wales Child Health Survey 2001 (HOIST). Centre for Epidemiology and Research, NSW Department of Health.

\section{References}

1. Proescholdbell RJ, Chassin L, MacKinnon DP. Home smoking restrictions and adolescent smoking. Nicotine \& Tobacco Research 2000; 2:159-167.

2. Rissel C, McClellan L, Bauman A. Factors associated with delayed tobacco uptake among Vietnamese-Asian and Arabic youth in Sydney, NSW. A N Z J Public Health 2000; 24: 2228.

\section{Infant sleeping position}

Infants placed on their back (supine) to sleep are at the lowest risk of sudden infant death syndrome (SIDS). SIDS is the sudden and unexpected death of an infant, where the death remains unexplained despite complete postmortem examination. ${ }^{1}$ Infants placed on their stomach (prone) to sleep have a much higher risk of SIDS, and those placed on their side also have increased risk, probably because of their tendency to roll into the prone position. ${ }^{2}$ Accordingly, the supine position (placing the infant on its back) is the preferred sleeping position for most healthy infants.
Following a national SIDS prevention campaign, the number of SIDS deaths in NSW has decreased by more than 75 per cent, over the last decade. ${ }^{3}$ Almost all of this decline can be attributed to a reduction in the practice of placing infants in the prone position to sleep. ${ }^{4}$ However, SIDS remains the single most common cause of death in infants in NSW outside the perinatal period, with 44 SIDS deaths in $2000 .^{3}$

In the New South Wales Child Health Survey 2001, mothers of infants aged less than 12 months were asked about the position in which, from birth, their infant was placed for sleep. Just under two-thirds (62.4 per cent) of mothers reported placing their infant on its back to sleep. The remaining mothers reported placing their infant in other sleeping positions: stomach (2.7 per cent), side (32.1 per cent), or other positions ( 0.3 per cent). Mothers from rural areas (54.5 per cent) were less likely than those from urban areas (64.5 per cent) to report placing their infant on its back to sleep (Figure 4).

The proportion of mothers who reported that they placed their infant on its back to sleep (62.4 per cent) was two 


\section{FIGURE 5}

FOLATE TABLETS OR CAPSULES TAKEN BEFORE OR DURING PREGNANCY, MOTHERS WITH BABIES LESS THAN 12 MONTHS OF AGE, NSW, 2001

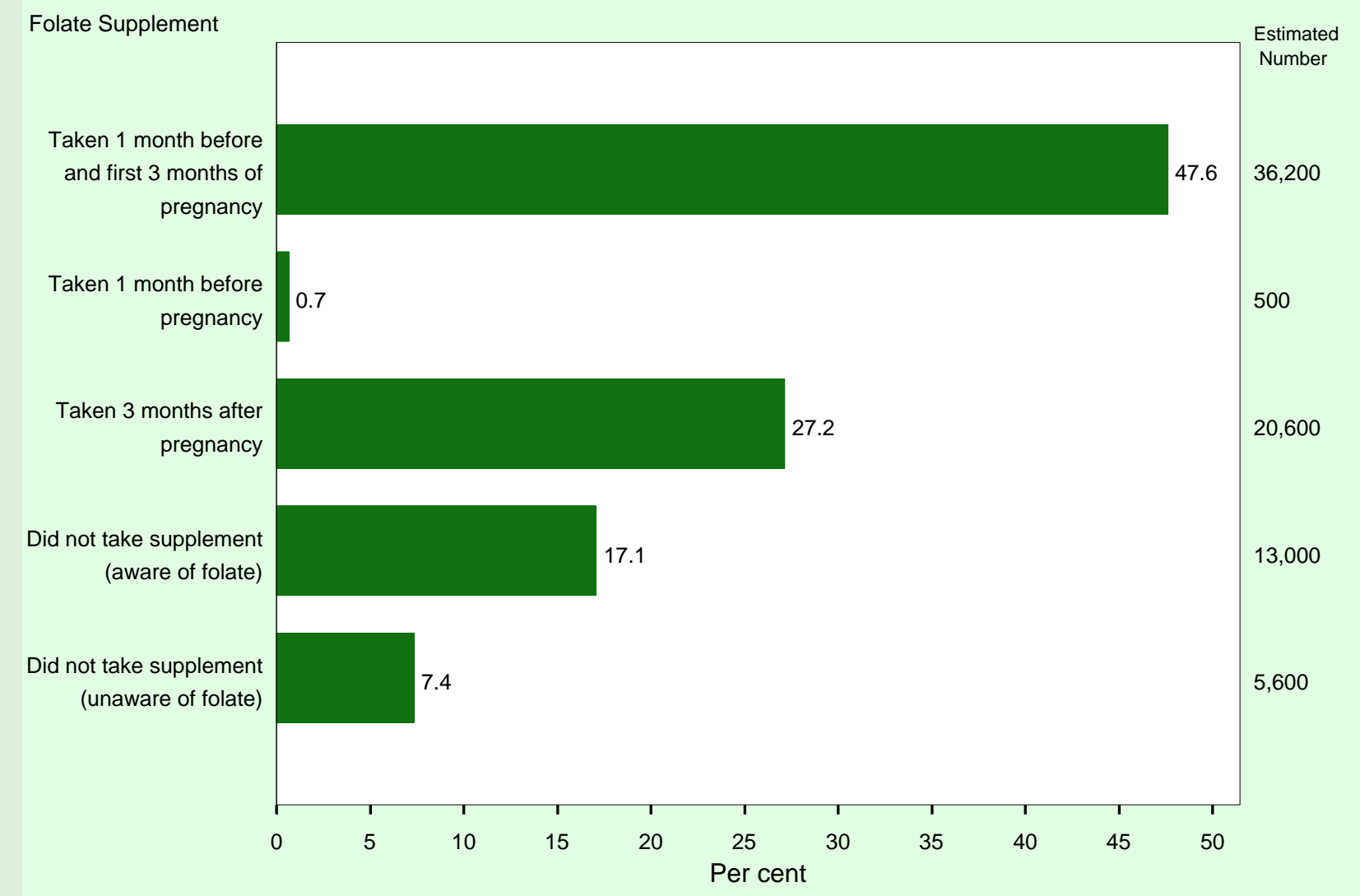

Note: Estimates based on 647 respondents.

Source: New South Wales Child Health Survey 2001 (HOIST). Centre for Epidemiology and Research, NSW Department of Health.

times greater than in a national survey in 1992 (30.8 per cent) ${ }^{5}$ In that survey, most mothers (57.3 per cent) reported placing their infants on their side to sleep.

\section{References}

1. Abraham B, d'Espaignet E, Stevenson C. Australian Health Trends 1995. Canberra: Australian Institute of Health and Welfare, 1996.

2. Scragg RKR, Mitchell EA. Side sleeping position and bed sharing in the sudden infant death syndrome. Ann Med 1998; 30: 345-349.

3. Australian Bureau of Statistics mortality data-deaths registered in NSW (HOIST). Sydney: Centre for Epidemiology and Research, NSW Department of Health, 2000.

4. Dwyer T, Ponsonby AL, Blizzard L, Newman NM, Cochrane JA. The contribution of changes in the prevalence of prone sleeping position to the decline of sudden infant death syndrome in Tasmania. JAMA 1995; 273: 783-789.

5. Australian Bureau of Statistics. Survey of infant sleeping positions. Catalogue no. 4386.0. Canberra: ABS, 1992.

\section{Folate intake during pregnancy}

Folate is a B group vitamin found naturally in foods such as fresh vegetables and fruit, orange juice, legumes, nuts, liver, and yeast. It is also present in fortified products such as breads and breakfast cereals and can be taken in supplement (tablet or capsule) form. An adequate intake of folate around the time of conception can reduce the risk of neural tube defects. ${ }^{1}$ Neural tube defects such as spina bifida, anencephaly and encephalocoele are major causes of disability in children and adults. Neural tube defects are reported in around 80 pregnancies in NSW each year. ${ }^{2}$

In the New South Wales Child Health Survey 2001, mothers of infants aged less than 12 months were asked a series of questions, to assess knowledge about folate and the use of folate supplementation before and during pregnancy. 


\section{Awareness of the link between folate and birth defects}

Approximately two-thirds (61.6 per cent) of mothers of infants aged less than 12 months were aware that the reason for taking additional folate prior to and during pregnancy was to prevent spina bifida or neural tube defects, or to prevent birth defects more generally. This was higher than the 40 per cent of women of childbearing age who knew of the link between folate and birth defects in a series of Australian surveys in 1999. ${ }^{3}$ In another survey of 287 randomly selected recently pregnant women in Western Australia in 1997-1998, approximately two-thirds of women reported that they were aware of the message to increase their folate intake before and early in pregnancy to reduce the risk of spina bifida. ${ }^{4}$

\section{Awareness of dietary sources of folate}

Around two-thirds (69.0 per cent) of respondents named vegetables and one-third (35.0 per cent) named breakfast cereal as foods containing folate, with smaller proportions citing fruit or fruit juice (16.6 per cent) and bread (5.7 per cent). Around one in five mothers (20.6 per cent) could not name any foods that contain folate.

\section{Dietary change to increase folate intake}

Under one-third (27.5 per cent) of mothers of infants aged less than 12 months reported that they had changed their diet to increase folate intake in the month before and/or in the first trimester of pregnancy. A further quarter of mothers (23.4 per cent) reported that they did not change their diet but considered that they already had an adequate folate intake; while the remainder of mothers (48.9 per cent) reported that they did not change their diet, with 84.9 per cent of these being aware of the benefits of folate. Overall, 66.9 per cent of women who did not change their diet were taking folate tablets or capsules.

\section{Use of folate tablets or capsules}

Approximately half (47.6 per cent) of mothers of infants aged less than 12 months reported that they had taken folate tablets or capsules both one month before and in the first trimester of pregnancy, while 27.2 per cent reported that they had taken these supplements in the first trimester, but not prior to pregnancy. One-quarter of respondents (24.5 per cent) reported that they had not taken folate tablets or capsules at all (Figure 5).

\section{References}

1. Lumley J, Watson L, Watson M, Bower C. Periconceptual supplementation with folate and/or multivitamins to prevent neural tube defects and other congenital malformations (Cochrane review). The Cochrane Library 1998. Issue 4. Oxford: Update Software.

2. Public Health Division, NSW Department of Health. NSW Mothers and Babies 2000. N S W Public Health Bull 2001; 13(S-3).
3. Watson MJ, Watson LF. Outcome evaluation of the folateneural tube defect health claim pilot. Australia New Zealand Food Authority, 2000. Web site at www.anzfa.gov.au/ mediareleasespublications/publications/ evaluating thefolateneuraltubedefecthealthclaimpilot/ evaluatingthefolaten1039.cfm, accessed 9 January 2002.

4. Miller M, Bower C, Payne J, Serna P. Folate-related knowledge and practices of Western Australian women before and during pregnancy (Abstract). Tetrology 2000; 62: 367.

\section{Breastfeeding}

Breastfeeding has health advantages for both infants and mothers. For infants, these include protection against diarrhoeal illnesses, respiratory infections, and otitis media; reduced risk of childhood obesity; and improved visual acuity and psychomotor development. For mothers, benefits include quicker recovery from childbirth and reduced risk of ovarian cancer and pre-menopausal breast cancer. ${ }^{1}$

The NHMRC in Australia now recommends exclusive breastfeeding for the first six months of life, in line with a recent revised policy of the World Health Organization (WHO). ${ }^{2}$ Previously, the WHO policy recommended exclusive breastfeeding for 4-6 months, but the benefits of extending the duration have been demonstrated. The NHMRC also recommends that breastfeeding, complimented by appropriate solid foods, should be continued until at least 12 months of age. ${ }^{2}$ According to the WHO definition, exclusively breastfed infants receive only breastmilk (plus medications including vitamins if required).

Recommendations for nationally-standardised monitoring of breastfeeding practices have recently been released, including 11 indicators for the monitoring of breastfeeding. ${ }^{3}$ Data is available from the New South Wales Child Health Survey 2001 for four of these indicators, including the percentage of mothers who ever breastfed, the percentage of mothers who breastfed their infant to any degree for 4-6 months, the median duration of breastfeeding among breastfed infants, and the percentage of those breastfed who were fully breastfed to four months and to six months. This data enable direct comparisons with other states and with forthcoming data from the National Health Survey 2001.

In the New South Wales Child Health Survey 2001, mothers of children aged less than two years were asked a series of questions about breastfeeding and infant feeding practices, which were used to determine the duration of any breastfeeding; and of full breastfeeding (that is consuming only breast milk with or without water). The questions used in the Child Health Survey did not allow measurement of exclusive breastfeeding, as defined by the WHO, as consumption of water, juice, and other nonbreastmilk fluids was not measured. 


\section{FIGURE 6}

DURATION OF BREASTFEEDING CHILDREN AGED LESS THANTWO YEARS, NSW, 2001

Per cent of infants

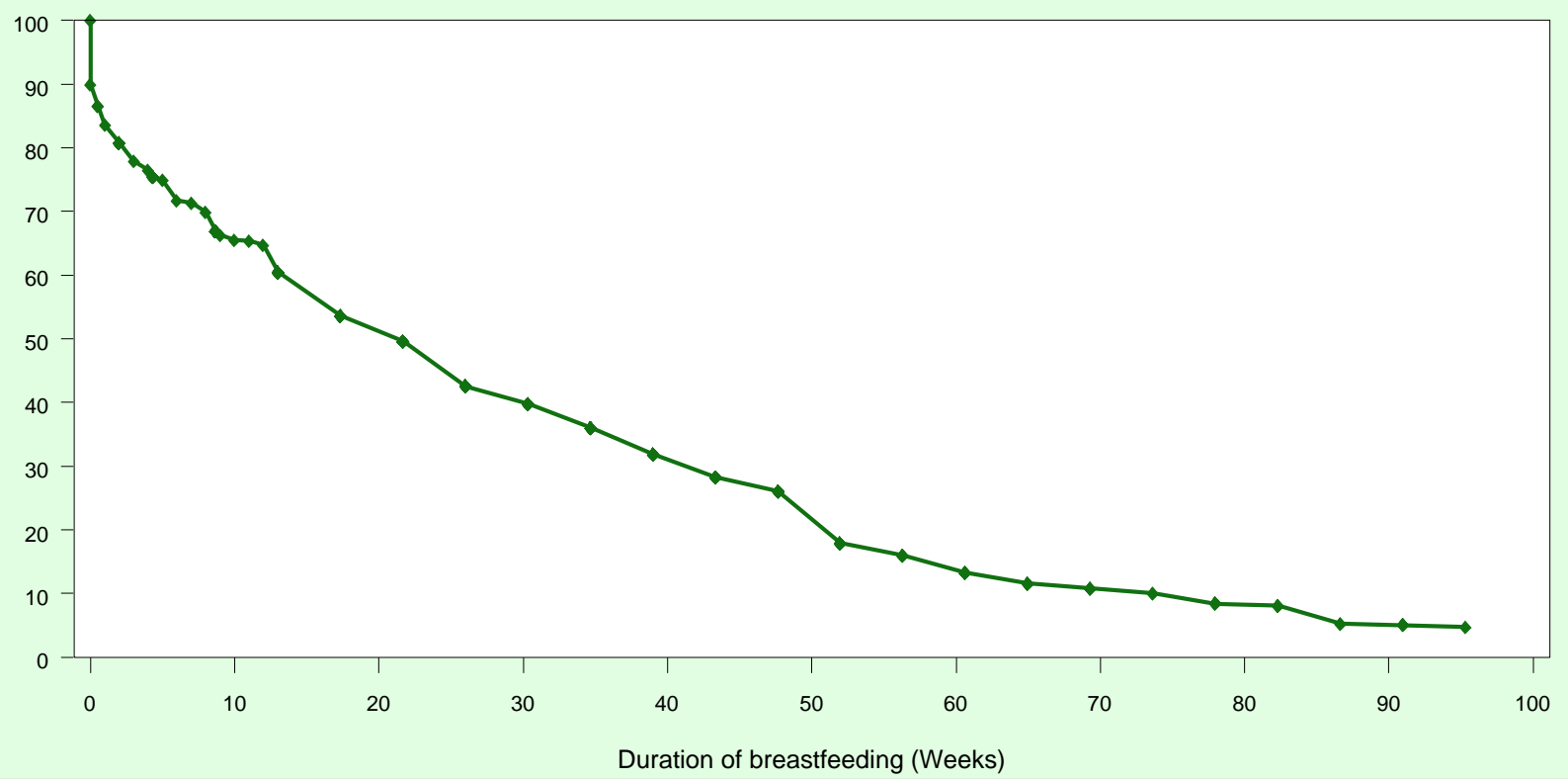

Note: Estimates derived using Kaplan-Meier survival analysis. Estimates based on 1487 respondents.

Source: New South Wales Child Health Survey 2001 (HOIST). Centre for Epidemiology and Research, NSW Department of Health.

\section{Duration of breastfeeding}

Most mothers (89.8 per cent) reported that their infant had been breastfed. However, many mothers breastfed for a short period. Only 76.5 per cent of mothers were breastfeeding at four weeks, 60.5 per cent were breast feeding at three months, 42.6 per cent were breastfeeding at six months, and only 17.9 per cent were still breastfeeding at 12 months (Figure 6). A higher proportion of mothers with tertiary level education ( 96.3 per cent) than mothers with less-than tertiary level education (86.5 per cent), reported that their infant was ever breastfed.

The proportion of mothers reporting that they breastfed for at least one week (83.7 per cent) was slightly higher than the 78.4 per cent of NSW mothers who reported breastfeeding at hospital discharge in the 1995 National Health Survey. ${ }^{4}$ The proportion of NSW mothers in the latter survey who reported that they were still breastfeeding at three months (60.0 per cent) and six months (44.0 per cent) was similar to the New South Wales Child Health Survey 2001.

\section{Full breastfeeding}

Infants who are fully breastfed receive breastmilk as the main source of nourishment. This includes infants who are exclusively breastfed-that is, who receive only breastmilk with no water, other liquids, or solids (except for vitamins, mineral supplements, or medicines); and infants who are predominantly breastfed-that is who receive breastmilk as well as other fluids including water, water-based drinks, or fruit juice, but not breastmilk substitutes or solids. Therefore, the fully breastfed rate is the combined rate of exclusively breastfed and predominantly breastfed. ${ }^{3}$

With regard to full breastfeeding, half of mothers (52.7 per cent) reported that their infant was fully breastfed at three months of age. Less than four in 20 mothers (15.1 per cent) reported that their infant was fully breastfed at six months of age.

These proportions were lower than the NSW estimates for 'exclusive' breastfeeding at three months (56.6 per cent) and six months (17.2 per cent) reported in the 1995 National Health Survey. ${ }^{4}$ However, a different definition was used in that survey whereby infants who were regularly consuming large amounts of fruit juice, and also receiving other food on an irregular basis were still classified as being 'exclusively' breastfed.

\section{Main reasons for breastfeeding}

Mothers of children aged less than two years who reported any breastfeeding were asked to report the main reason they breastfed. The main reasons cited were that breastmilk is better for the infant ( 95.2 per cent), it prevents allergies (65.4 per cent), it is the right thing to do (60.6 per cent), it is cheaper ( 57.7 per cent), other people advised me to 


\section{FIGURE 7}

USUAL DAILY CONSUMPTION OF FRUIT AND VEGETABLES BY AGE GROUP, CHILDREN AGED 2-12 YEARS, NSW, 2001
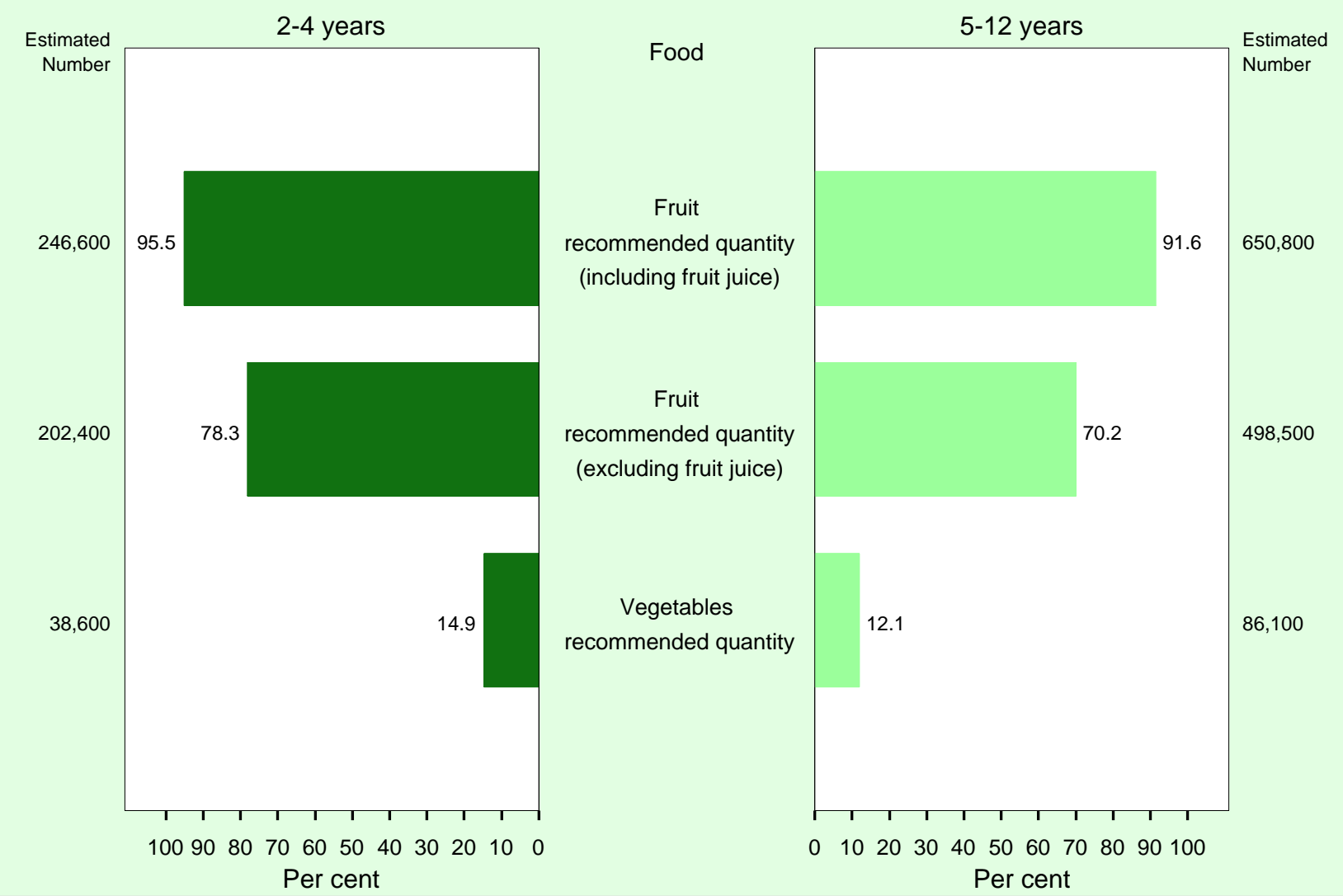

Note: Definitions of serves and the recommended number of serves are based on The Australian guide to healthy eating. (Commonwealth Department of Health and Family Services, 1998). Estimates based on 7916 respondents.

Source: New South Wales Child Health Survey 2001 (HOIST). Centre for Epidemiology and Research, NSW Department of Health.

breastfeed (37.1 per cent), breastfeeding helps weight loss following pregnancy (28.7 per cent) and the infant's father wanted me to breastfeed (26.3 per cent).

\section{References}

1. National Health and Medical Research Council. Draft dietary guidelines for children and adolescents. Canberra: AusInfo, 2001.

2. World Health Organization. Nutrition and Infant Feeding. Web site at www.who.int/child-adolescent-health/ NUTRITION/infant.htm, accessed 11 January 2002.

3. Webb K, Marks G, Lund-Adams M, Rutishauser IHE, Abraham B. Towards a national system for monitoring breastfeeding in Australia: Recommendations for population indicators, definitions, and next steps. Canberra: Australian Food and Nutrition Monitoring Unit, Commonwealth Department of Health and Aged Care, 2001.

4. Donath S, Amir LH. Rates of breast-feeding in Australia by state and socioeconomic status: Evidence from the 1995 National Health Survey. J Paediatr Child Health 2000; 36: 164-168.

\section{Food intake}

Many dietary factors are linked to health and disease, either as protective influences or as risk factors. Diet contributes substantially to risk of or protection from many common chronic diseases, including: coronary heart disease, stroke, cancer, diabetes mellitus, osteoporosis, dental caries, gall bladder disease, diverticular disease. Healthy diets in childhood are important, not only because they shape diets in later life but because many chronic diseases, including cardiovascular diseases and osteoporosis, may have their beginnings in childhood.,

The current sources of dietary recommendation for Australian children are the Draft dietary guidelines for children and adolescents and infant feeding guidelines and the Australian guide to healthy eating. ${ }^{3,4,5}$ The Australian guide to healthy eating recognises different eating patterns, by providing different recommendations for diets based largely on breads and cereals and for diets that include more of all food groups. Its recommendations vary by age and sex. 


\section{FIGURE 8}

USUAL CONSUMPTION OF MILK, BY AGE GROUP, CHILDREN AGED 2-12 YEARS, NSW, 2001
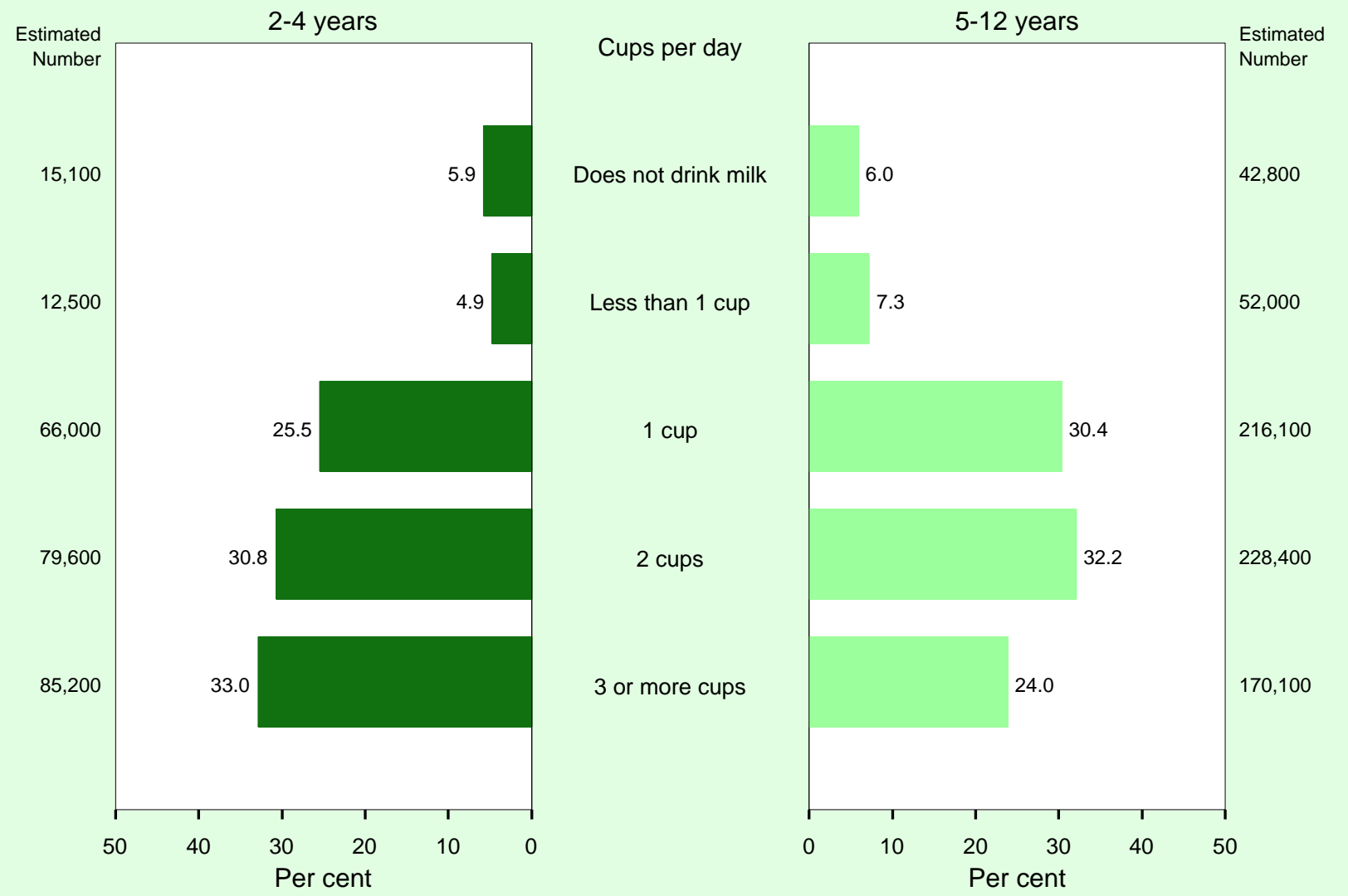

Note: Milk refers to cow's milk only. Estimates based on 7916 respondents.

Source: New South Wales Child Health Survey 2001 (HOIST). Centre for Epidemiology and Research, NSW Department of Health.

The New South Wales Child Health Survey 2001 included questions about consumption of specific foods that relate to protective and high risk dietary factors: fruit, vegetables, milk, fruit juice, soft drinks, and hot chips or french fries.

Fruit and vegetables are a significant source of antioxidants, mainly vitamins and minerals, which play an important role in removing damaging 'free radicals' formed during normal metabolism. Evidence suggests that antioxidant nutrients play an important protective role in many diseases, including cardiovascular and eye diseases. ${ }^{6}$

\section{TABLE 7}

MINIMUM RECOMMENDED DAILY SERVES OF FRUIT AND VEGETABLES NEEDEDTO ACHIEVE A HEALTHY DIET FOR CHILDREN, BY AGE GROUP ${ }^{4}$

\begin{tabular}{|lcc|}
\hline Age group & Serves of fruits & Serves of vegetables \\
\hline $2-7$ years & 1 & 2 \\
$8-11$ years & 1 & 3 \\
12 years & 3 & 4 \\
\hline
\end{tabular}

Fruit and vegetables are also important sources of dietary fibre, complex carbohydrates and folate. An increase in their consumption will most likely result in a corresponding decrease in fat intake.

Milk is an excellent source of many nutrients, including calcium, protein, riboflavin, and vitamin B12. ${ }^{3}$ Calcium is important for bone growth and for attaining peak bone mass at adolescence, which protects against osteoporosis and fractures in later life. ${ }^{2}$

Fruit juice is a good source of vitamins such as vitamin C and folate, and one-half cup of juice supplies one daily serve of fruit. However, because most fruit juices contain added sugars and little fibre, they should not be used as a substitute for fresh fruits. ${ }^{3}$ Increasing juice consumption among children in recent years has been accompanied by reduced consumption of milk (and hence calcium). Additionally, excessive consumption of fruit juice has been associated with carbohydrate malabsorption, nonspecific chronic diarrhoea, and failure to thrive, as well as excessive energy intake and obesity. Nursing-related 


\section{FIGURE 9}

\section{CONSUMPTION OF SELECTED FOODS BY AGE GROUP, CHILDREN AGED 2-12 YEARS, NSW, 2001}
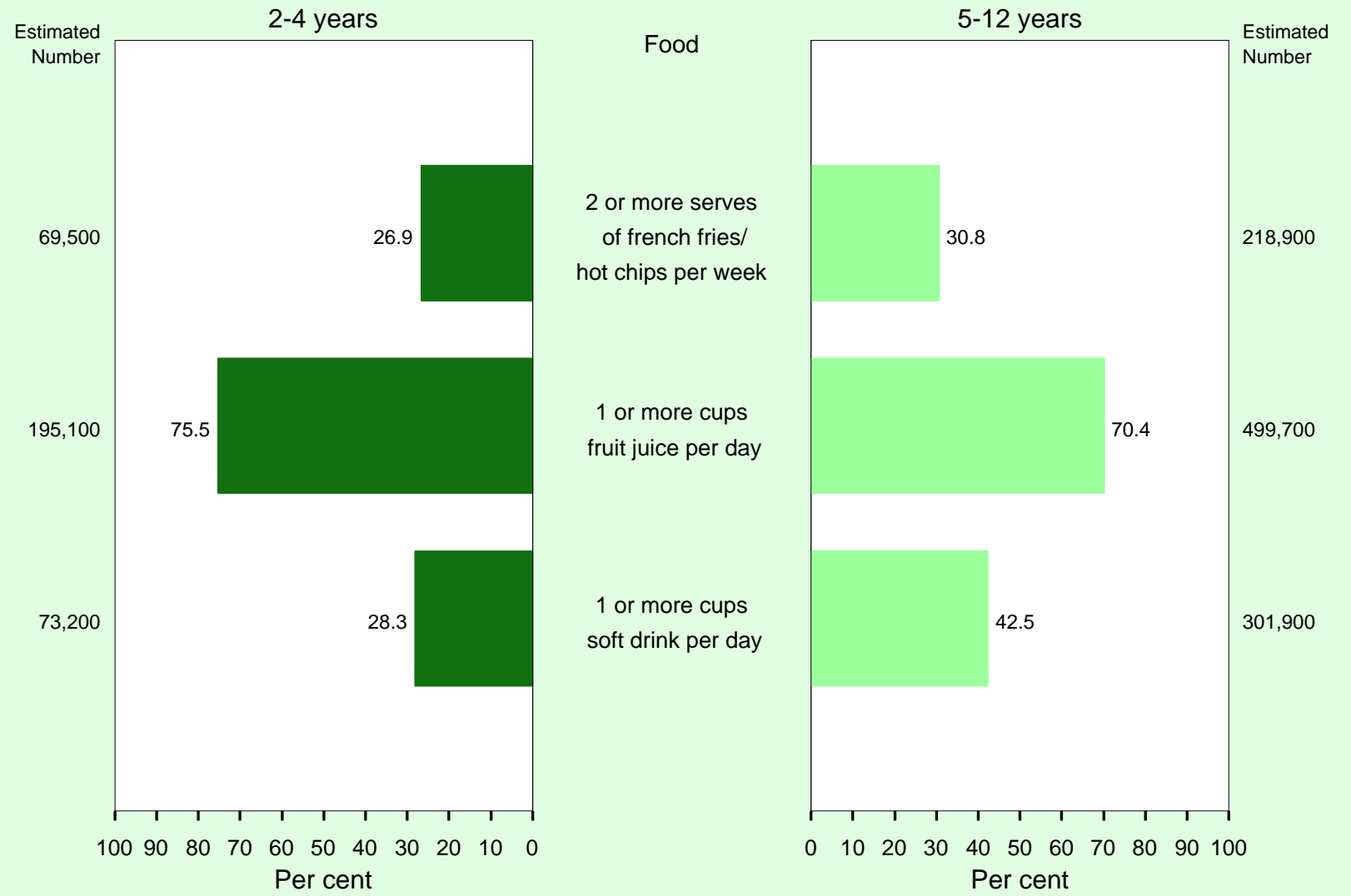

Note: Estimates based on 7916 respondents.

Source: New South Wales Child Health Survey 2001 (HOIST). Centre for Epidemiology and Research, NSW Department of Health.

bottle caries may also result from prolonged feeding of fruit juice to infants and young children from bottles. ${ }^{7.8}$

Soft drinks, cordials and sports drinks contain large amounts of sugar and energy. Consumption of these beverages can adversely affect nutrition by displacing milk and fruit juices in the diet. ${ }^{3}$ Excessive consumption of soft drinks has been associated with childhood obesity and increases the risk of dental caries. ${ }^{7,8,9}$ Consumption of carbonated drinks, particularly cola drinks, may increase the risk of bone fractures in adolescent females. ${ }^{10}$

Hot chips or french fries are a high-fat food commonly consumed by children both at home and away from home. Excessive fat intake contributes to overweight and obesity among children, which may lead to the development of a range of chronic diseases, including cardiovascular disease, diabetes mellitus, cancer, musculoskeletal problems, and psychological problems. ${ }^{11}$ Potato chips contribute around eight per cent of total fat intake of children aged 2-12 years. ${ }^{3}$ Limiting the use of fried foods such as hot chips and french fries, and choosing lower fat foods when eating at fast food restaurants, are suggested as ways to foster positive practices related to moderation of fat intake in children. ${ }^{12}$

\section{Fruit and vegetables}

The minimum recommendations for daily consumption of fruit and vegetables used in analysis of the New South Wales Child Health Survey 2001 are shown in Table 7. These were based on the Australian guide to healthy eating. ${ }^{4}$ However, the Australian guide to healthy eating gives no recommendations for children aged 2-3 years, so we applied the recommendations for children aged 4-7 years to children aged 2-3 years.

In the New South Wales Child Health Survey 2001, one serve of fruit was calculated as half-a-piece of fruit, onethird of a cup of canned fruit, or one tablespoon of dried fruit. Since the Australian guide to healthy eating stated that the recommended serve of fruit was one medium piece of fruit, two small pieces of fruit, a cup of diced canned fruit, half a cup of juice, or one-and-a half tablespoons of dried fruit, we converted our serves to this standard by dividing them by two. 
In the New South Wales Child Health Survey 2001, most (92.7 per cent) children aged 2-12 years, (95.5 per cent of children aged 2-4 years, and 91.6 per cent of children aged 5-12 years) were reported to consume the recommended daily minimum quantity of fruit, including fruit juice (Figure 7). However, around 60 per cent of the serves of fruit consumed by children were in the form of fruit juice. Because most fruit juices contain added sugars and little fibre, they are not recommended as a substitute for fresh fruits. ${ }^{3}$ If fruit juice was excluded, the proportion of children reported to consume the recommended minimum daily quantity of fruits dropped considerably, to 78.3 per cent among children aged $2-4$ years and 70.2 per cent among children aged 5-12 years, or 72.4 per cent overall.

In the New South Wales Child Health Survey 2001, one serve of vegetables was calculated as a quarter of a cup of salad or four sticks of vegetables. Since the Australian guide to healthy eating recommended that one serve of vegetables was one cup of salad or vegetables, we converted our serves to this standard by dividing them by four. In the New South Wales Child Health Survey 2001, 12.9 per cent of all children aged 2-12 years, or less than one in seven children aged 2-4 years (14.9 per cent) and 5-12 years (12.1 per cent) were reported to consume the recommended daily minimum quantity of vegetables.

Fruit and vegetable intake, as measured on one day, in the National Nutrition Survey: Foods eaten Australia 1995, showed that high a proportion of children ate no fruit on the day of the survey: around one third of children aged under 12 years did not eat fruit or fruit products. ${ }^{13}$ However, this survey did not measure 'usual' consumption of fruit and vegetables among children, so the proportion of children consuming no fruit, or meeting recommended serves, cannot be directly compared with the results of the New South Wales Child Health Survey 2001.

\section{Milk}

The minimum daily number of serves of dairy products recommended in the Australian guide to healthy eating is two serves for children aged 4-11 years and three serves for children aged 12 years. ${ }^{4}$ One cup of milk $(250 \mathrm{~mL})$ provides one serve.

In the New South Wales Child Health Survey 2001, parents or carers were asked about consumption of milk, but not about other dairy products. A high proportion of children aged 2-4 years (89.3 per cent) and 5-12 years (86.6 per cent) were reported to drink one or more cups of milk per day. Among children aged 2-4 years, approximately onequarter (25.5 per cent) were reported to drink one cup of milk per day, while a greater proportion were reported to drink two cups per day (30.8 per cent) or three or more cups per day (33.0 per cent). Milk consumption was lower among older children, with around one-third of children aged 5-12 years reported to drink one cup of milk per day (30.4 per cent) or two cups per day (32.2 per cent), while one-quarter were reported to drink three or more cups per day (24.0 per cent) (Figure 8).

Almost two-thirds of children aged 2-4 years (63.8 per cent) and more than half of children aged 5-12 years (56.2 per cent) were reported to be meeting the recommended amounts for dairy products from milk alone. The remaining children may still have been meeting the recommended amounts through consumption of other dairy products such as cheese and yoghurt.

\section{Fruit juice}

More than three-quarters of children aged 2-4 years (75.5 per cent) and a slightly smaller proportion of children aged 5-12 years (70.4 per cent) were reported to drink at least one cup of fruit juice per day (Figure 9). Among children aged 0-4 years, similar proportions were reported to drink one cup of juice per day (28.3 per cent), two cups per day (23.4 per cent) or three or more cups per day (24.0 per cent). Consumption of fruit juice was lower among older children, with around one-third of children aged 5-12 years reported to drink one cup of fruit juice per day (33.2 per cent), and smaller proportions reported to drink two cups per day (21.8 per cent), or three or more cups per day (15.5 per cent).

\section{Soft drinks, cordials and sports drinks}

Just over one-quarter of children aged 2-4 years (28.3 per cent) were reported to drink at least one cup of soft drink, cordial or sports drinks per day, with 12.9 per cent reported to drink two or more cups per day. Children aged 5-12 years consumed more of these drinks, with 42.5 per cent reported to consume one or more cups per day, and half of these (22.1 per cent) reported to drink two or more cups per day (Figure 9).

\section{Hot chips or french fries}

In the New South Wales Child Health Survey 2001, one serve of hot chips or french fries was calculated as half a cup of chips or french fries. Potato chips or french fries were commonly consumed by children. Only 10.1 per cent of children aged 2-4 years and 7.4 per cent of children aged 5-12 years were reported to not eat hot chips or french fries. Around two-thirds of children aged 2-4 years (65.6 per cent) and 5-12 years ( 68.8 per cent) were reported to eat at least one serve of hot chips or french fries per week. Around one-quarter (26.9 per cent) of children aged 2-4 years ate two or more serves of hot chips compared with around one-third (30.8 per cent) of children aged 5-12 years (Figure 9). Only around one in 10 were reported to eat three or more serves each week with this proportion being higher for children aged 5-12 years (12.2 per cent) compared with 8.4 per cent of children aged $2-4$ years.

\section{References}

1. Van Horn L, Greenland P. Prevention of coronary artery disease is a pediatric problem. JAMA 1997; 278: 1779-1780. 
2. Mascarenhas MR, Tershakovec AM, Stettler N. Nutrition interventions in childhood for the prevention of chronic diseases in adulthood. Curr Opin Pediatr 1999; 11:598-604.

3. National Health and Medical Research Council. Draft dietary guidelines for children and adolescents and infant feeding guidelines. Canberra: AusInfo, 2001.

4. Commonwealth Department of Health and Family Services. Australian guide to healthy eating. Canberra: Commonwealth Department of Health and Family Services, 1998.

5. Dennison BA. Fruit juice consumption by infants and children: a review. J Am Coll Nutr 1996; 15: 4S-11S.

6. Machlin L. Critical assessment of epidemiological data concerning the impact of antioxidant nutrients on cancer and cardiovascular disease. Crit Rev Food Sci Nutr, 1995; 35: 41-50.

7. Dennison BA. Fruit juice consumption by infants and children: a review. J Am Coll Nutr 1996; 15: 4S-11S.

8. Watt RG, Dykes J, Sheiham A. Preschool children's consumption of drinks: Implications for dental health. Community Dent Health 2000; 17: 8-13.

9. Ludwig DS, Peterson KE, Gortmaker SL. Relation between consumption of sugar-sweetened drinks and childhood obesity: a prospective, observational analysis. Lancet 2001; 357: 490-491.
10. Wyshak G. Teenaged girls, carbonated beverage consumption, and bone fractures. Arch Pediatr Adolesc Med 2000; 154: 610-613.

11. Wabitsch M. Overweight and obesity in European children: Definition and diagnostic procedures, risk factors and consequences for later health outcome. Eur J Pediatrics 2000; 159: S8-S13.

12. Reid J, George J, Pears R. Food and nutrition guidelines for children aged 2-12 years. Auckland: New Zealand Department of Health, 1992.

13. Australian Bureau of Statistics and Commonwealth Department of Health and Family Services. National Nutrition Survey: Foods eaten Australia 1995. Catalogue no. 4804.0. Canberra: ABS, 1999.

\section{Food security and hunger}

Food security is considered to exist when an adequate amount of nutritionally-appropriate and personallyacceptable food is available, and is able to be acquired in socially acceptable ways. Lack of food security endangers physical health through malnutrition and affects psychological wellbeing. If periodic, it may be associated

\section{FIGURE 10}

\section{EVER RAN OUT OF FOOD IN THE LAST 12 MONTHS BY AREA HEALTH SERVICE OF RESIDENCE, HOUSEHOLDS WITH CHILDREN AGED 0-12 YEARS, NSW, 2001}

Health Area

Central Sydney

Northern Sydney

Western Sydney

Wentworth

South-West Sydney

Central Coast

Hunter

Illawarra

South-East Sydney

Northern Rivers

Mid-North Coast

New England

Macquarie

Mid-Western

Far West

Greater Murray

Southern

All NSW
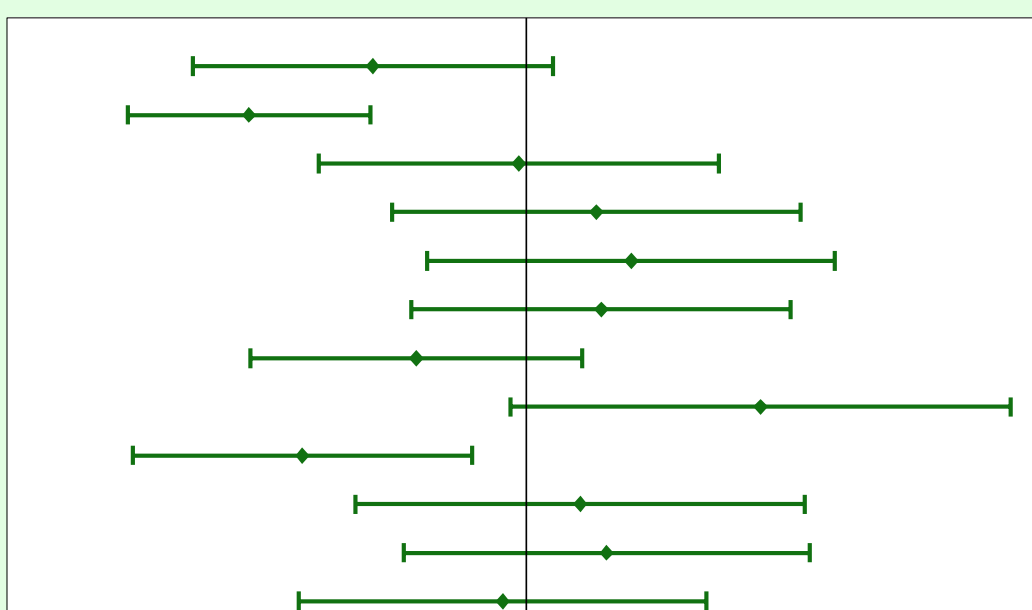

0
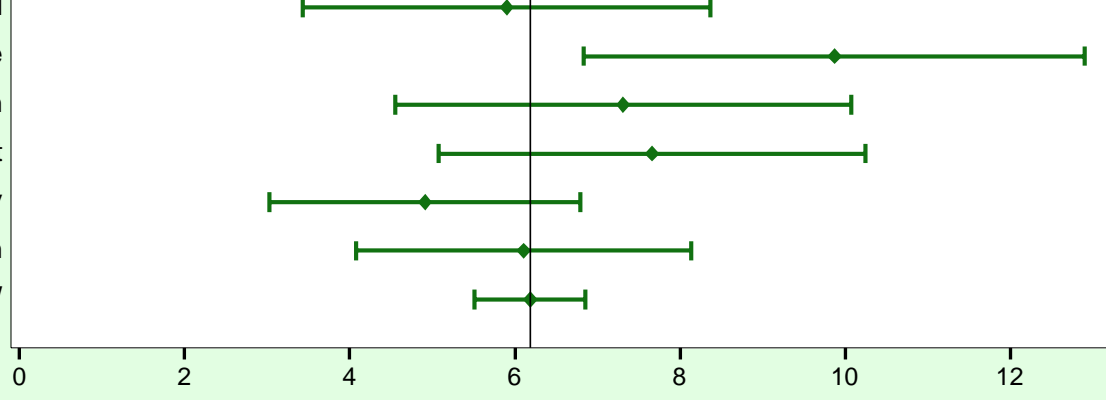

6

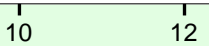

14

Per cent

Note: Estimates based on 9425 respondents.

Source: New South Wales Child Health Survey 2001 (HOIST). Centre for Epidemiology and Research, NSW Department of Health. 


\section{TABLE 8}

EVER RAN OUT OF FOOD IN THE LAST 12 MONTHS BY AREA HEALTH SERVICE OF RESIDENCE, HOUSEHOLDS WITH CHILDREN AGED 0-12 YEARS, NSW, 2001

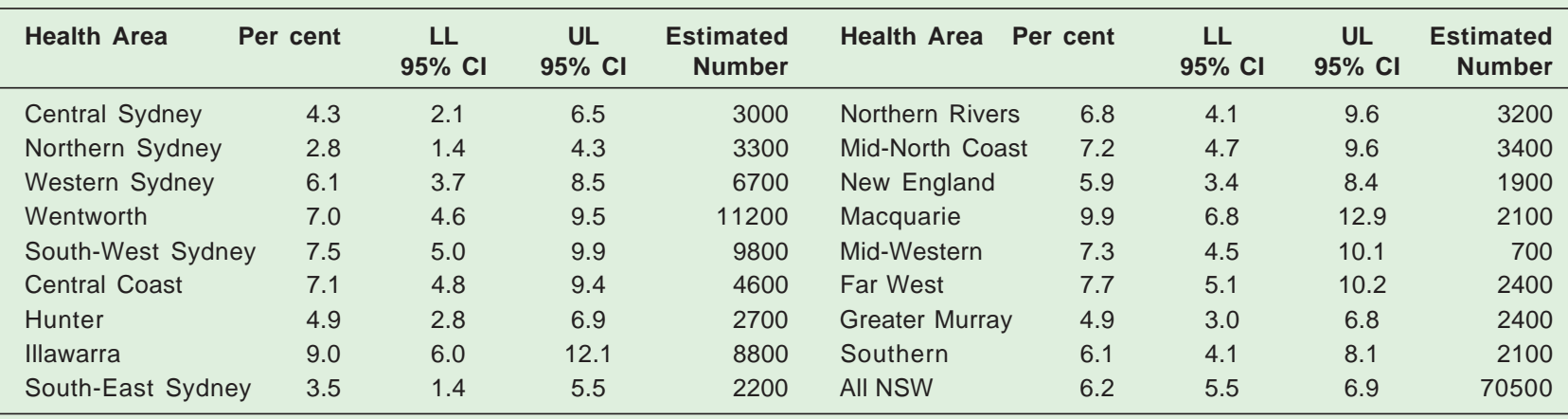

Note: Estimates based on 9425 respondents.

Source: New South Wales Child Health Survey 2001 (HOIST). Centre for Epidemiology and Research, NSW Department of Health.

with cyclical weight gain and weight loss, and with obesity. ${ }^{1}$ At the household level, the consequences of food insecurity include disruption of eating patterns and eating rituals; at the broader societal level, they include reduced productivity and threat to harmonious community life. ${ }^{2}$

In the New South Wales Child Health Survey 2001, all parents or carers were asked whether there were any times in the last 12 months that they had run out of food and could not afford to buy more. Those who reported that this had happened were asked a further series of questions about how this had affected their ability to feed their children.

Overall, 6.2 per cent of respondents reported that they had run out of food and couldn't afford to buy more, on at least one occasion, in the last 12 months. This proportion varied among area health services, from 2.8 per cent in Northern Sydney Health Area to 9.9 per cent in Macquarie Health Area (Figure 10, Table 8). The overall proportion was higher than that reported in the National Nutrition Survey: Foods eaten Australia 1995, where 5.0 per cent of adults aged over 19 years reported that they had run out of food and could not afford to buy more. ${ }^{3}$

Among respondents who had run out of food, threequarters (74.6 per cent) reported that, as a result, they ate the same thing for several days in a row. Smaller proportions of these parents or carers reported that their children were not fed balanced meals ( 43.7 per cent), were not eating enough (25.5 per cent), or were sometimes hungry (32.3 per cent).

\section{References}

1. Parnell WR, Reid J, Wilson NC, McKenzie J, Russell DG. Food security: Is New Zealand a land of plenty? New Zealand Medical Journal 2001: 114: 141-145.
2. Hamelin A, Habicht J, Beaudry M. Food insecurity: consequences for the household and broader social implications. J Nutr 1999; 129: S525-S528.

3. Australian Bureau of Statistics and Commonwealth Department of Health and Family Services. National Nutrition Survey: Selected highlights Australia 1995. Catalogue no. 4802.0. Canberra: ABS, 1997.

\section{Sun protection}

Australia has the highest incidence of skin cancer in the world and melanoma is the third most common potentially fatal cancer in Australia. Unprotected exposure to solar ultra-violet radiation (UVR) is the primary modifiable risk factor in the development of skin cancer. Childhood exposure to UVR has been shown to be particularly important in increasing the risk of skin cancer later in life. ${ }^{1}$

Sun protection behaviours play a key role in minimising the risk of developing skin cancer. The Slip, Slop, Slap ('slip on a shirt, slop on some sunscreen and slap on a hat') sun protection message has been promoted throughout Australia for over 20 years. ${ }^{1}$ In addition to this campaign, the more recent SunSmart campaign, adopted first in Victoria in 1988 through the Anti-Cancer Council, promotes sunlight avoidance by staying indoors during certain times of the day and wearing protective clothing to prevent exposure to UVR. ${ }^{2}$

In the New South Wales Child Health Survey 2001, all parents or carers were asked to identify actions they could take to reduce their child's risk of getting skin cancer. Respondents of children aged 12 months and over were also asked to describe their use of sun protection measures, and whether their child had been sunburnt, last summer. 


\section{FIGURE 11}

\section{USE OF HATS, SUNSCREEN AND PROTECTIVE CLOTHING LAST SUMMER BY AGE GROUP, CHILDREN}

AGED 1-12 YEARS, NSW, 2001

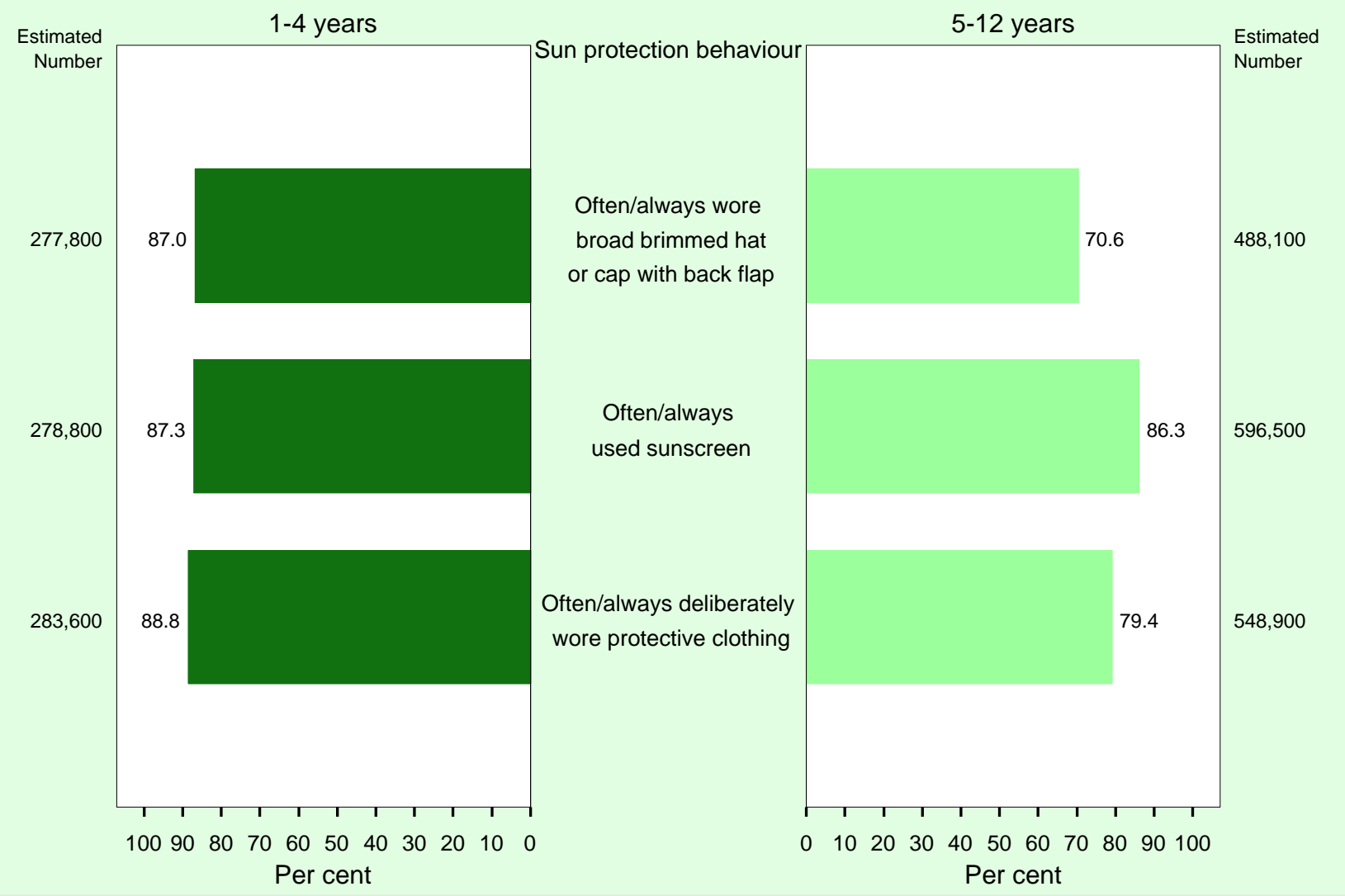

Note: Estimates based on 8372 children who were ever in the sun for at least 15 minutes between 11.00 a.m. and 3.00 p.m.

Source: New South Wales Child Health Survey 2001 (HOIST). Centre for Epidemiology and Research, NSW Department of Health.

\section{Awareness of sun protection measures}

When asked to name steps they could take to reduce their child's risk of getting skin cancer, most parents or carers mentioned applying sunscreen ( 94.3 per cent) and wearing a broad-brimmed hat or cap with flap (81.3 per cent). A smaller proportion mentioned wearing protective clothing (67.9 per cent). Less than one-quarter mentioned not going outside in the middle of the day (22.9 per cent); even fewer mentioned staying in the shade (16.7 per cent); while only 6.4 per cent mentioned wearing sunglasses.

\section{Use of sun protection measures}

When out in the sun for 15 minutes or more in the previous summer. Most children aged 1-12 years were reported to have worn a broad-brimmed hat or cap with a flap (75.8 per cent), often or always used sunscreen (86.6 per cent), and worn protective clothing ( 82.4 per cent). Reported use of sunscreen was similar among children aged 1-4 and 5-12 years. However, smaller proportions of children aged 5-12 years were reported to have often or always worn a broad-brimmed hat or cap with a flap (70.6 per cent) or protective clothing (79.4 per cent) (Figure 11).

\section{Frequency of sunburn}

More than one-third (35.6 per cent) of children aged 1-12 years were reported, in the previous summer, to have been sunburnt to the point where their skin was still sore and tender the next day. This proportion was slightly higher among females ( 37.9 per cent) than males (33.5 per cent). More children from rural areas (41.7 per cent) were reported to have had at least one episode of sunburn, compared with children from urban areas (33.7 per cent). Less than 4.0 per cent of children from both rural and urban areas were reported to have been sunburnt three or more times in the previous summer.

\section{References}

1. National Health and Medical Research Council. Primary prevention of skin cancer in Australia. Canberra: NHMRC, 1996.

2. SunSmart Web site at www.sunsmart.com.au, accessed 21 May 2002. 
FIGURE 12

PLACES WHERE CHILD WAS RESCUED, CHILDREN AGED 0-12 YEARS, WHO HAD EVER BEEN RESCUED FROM DROWNING. NSW. 2001

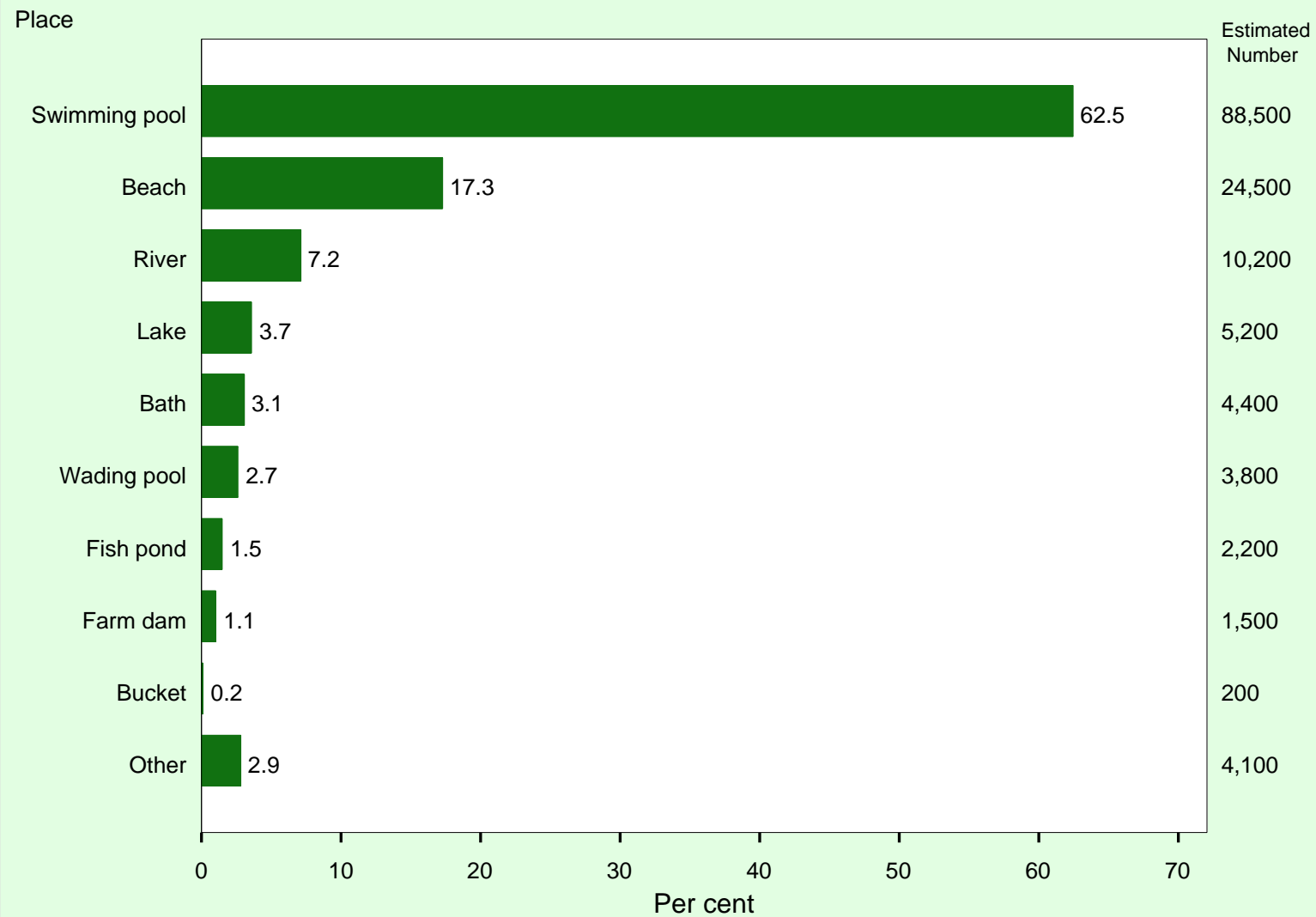

Note: Respondents could nominate more than one place. Percentages will total more than 100. Estimates based on 1157 respondents.

Source: New South Wales Child Health Survey 2001 (HOIST). Centre for Epidemiology and Research, NSW Department of Health

\section{Water safety: Drowning}

There were 16 unintentional drownings of children aged under five years in NSW in 1999, and an estimated 14 in 2000 , representing about one in five unintentional drownings across all age groups. Around two-thirds of drownings occur in males. ${ }^{1}$ Swimming pools are the most common location for drowning in children, followed by lakes, lagoons or waterholes, and bathtubs. ${ }^{2}$

In the New South Wales Child Health Survey 2001, all parents or carers were asked whether their child had ever been rescued from drowning in any body of water, including a beach, river, bath, bucket, pond, or wading pool. Respondents were not asked whether their child had required medical assistance or had signs and symptoms of injury from drowning.

Overall, more than one in 10 children aged $0-12$ years (12.4 per cent) were reported to have been rescued from drowning. This proportion was higher among children aged 5-12 years (14.8 per cent) compared with children aged $0-4$ years (8.5 per cent), and higher among males
(13.0 per cent) than females ( 11.8 per cent). It was slightly higher among children from rural areas (13.3 per cent), compared with those from urban areas (12.1 per cent).

By far the most common places from which children had been rescued were swimming pools (62.5 per cent of rescues), followed by beaches (17.3 per cent) and rivers (7.2 per cent) (Figure 12). Less than five per cent of reported rescues were from bathtubs, lakes, wading pools, or other bodies of water.

\section{References}

1. Public Health Division. The health of the people of NSWReport of the Chief Health Officer 2002. Sydney: NSW Department of Health, 2002.

2. Moon L, Rahman N, Bhatia K. Australia's children: Their health and wellbeing 1998. AIHW Catalogue no. PHE 7. Canberra: Australian Institute of Health and Welfare, 1998. 


\section{FIGURE 13}

SPORTS AND ACTIVITIES PLAYED INTHE LAST 12 MONTHS BY SEX, CHILDREN AGED 5-12 YEARS, NSW, 2001

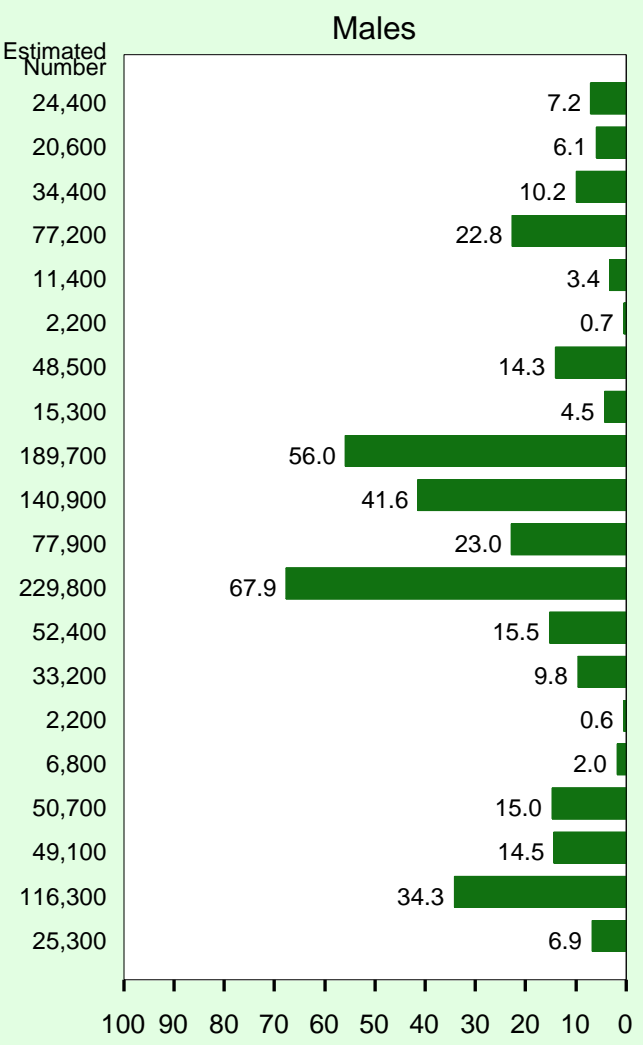

Per cent

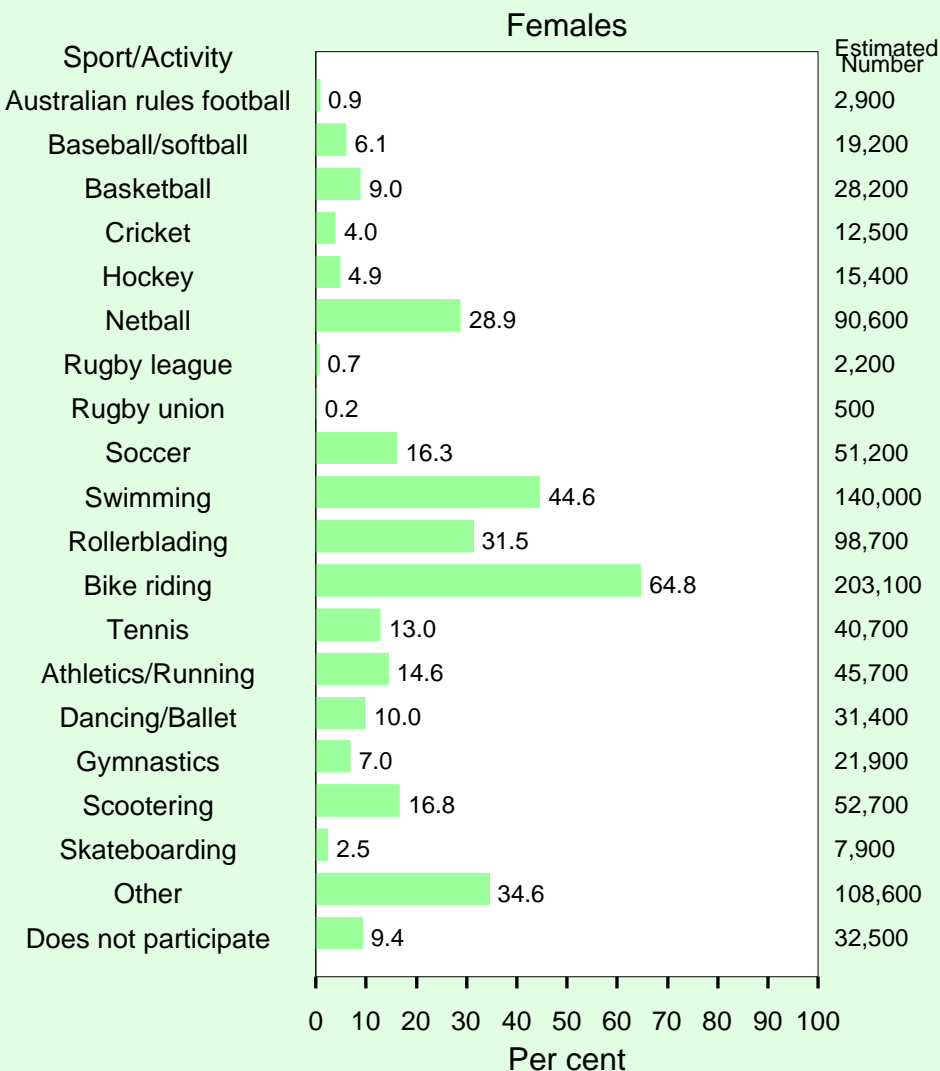

Per cent

Note: Respondents could list more than one sport or activity. Percentages will total more than 100 . Estimates based on 5888 respondents.

Source: New South Wales Child Health Survey 2001 (HOIST). Centre for Epidemiology and Research, NSW Department of Health.

\section{Physical activity and inactivity}

Weight-bearing physical activity in childhood is associated with higher bone mineral density and reduced risk of osteoporosis in adulthood. ${ }^{1}$ Physical activity may also have positive effects on blood lipids, blood pressure, body composition, glucose metabolism, and the psychological health of children. ${ }^{2}$ Additionally, an active lifestyle during childhood is likely to assist in establishing activity patterns that will continue into adulthood, with consequent reduction in the risk of obesity, cardiovascular disease, diabetes, cancer of the colon, and osteoporosis, all of which may have their beginnings in childhood.

Factors associated with higher levels of activity in childhood and adolescence include: access to facilities and programs; participation in sports; time spent outdoors; and perceived competence at physical activities. Factors associated with lower levels of activity include: being sedentary after school and on weekends, and depression. ${ }^{2}$ Booth et al. constructed three categories of physical activity in children for a school-based survey in NSW in 1997. ${ }^{3}$ The categories were: active (participation in at least 3.5 hours moderate intensity activity over at least five sessions during a normal week); vigorous (participation in vigorous activities at least three times per week for at least 20 minutes per session); and inactive (students who do not register in other categories) ${ }^{4}$ This measurement was based on physical activity recommendations for adolescents by Sallis et al..$^{5}$ In the school survey, around 80 per cent of NSW children were reported to be sufficiently physically active (that is, in the adequate or vigorous activity groups) $)^{4}$

Television viewing may promote childhood obesity through two mechanisms: reduced physical activity; and increased dietary energy intake, either during viewing or as a result of food advertising. ${ }^{6}$ Observational studies have reported inconsistent associations between time spent watching television and prevalence of obesity. However, recent evidence from intervention trials suggests that reducing television viewing reduces the risk of obesity, and promotes weight loss in obese children. ${ }^{7}$ 


\section{FIGURE 14}

\section{TIME SPENT PLAYING COMPUTER GAMES OR WATCHING TELEVISION OR VIDEOS, CHILDREN AGED 5-12 YEARS, NSW, 2001}
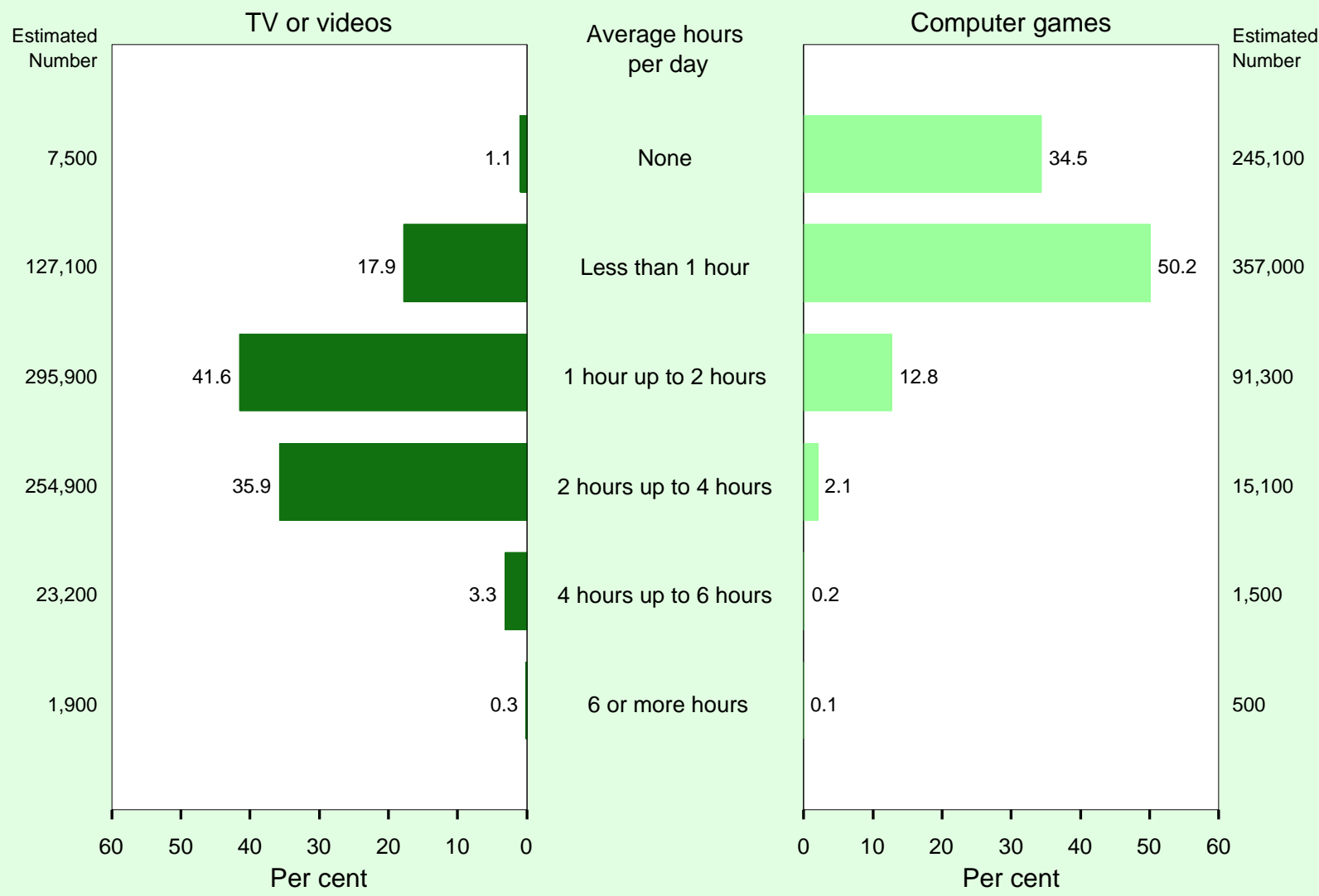

Note: Estimates based on 5888 respondents.

Source: New South Wales Child Health Survey 2001 (HOIST). Centre for Epidemiology and Research, NSW Department of Health.

It is not possible to accurately measure levels of physical activity among children in an interview survey such as the New South Wales Child Health Survey 2001, because parents or carers cannot accurately estimate the child's activity levels. Instead, parents and carers were asked about participation in sports and outdoor activities, and in organised physical activities outside school, as markers of activity levels. Additionally, respondents were asked whether they had actively discouraged their child from playing specific sports because of concerns for injury or safety. Parents or carers of children aged 5-12 years were also asked about the time their child spent watching television and playing computer games.

\section{Participation in sports and outdoor activities}

Overal, 91.9 per cent of children aged 5-12 years participated in sports and outdoor activities in the last 12 months (93.1 per cent for males and 90.6 per cent for females). The most frequently-reported sports and activities among males were: bike riding (67.9 per cent), soccer (56.0 per cent), swimming (41.6 per cent), cricket ( 22.8 per cent), rollerblading (23.0 per cent), tennis (15.5 per cent), rugby league (14.3 per cent), scootering (15.0 per cent), basketball (10.2 per cent), and Australian rules football (7.2 per cent). Only 4.5 per cent reported playing rugby union. The most frequently reported sports and activities among females were: bike riding ( 64.8 per cent), swimming ( 44.6 per cent), rollerblading (31.5 per cent), netball (28.9 per cent), scootering (16.8 per cent), soccer (16.3 per cent), and tennis (13.0 per cent) (Figure 13).

\section{Frequency of participation in organised physical activities outside school}

Overall, 58.1 per cent of children aged 5-12 years were reported to have 'participated in sports with a coach outside school hours' at least once per week in the past 12 months. Almost two-thirds of males (64.7 per cent) and half of females (51.5 per cent) were reported to participate at least once per week; while more than a third of males (38.9 per 
cent) and almost one-quarter of females (23.3 per cent) were reported to participate more than once per week.

Smaller proportions of children were reported to participate in 'other' organised physical activities, such as dance, gymnastics, or martial arts, outside school hours. Females (42.8 per cent) were more likely than males (19.0 per cent) to be reported to participate in these activities at least once per week.

\section{Injury and safety concerns about sports and outdoor activities}

In the New South Wales Child Health Survey 2001, 31.8 per cent of parents or carers of children aged 5-12 years reported discouraging children from playing sport (38.9 per cent for males and 24.2 per cent for females) because of concerns for injury and safety. Among males, the most frequently discouraged sport was rugby league (22.8 per cent), followed by rugby union (7.5 per cent) and Australian rules football (2.9 per cent). Among females, the most frequently discouraged sports and activities were roller-blading (2.6 per cent), rugby league ( 2.0 per cent), and soccer (2.0 per cent).

At least among males, the sports that were most discouraged by parents or carers were consistent with those most associated with sporting injuries. The sports causing the most injuries among NSW high school students in 1994-1995 were: rugby union, rugby league, gymnastics, netball, hockey, and Australian rules football. ${ }^{8}$

\section{Time spent watching television or videos and playing computer games}

Children of both sexes aged 5-12 years were most commonly reported to watch an average of between one and two hours of television or videos per day (41.3 per cent of males and 42.0 per cent of females). Around one in five children of both sexes (16.8 per cent of males and 19.0 per cent of females) were reported to watch an average of less than one hour per day. Just over one-third (37.6 per cent of males and 34.1 per cent of females) were reported to watch an average of between two and four hours per day, while a small minority (3.4 per cent of males and 3.8 per cent of females) were reported to watch four or more hours per day. Overall, 39.5 per cent of all children aged 5-12 years watched an average of two or more hours of television per day.

Although television and video watching was similar among males and females aged 5-12 years, males were reported to spend more time playing computer games. More than three-quarters of males (77.3 per cent) were reported to play computer games, compared with just over half of females (53.0 per cent). More than one in five males (21.9 per cent) were reported to play computer games for an average of more than one hour per day, while the comparable figure for females was less than one in $10(8.2$ per cent) (Figure 14).

\section{References}

1. French SA, Fulkerson JA, Story M. Increasing weight-bearing physical activity and calcium intake for bone mass growth in children and adolescents: A review of intervention trials. Prev Med 2000; 31: 722-731.

2. Sallis JF, Prochaska JJ, Taylor WC. A review of correlates of physical activity in children and adolescents. Med Sci Sports Exerc 2000; 32: 963-975.

3. Booth M, Macaskill P, McLellan L, et al. NSW Schools Fitness and Physical Activity Survey 1997. Sydney: NSW Department of School Education, 1997.

4. Booth ML, Okley AD, Chey T, Bauman AE, Macaskill P. Epidemiology of physical activity participation among New South Wales school students. Aust NZ J Public Health 2002; 26: $371-4$

5. Sallis, JF, Patrick K, Long BJ. Overview of the International Consensus Conference on Physical Activity Guidelines for Adolescents. Paediatric Exercise Science 1994; 6(4): 299-301.

6. Bar-On ME. The effects of television on child health: Implications and recommendations. Arch Dis Child 2000; 83: 289-292.

7. Robinson TN. Television viewing and childhood obesity. Pediatr Clin North Am 2001; 48: 1017-25.

8. Northern Sydney Area Health Service. New South Wales Sports Injury Report. Sydney: NSAHS, 1997. 


\section{HEALTH STATUS}

While most children are healthy, it is important to monitor health problems in children to detect emerging patterns of illness and to inform policy and planning of child health services. This section reports on asthma, oral health, disability, emotional and behavioural problems in children, and health status as measured by the Child Health Questionnaire (CHQ).

\section{Asthma}

Asthma is a chronic inflammatory disorder of the airways of the lung. Swelling of the airway lining, over-production of mucus, and contraction of the airway muscles in reaction to certain triggers, causes reversible airway narrowing and obstruction of breathing. The airways become hypersensitive, and the inflammatory process can cause permanent changes in the airways in the long term. ${ }^{1}$ The prevalence of asthma in Australian children is among the highest in the world and is increasing. ${ }^{2}$
The consequences of asthma in children can include: disturbed sleep; tiredness; and reduced participation in play at school, organised sport, and other activities. Asthma ranks among the top 10 problems managed by general practitioners and is a major cause for hospital admission in children. ${ }^{2}$

While asthma is not curable, it can be effectively managed. Current recommended management strategies include: increased use of preventer medications; reduced use of reliever medications where appropriate; use of structured written asthma management plans; avoidance of triggers (where known); self management education, and regular review by a general practitioner. ${ }^{1,3}$ Research has shown that most patients with asthma management plans found it useful for managing their asthma. ${ }^{4}$

The New South Wales Child Health Survey 2001 included questions that assessed prevalence, severity, and management of asthma among children aged 2-12 years.

\section{FIGURE 15}

CURRENT ASTHMA AND WRITTEN ASTHMA MANAGEMENT PLAN BY AREA HEALTH SERVICE OF RESIDENCE, CHILDREN AGED 2-12 YEARS, NSW, 2001

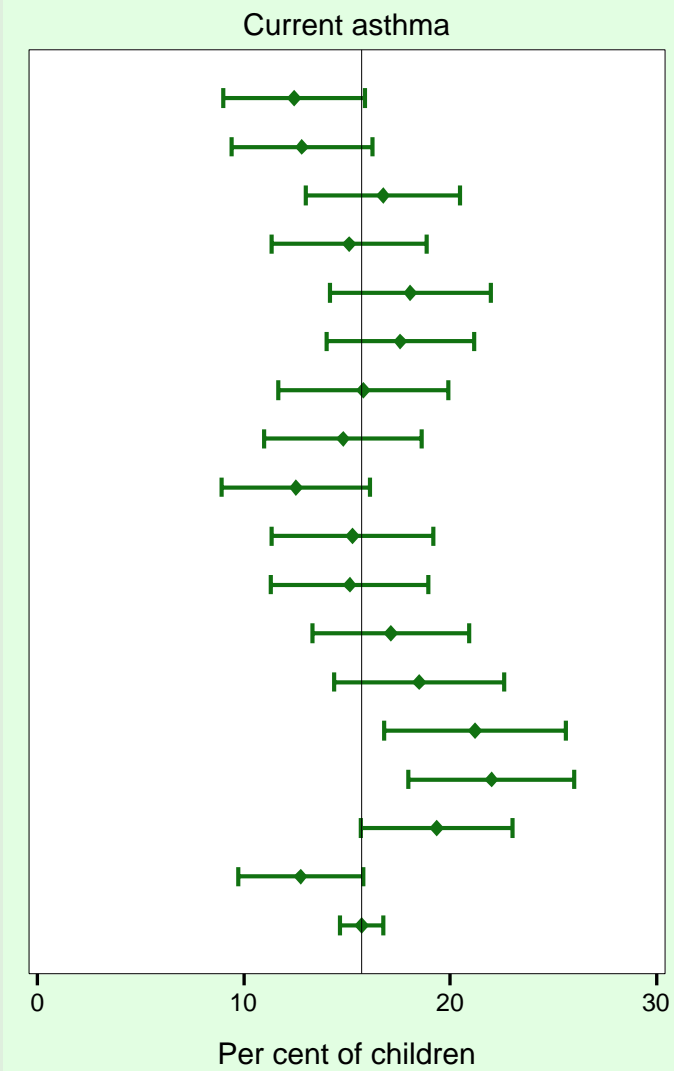

Health Area
Central Sydney
Northern Sydney
Western Sydney
Wentworth
South-West Sydney
Central Coast
Hunter
Illawarra
South-East Sydney
Northern Rivers
Mid-North Coast
New England
Macquarie
Mid-Western
Far West
Greater Murray
Southern
All NSW

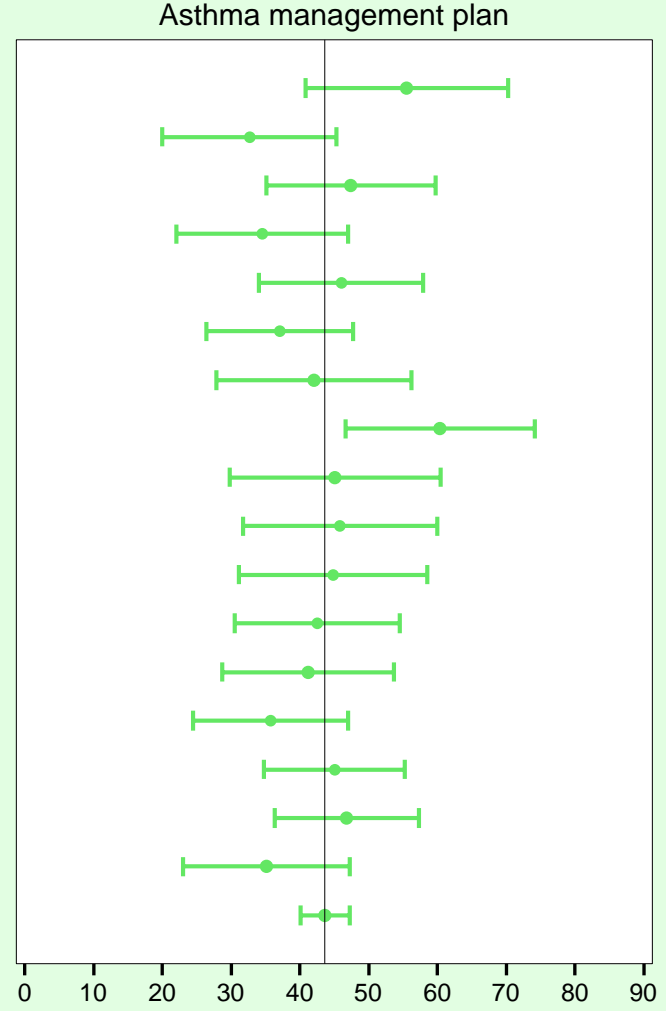

Per cent of children with current asthma

Note: Current asthma $=$ symptoms of asthma or medication for treatment or prevention of asthma in the last 12 months. Current asthma estimates based on 7916 respondents. Asthma management plan estimates based on 1296 respondents.

Source: New South Wales Child Health Survey 2001 (HOIST). Centre for Epidemiology and Research, NSW Department of Health. 


\section{TABLE 9}

CURRENT ASTHMA AND WRITTEN ASTHMA MANAGEMENT PLAN BY AREA HEALTH SERVICE OF RESIDENCE, CHILDREN AGED 2-12 YEARS, NSW, 2001

\begin{tabular}{|c|c|c|c|c|c|c|c|c|}
\hline Health Area & cent & LL $95 \% \mathrm{Cl}$ & UL 95\% Cl & $\begin{array}{r}\text { Estimates } \\
\text { Number }\end{array}$ & Per cent & LL 95\% Cl & UL $95 \% \mathrm{Cl}$ & $\begin{array}{r}\text { Estimates } \\
\text { Number }\end{array}$ \\
\hline \multicolumn{4}{|l|}{ Current asthma } & \multicolumn{5}{|c|}{ Asthma management plan } \\
\hline Central Sydney & 12.4 & 9.0 & 15.9 & 7000 & 55.5 & 40.8 & 70.3 & 3900 \\
\hline Northern Sydney & 12.8 & 9.4 & 16.2 & 12600 & 32.7 & 20.0 & 45.3 & 4100 \\
\hline Western Sydney & 16.7 & 13.0 & 20.5 & 15300 & 47.4 & 35.1 & 59.7 & 7200 \\
\hline Wentworth & 15.1 & 11.4 & 18.9 & 20400 & 34.5 & 22.0 & 47.0 & 7000 \\
\hline South-West Sydney & 18.1 & 14.2 & 22.0 & 19800 & 46.0 & 34.1 & 57.9 & 9100 \\
\hline Central Coast & 17.6 & 14.0 & 21.2 & 9700 & 37.0 & 26.3 & 47.7 & 3600 \\
\hline Hunter & 15.8 & 11.7 & 19.9 & 7400 & 42.1 & 27.9 & 56.2 & 3100 \\
\hline Illawarra & 14.8 & 11.0 & 18.6 & 12300 & 60.4 & 46.6 & 74.1 & 7400 \\
\hline South-East Sydney & 12.5 & 8.9 & 16.1 & 6800 & 45.1 & 29.7 & 60.4 & 3100 \\
\hline Northern Rivers & 15.3 & 11.3 & 19.2 & 6300 & 45.8 & 31.7 & 59.9 & 2900 \\
\hline Mid-North Coast & 15.1 & 11.3 & 19.0 & 6200 & 44.8 & 31.1 & 58.5 & 2800 \\
\hline New England & 17.1 & 13.3 & 20.9 & 4900 & 42.5 & 30.5 & 54.5 & 2100 \\
\hline Macquarie & 18.5 & 14.4 & 22.6 & 3400 & 41.2 & 28.7 & 53.7 & 1400 \\
\hline Mid-Western & 21.2 & 16.8 & 25.6 & 1700 & 35.7 & 24.4 & 47.0 & 600 \\
\hline Far West & 22.0 & 18.0 & 26.0 & 6000 & 45.0 & 34.8 & 55.3 & 2700 \\
\hline Greater Murray & 19.3 & 15.7 & 23.0 & 8300 & 46.8 & 36.3 & 57.3 & 3900 \\
\hline Southern & 12.7 & 9.7 & 15.8 & 3700 & 35.2 & 23.1 & 47.3 & 1300 \\
\hline All NSW & 15.7 & 14.7 & 16.8 & 151900 & 43.6 & 40.1 & 47.2 & 66300 \\
\hline
\end{tabular}

Note: $\quad$ Current asthma $=$ symptoms of asthma or medication for treatment or prevention of asthma in the last 12 months. Current asthma estimates based on 7916 respondents. Asthma management plan estimates based on 1296 respondents.

Source: New South Wales Child Health Survey 2001 (HOIST). Centre for Epidemiology and Research, NSW Department of Health.

\section{Asthma prevalence}

Approximately one quarter (26.4 per cent) of parents or carers reported ever being told by a doctor or at a hospital, that their child had asthma. This proportion was higher in males (29.8 per cent) than females (22.8 per cent); and the proportion increased with age, from 17.3 per cent among children aged two years, to 29.6 per cent among children aged 12 years.

Overal 15.7 per cent of children were reported to have current asthma (symptoms of asthma, or medication for asthma, in the last 12 months). Again, this proportion was higher in males (18.4 per cent) than females (12.9 per cent). Among males, current asthma was most frequently reported in the 6-8 year age group, affecting just over 20.0 per cent of males in this age group. Among females, current asthma was most frequently reported in the 9-10 year age group, affecting around 15.0 per cent of females in this age group. The prevalence of current asthma varied among area health services, with generally higher rates reported in rural areas. Current asthma was most frequently reported in Mid Western (21.2 per cent) and Far West (22.0 per cent) Health Areas (Figure 15, Table 9).

The reported overall prevalence of current asthma was consistent with other recent studies in NSW, which reported prevalence of current asthma as 22 per cent in a study based in Lismore, ${ }^{5}$ and 18 per cent in a study based in Wagga Wagga (children aged $3-5$ years). ${ }^{2}$

\section{Asthma severity}

More than half of children with current asthma (59.3 per cent) were reported to have visited a general practitioner (GP) for an asthma attack in the last 12 months. This proportion was similar among males (59.2 per cent) and females (59.3 per cent). More than one in five children (23.3 per cent) with current asthma were reported to have three or more GP visits for asthma attacks in the last 12 months. Reported visits to emergency departments were less frequent: 16.1 per cent of males and 16.4 per cent of females were reported to have visited an emergency department for an asthma attack in the last 12 months.

For more than half the children with current asthma (58.2 per cent), asthma was reported to have limited the child's usual activities in the last 12 months. The mean number of days of limited activity for children with current asthma was 9.3 days, while the median number was two days. Around half the children with current asthma were reported to have had disturbed sleep in the last month as a result of asthma (48.2 per cent). The mean number of nights of disturbed sleep for children with current asthma was 2.9 nights, while the median number was 0 nights. 


\section{Asthma management}

Less than half the children with current asthma (43.6 per cent) were reported to have a written asthma management plan from their doctor. This proportion was similar among males (41.9 per cent) and females (46.1 per cent). It varied among area health services, from 32.7 per cent in Northern Sydney to 60.4 per cent in Illawarra Health Area (Figure 15).

Overall, 61.6 per cent of children with current asthma were reported to have used a reliever medication in the last month; with the proportion being slightly higher for females (63.8 per cent) compared with males (60.1 per cent). Approximately one-quarter (26.6 per cent-27.2 per cent of males and 25.6 per cent of females) were reported to have used a reliever on less than half the days of the last month, with a smaller proportion (27.7 per cent) reported to use the reliever more frequently (29.6 per cent of males and 24.8 per cent of females).

Of children with current asthma, 59.4 per cent (56.4 per cent of males; 64.3 per cent of females) were reported to use a preventer medication in the last month. Overall, 39.3 per cent of children were reported to use a preventer every day (42.8 per cent of males; 33.8 per cent of females), and 8.6 per cent to use a preventer on most days ( 7.1 per cent of males; 10.8 per cent females). Overall, 18.3 per cent used a preventer on less than half the days of the previous month (18.7 per cent of males; 17.7 per cent of females) and approximately one quarter (26.2 per cent) were reported not to use a preventer in the last month (24.4 per cent males; 29.1 per cent females).

\section{References}

1. Australian Department of Health and Ageing. Health Insite: Asthma. Web site at www.healthinsite.gov.au/ T.cfm?PID=4765, accessed 17 January 2002.

2. Woolcock AJ, Bastiampillai SA, Marks GB, Keena VA. The burden of asthma in Australia. Med J Aust 2001; 175: 141-5.

3. Gibson PG, Coughlan J, Wilson AJ et al. Self management education and regular practitioner review for adults with asthma. Cochrane Database of Systematic Reviews [computer file]. Oxford: Update Software, 2000.

4. Douglass J, Aroni R, Goeman D, Stewart K, Sawyer S, Thien F, Abramson M. A qualitative study of action plans for asthma. BMJ 2002; 324: 1003 .

5. Haby MM. Peat JK, Marks GB, Woolcock AJ, Leeder SR. Asthma in preschool children: Prevalence and risk factors. Thorax 2001; 56: 589-95.

\section{Oral health}

The oral health of Australian children has improved over recent decades, with a dramatic decline in the experience of dental caries. ${ }^{1}$ However, there are clear inequalities in oral health, with higher rates of dental caries in children living in socially disadvantaged areas, rural and remote areas, and among Aboriginal and overseas-born children. There is also evidence of differential access to dental services according to country of birth, language spoken at home, insurance status, and mother's educational status. ${ }^{1,2,3}$

The oral health of children is most commonly assessed by their experience of dental caries, expressed as a score for decayed, missing, or filled teeth (DMFT). However, it is not possible to measure experience of dental caries in a telephone survey such as the New South Wales Child Health Survey 2001. Accordingly, the survey focused on the use of dental health services, including the frequency and place of dental visits and the treatments received. Distinction was made between short assessments of oral health, made as part of the Save Our Kids Smiles (SOKS) program, which the NSW Department of Health introduced in 1996; and visits to dental professionals, during which a full oral examination is conducted. The SOKS program is based in schools or pre-schools and involves children in Kindergarten, and Years 2, 4, 6 and 8 being offered free oral health education, oral health assessment, and clinical care on a priority-based system. ${ }^{4}$

In the New South Wales Child Health Survey 2001, parents or carers were asked about any dental injuries suffered by their child in the previous 12 months. Other reports have shown that most injuries to deciduous (milk) teeth occur at home, while most injuries to children's permanent teeth occur at home or school. Falls are the most common cause, although bicycle and traffic accidents, sports accidents, and violence, are also common causes. ${ }^{2,5}$ Mouthguards prevent dental injuries but are not widely used outside a few organised sports. Sports in which participants are at most risk of dental injuries include: rugby union, swimming, rugby league, basketball, cricket, hockey, soccer, netball, squash, softball-baseball, and tennis. ${ }^{6}$

\section{Save Our Kids Smiles (SOKS) assessments}

In the New South Wales Child Health Survey 2001, parents or carers of children aged 5-12 years were asked whether their child had a dental assessment at school as part of the SOKS program in the last 12 months. The New South Wales Child Health Survey 2001 captured information about SOKS assessments occurring between March 2000 and September 2001. Changes in eligibility for SOKS assessments occurred during this period. In 2000, all NSW children in the respective years being screened were eligible, while in 2001, assessments were offered only to children in these grades in schools designated as 'high risk' for poor oral health.

Just over half (53.1 per cent) of all children aged 5-12 years were reported to have had a dental assessment at school, as part of the SOKS program, in the last 12 months. This proportion was higher among children aged 8-12 years (57.4 per cent) than those aged 5-7 years ( 45.8 per cent). The reasons for this age difference are unclear but may relate to the timing of the survey interviews relative to the timing of the conduct of SOKS assessments around the state. 


\section{FIGURE 16}

\section{PLACE OF LAST DENTAL VISIT, CHILDREN AGED 1-12 YEARS, NSW, 2001}

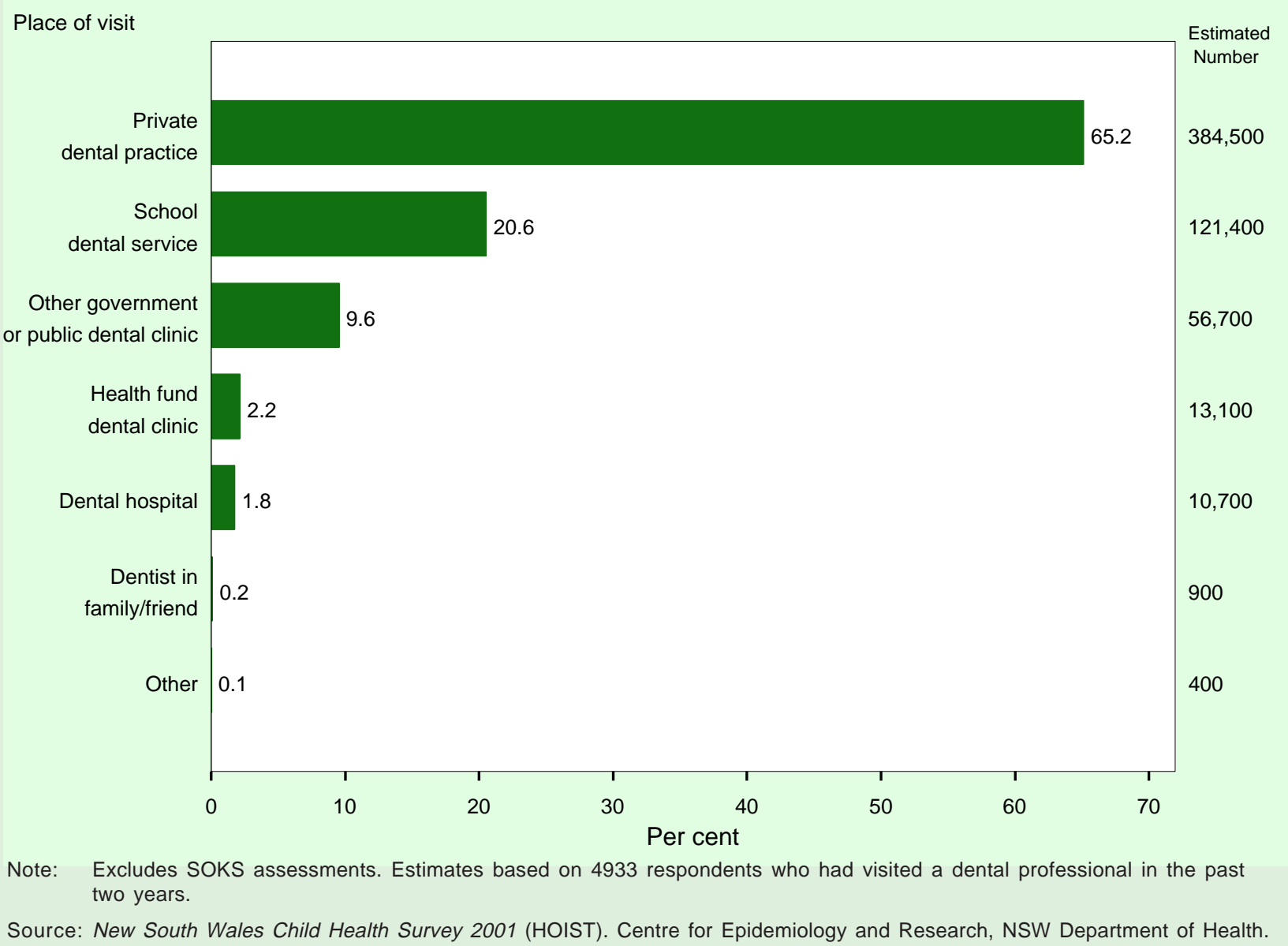

\section{Visits to dental professionals}

Overall, 61.6 per cent of children aged 1-12 years were reported to have ever visited a dental professional. This proportion was lower among indigenous children (52.5 per cent) than non-indigenous children ( 61.5 per cent), but was similar for children living in non-English speaking households (57.3 per cent) and English speaking households ( 60.7 per cent). The proportion of children reported as ever visiting a dental professional increased with age (4.0 per cent for children aged one year compared with 25.6 per cent for children aged 2-4 years, 67.6 per cent for children aged 5-7 years, and 90.0 per cent for children aged 8-12 years).

Forty-three (43.1per cent) of children aged 1-12 years reported visiting a dental professional (excluding SOKS assessment) in the last 12 months. This proportion increased with age (3.6 per cent for children aged one year compared with 20.8 per cent for children aged 2-4 years, 46.7 per cent for children aged 5-7 years, and 61.5 per cent for children aged 8-12 years).
Almost two-thirds (65.2 per cent) of dental visits (excluding SOKS assessments) made within the last two years were to private dental practices. One in five (20.6 per cent) were at school dental services and 9.6 per cent were at other public clinics. A minority reported attending a dental hospital (1.8 per cent) or a health fund dental clinic (2.2 per cent) (Figure 16). Of respondents who visited private dentists, 16.1 per cent were eligible for public dental care. The main reasons stated for using services provided by private dental professionals, when families were eligible for public dental care, were longer waiting times at public clinics (23.9 per cent), issues with continuity of care (15.8 per cent), better quality of care at private clinics (13.6 per cent), and poor access to public clinics (13.5 per cent).

The proportion of visits made at private dental clinics was considerably higher than that reported in National Dental Telephone Interview Survey 1999, where only around 40 per cent of NSW children aged 6-11 years had made their last visit to a private practitioner. ${ }^{3}$ 


\section{FIGURE 17}

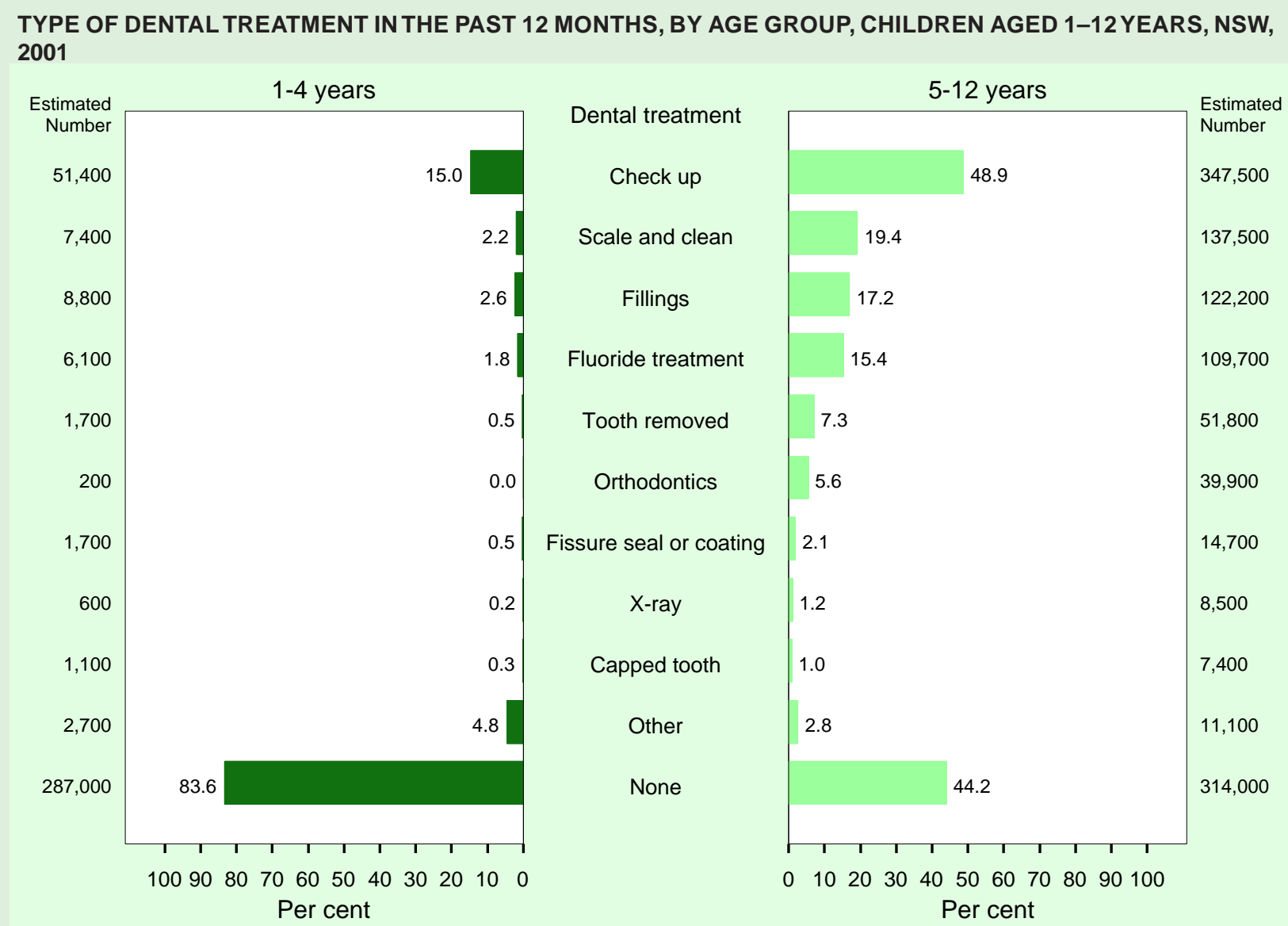

Note: Excludes SOKS assessments. Estimates based on 8689 respondents.

Source: New South Wales Child Health Survey 2001 (HOIST). Centre for Epidemiology and Research, NSW Department of Health.

\section{Dental treatments}

Overall, 37.9 per cent of children were reported to have had a dental check-up in the past 12 months (excluding SOKS assessments). This proportion varied by age group, with 15.0 per cent of children aged $1-4$ years and 48.9 per cent of children aged 5-12 years reported to have checkups. The most frequent dental procedures reported for children aged 5-12 years were scale and clean (19.4 per cent), fillings (17.2 per cent), fluoride treatment (15.4 per cent), removal of teeth (7.3 per cent), and orthodontics (5.6 per cent) (Figure 17). Children aged 5-12 years were around three times more likely than younger children to be reported to have had these dental procedures in the past 12 months.

\section{Dental injuries}

Overall, 3.9 per cent of children aged 5-12 years were reported to have seen a dental professional for treatment of a dental injury in the previous 12 months. This proportion was greater among children aged 8-12 years (3.7 per cent) compared with 5-7 years ( 2.4 per cent); and among males (3.9 per cent) compared with females (2.5 per cent).

\section{References}

1. Australian Institute of Health and Welfare Dental Statistics and Research Unit. Australia's oral health and dental services. AIHW Catalogue no. DEN 13. Adelaide: AIHW DSRU, 1998.

2. Australian Health Ministers' Advisory Council, Steering Committee for National Planning for Oral Health. Oral health of Australians: National planning for oral health improvement-Final report. Adelaide: South Australian Department of Human Services, 2001.

3. Australian Institute of Health and Welfare Dental Statistics and Research Unit. Oral Health and Access to Dental Care1994-96 and 1999 (Technical Report NDTIS 1999). Adelaide: AIHW DSRU, 2001. Available at www.adelaide.edu.au/ socprev-dent/dsru/publications.

4. NSW Department of Health. Review of the Save our Kids Smiles (SOKS) Program. Volume 1-Report. Sydney: NSW Department of Health, 2001.

5. Bastone EB, Freer TJ, McNamara JR. Epidemiology of dental trauma: A review of the literature. Aust Dent J 2000; 45: 2-9. 


\section{FIGURE 18}

\section{PREVALENCE AND SEVERITY OF SPEECH DIFFICULTIES BY SEX, CHILDREN AGED 2-12 YEARS, NSW, 2001}
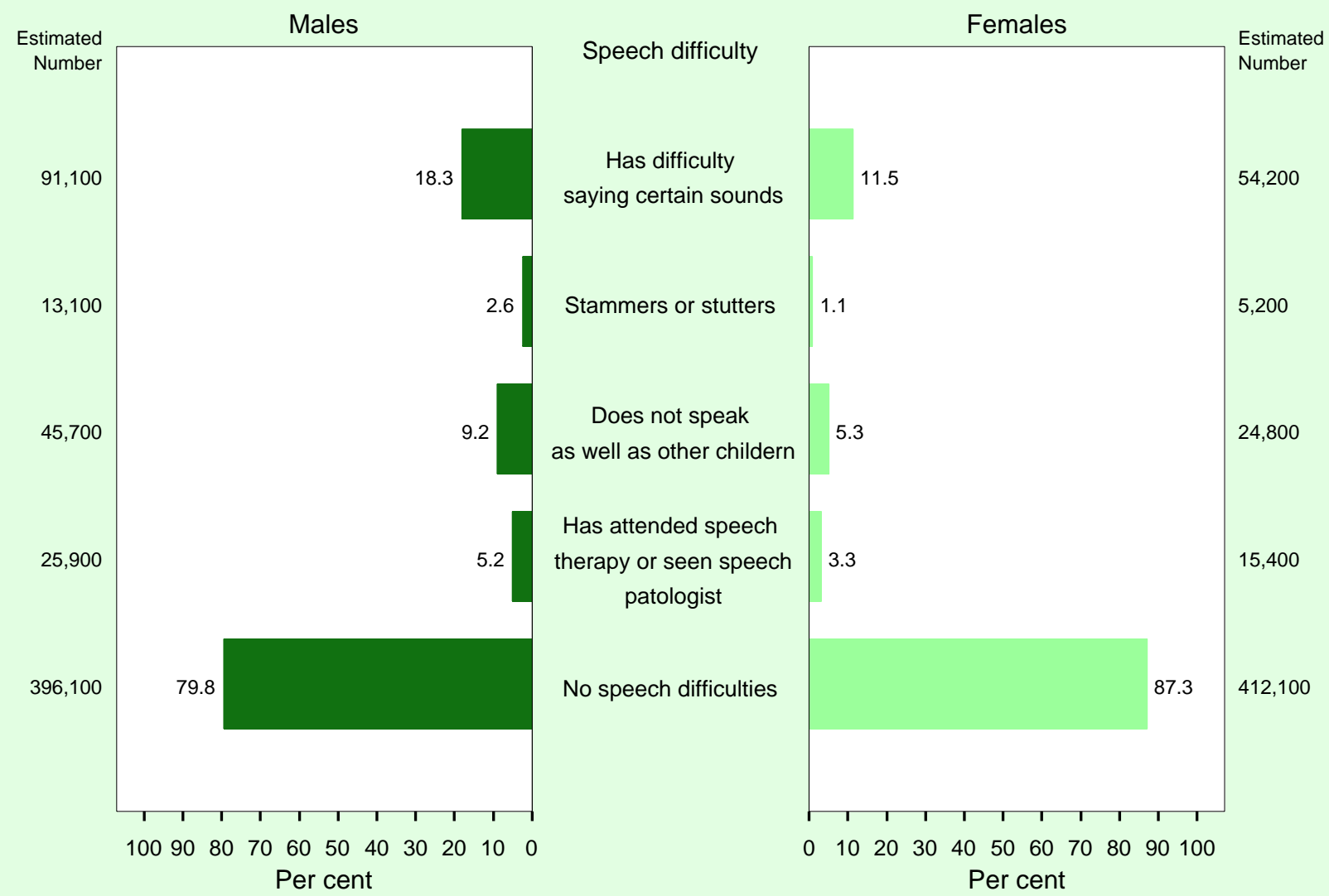

Note: Respondent could name more than one speech difficulty. Percentages will total more than 100 . Estimates based on 7916 respondents.

Source: New South Wales Child Health Survey 2001 (HOIST). Centre for Epidemiology and Research, NSW Department of Health.

6. Love RM, Carman N, Carmichael S, MacFadyen E. Sportsrelated claims to the New Zealand Accident Rehabilitation and Compensation Insurance Corporation, 1993-1996: Analysis of the 10 most common sports, excluding rugby union. N Z Dent J 1998; 94: 146-149.

\section{Disability}

The Australian Bureau of Statistics 1998 Survey of Disability, Ageing and Carers, reported that around one in 15 NSW children aged $0-14$ years (6.6 per cent) had a disability, with males ( 8.3 per cent) more frequently affected than females ( 4.8 per cent). Most of these children were restricted in their ability to perform core activities (such as self-care, mobility, or communication) and/or to participate in schooling. ${ }^{1}$

The New South Wales Child Health Survey 2001 included questions about visual, hearing, and speech impairments. These impairments can have adverse effects on communication skills, educational attainment, and quality of life. Published prevalence rates for communication disorders in children vary from 2-3 per cent to about 20 per cent, depending on the age of the children studied and the definition of the disorder. ${ }^{2}$ In the 1998 Australian Bureau of Statistics survey, sensory and speech impairments were the second most frequent cause of disability in children, after intellectual impairments. Around half of children with hearing or speech loss were restricted in their ability to communicate with others and/or had difficulties at school. ${ }^{3}$

The New South Wales Child Health Survey 2001 also included questions about ear infections. In otitis media (middle ear infection), fluid accumulates in the middle ear space, leading to conductive hearing loss. This may persist for weeks to months, after every episode of acute otitis media. Recurrent episodes may be associated with problems in the development of speech, language, and cognitive abilities. ${ }^{4}$

\section{Visual impairments}

Most children aged 2-12 years (92.6 per cent) were reported to have normal vision. Most of the children who did not have normal vision (7.4 per cent) were reported to wear glasses, and most of these ( 89.2 per cent) had no difficulty seeing words with their glasses on. 
Approximately one in 100 children ( 0.8 per cent) were reported to have difficulty seeing words, even with glasses on, or were blind in both eyes.

\section{Hearing impairments and ear infections}

Two-thirds (66.6 per cent) of children aged 2-12 years were reported to have had their hearing tested. One in 30 children (3.4 per cent) was reported to have any form of hearing loss, and 0.2 per cent were reported to currently wear a hearing aid.

Under half of all children aged $0-4$ years (42.0 per cent) were reported to have ever had an ear infection diagnosed by a doctor. Less than one in 10 (7.4 per cent) were reported to have ever had a discharge from an ear, or 'runny ear' (7.8 per cent of males; 6.9 per cent of females), while 2.2 per cent were reported to have had grommets inserted for treatment of chronic otitis media (2.6 per cent of males; 1.7 per cent of females).

\section{Speech difficulties}

Most children (83.4 per cent) were reported to have no speech difficulties. Overall, 16.6 per cent were reported to have a speech difficulty, with the rate being higher among males (20.2 per cent) compared with females (12.7 per cent). Compared with other children their age, 18.3 per cent of males and 11.5 per cent of females were reported to have difficulties saying certain sounds, while 9.2 per cent of males and 5.3 per cent of females were reported to not speak as well as other children. Also, 2.6 per cent males were reported to stammer or stutter, compared with 1.1 per cent of females. One in 20 males ( 5.2 per cent) and one in 30 females ( 3.3 per cent) were reported to have attended speech therapy or seen a speech pathologist (Figure 18).

\section{References}

1. Australian Bureau of Statistics. Disability Ageing and Carers, Summary Tables, New South Wales, 1998. Canberra: ABS, 1999.

2. Victorian Department of Human Services, Community Care Division Web site at http://hnb.dhs.vic.gov.au/comcare/ yafs_yf.nsf/6e, accessed 21 June 2002

3. Australian Bureau of Statistics. Disability Ageing and Carers, Disability and long term health conditions, Australia, 1998. Canberra: ABS, 2000.

4. Klein JO. The burden of otitis media. Vaccine 2000;19: S2-S8.

\section{General health status-The Child Health Questionnaire}

In the New South Wales Child Health Survey 2001, the general health status of children aged 5-12 years was assessed using the Child Health Questionnaire (CHQ), a multi-dimensional instrument that measures the functional health and wellbeing of children. The 28-item parentproxy form, CHQ PF28, is designed for administration to parents or carers of children aged 5-15 years. It has concepts of 'global health', 'physical functioning', 'rolesocial limitations (emotional-behavioural)', 'role- social limitations (physical)', 'bodily pain-discomfort', 'behaviour', 'global behaviour', 'mental health', 'selfesteem', 'general health perceptions', 'change in health', 'parental impact (emotional)', 'parental impact (time)', 'family cohesion', and 'family activities'. All questions are based on recall of the child's health over the past four weeks. ${ }^{1}$

The CHQ has been reported to be a reliable and valid measure of functional child health and wellbeing for the Australian population, encompassing children who are generally healthy and children with health problems related to physical and social functioning. ${ }^{2}$

This report does not report on the concept 'change in health', which measures general health now compared with one year ago, since this concept was not included in the New South Wales Child Health Survey 2001. In addition, we have only included one of two measures of general health (global health) and behaviour (global behaviour); and the report does not include the concepts of 'general health perceptions' and 'behaviour', both of which are scored differently.

The CHQ rating for each concept is reported by a mean and standard deviation (SD) (Table 10). This table provides population data for the parent-reported CHQ. These values can be used as a benchmark to compare subgroups of children or to monitor the health trends of the child health population aged $0-12$ years over time.

In the rating of 'global health', approximately half of all children were rated to have excellent health (51.6 per cent), one-third to have very good health (34.6 per cent), 11.1 per cent to have good health, and 2.1 per cent to have fair or poor health. The mean rating of 'global health' was slightly higher for children in rural areas (89.3), compared with urban areas (88.0). The mean rating of 'physical functioning' was slightly higher for females (96.4) compared with males (95.7) and among children aged 5-7 years (96.7) compared with children aged 8-12 years (95.6). The mean rating for 'body pain-discomfort' was slightly higher for males (84.4) compared with females (83.9) and among children aged 5-7 years (85.0) compared with children aged 8-12 years (83.6).

The mean rating for 'global behaviour' was higher for females (83.3) compared with males (77.5) and among children aged 8-12 years (81.1) compared with children aged 5-7 years (78.9). The mean rating for 'mental health' was similar for females (80.1) compared with males (79.0), and among children in rural areas (80.2) and urban areas (79.3). The mean rating for 'parental impact-emotional' was higher for females (83.0) compared with males (80.5) and for 'parental impact—-time' among children aged 812 years (93.1) compared with children aged 5-7 years (92.2). The mean rating for 'parental impact-time' was slightly higher for females (93.2) compared with males (92.2) and among children in rural areas (93.4) compared 
TABLE 10

\section{CHILD HEALTH QUESTIONNAIRE CONCEPTS AND MEAN RATING SCORES}

\begin{tabular}{|c|c|c|c|c|c|}
\hline Concept & $\begin{array}{l}\text { No. of questions } \\
\text { in the rating } \\
\text { (Rating scale) }\end{array}$ & Mean & SD & $\begin{array}{l}\text { Interpretation } \\
\text { - low score }(0)\end{array}$ & $\begin{array}{l}\text { Interpretation } \\
\text { - high score (100) }\end{array}$ \\
\hline Global health ${ }^{1}$ & $\begin{array}{l}1 \text { (Excellent, very } \\
\text { good, good, fair } \\
\text { or poor) }\end{array}$ & 88.3 & 0.2 & $\begin{array}{l}\text { Parent believes child's } \\
\text { health is poor }\end{array}$ & $\begin{array}{l}\text { Parent believes child's } \\
\text { health is excellent }\end{array}$ \\
\hline Physical functioning & $\begin{array}{l}3 \text { (Limited a lot, } \\
\text { limited some, limited } \\
\text { a little, not limited) }\end{array}$ & 96.0 & 0.2 & $\begin{array}{l}\text { Child is limited a lot in } \\
\text { performing all physical } \\
\text { activities including bending, } \\
\text { stooping and lifting, due to } \\
\text { health problems }\end{array}$ & $\begin{array}{l}\text { Child performs all types of } \\
\text { physical activities, including } \\
\text { the most vigorous, without } \\
\text { limitations due to health } \\
\text { problems }\end{array}$ \\
\hline $\begin{array}{l}\text { Role-social } \\
\text { limitations } \\
\text { (emotional- } \\
\text { behavioural) }\end{array}$ & $\begin{array}{l}1 \text { (Limited a lot, } \\
\text { limited some, } \\
\text { limited a little, not } \\
\text { limited) }\end{array}$ & 95.9 & 0.3 & $\begin{array}{l}\text { Child is limited a lot in school } \\
\text { work or activities with friends } \\
\text { as a result of emotional or } \\
\text { behavioural problems }\end{array}$ & $\begin{array}{l}\text { Child has no limitations in } \\
\text { school work or activities } \\
\text { with friends as a result of } \\
\text { emotional or behavioural } \\
\text { problems }\end{array}$ \\
\hline $\begin{array}{l}\text { Role-social } \\
\text { limitations } \\
\text { (physical) }\end{array}$ & $\begin{array}{l}1 \text { (Limited a lot, } \\
\text { limited some, limited } \\
\text { a little, not limited) }\end{array}$ & 95.6 & 0.3 & $\begin{array}{l}\text { Child is limited a lot in school } \\
\text { work or activities with friends } \\
\text { as aresult of physical health }\end{array}$ & $\begin{array}{l}\text { Child has no limitations in } \\
\text { school work or activities } \\
\text { with friends as a result of } \\
\text { physical health }\end{array}$ \\
\hline $\begin{array}{l}\text { Bodily pain- } \\
\text { discomfort }\end{array}$ & $\begin{array}{l}1 \text { (None of the time, } \\
\text { once or twice, a few } \\
\text { times, fairly often, } \\
\text { very often, every day } \\
\text { or almost every day) }\end{array}$ & 84.1 & 0.3 & $\begin{array}{l}\text { Child has body pain or } \\
\text { discomfort every day }\end{array}$ & $\begin{array}{l}\text { Child has no body pain or } \\
\text { discomfort }\end{array}$ \\
\hline Global behaviour ${ }^{1}$ & $\begin{array}{l}1 \text { (Excellent, very good, } \\
\text { good, fair or poor) }\end{array}$ & 80.3 & 0.4 & $\begin{array}{l}\text { Child's behaviour is poor } \\
\text { compared with other children } \\
\text { of the same age }\end{array}$ & $\begin{array}{l}\text { Child's behaviour is } \\
\text { excellent compared with } \\
\text { other children of the } \\
\text { same age }\end{array}$ \\
\hline Mental health ${ }^{1}$ & $\begin{array}{l}3 \text { (All of the time, most } \\
\text { of the time, some of the } \\
\text { time, a little of the time, } \\
\text { never) }\end{array}$ & 79.5 & 0.3 & $\begin{array}{l}\text { Child feels lonely, nervous, } \\
\text { bothered or upset all of the } \\
\text { time }\end{array}$ & $\begin{array}{l}\text { Child feels lonely, nervous, } \\
\text { bothered or upset none } \\
\text { of the time }\end{array}$ \\
\hline Self-esteem ${ }^{1}$ & $\begin{array}{l}3 \text { (Very satisfied, } \\
\text { somewhat satisfied, } \\
\text { neither satisfied nor } \\
\text { dissatisfied, somewhat } \\
\text { satisfied, very } \\
\text { dissatisfied) }\end{array}$ & 84.5 & 0.3 & $\begin{array}{l}\text { Child is very dissatisfied with } \\
\text { school abilities, friendships } \\
\text { and life overall }\end{array}$ & $\begin{array}{l}\text { Child is very satisfied with } \\
\text { school abilities, } \\
\text { friendships and life overall }\end{array}$ \\
\hline $\begin{array}{l}\text { Parental impact } \\
\text { (emotional) }\end{array}$ & $\begin{array}{l}2 \text { (None at all, a little } \\
\text { bit, some, quite a bit, } \\
\text { a lot) }\end{array}$ & 81.7 & 0.4 & $\begin{array}{l}\text { Parent experiences a lot of } \\
\text { emotional worry or concern as } \\
\text { a result of child's physical } \\
\text { health, emotional wellbeing or } \\
\text { behaviour }\end{array}$ & $\begin{array}{l}\text { Parent doesn't experience } \\
\text { emotional worry or concern } \\
\text { as a result of child's hysical } \\
\text { health, emotional wellbeing } \\
\text { or behaviour }\end{array}$ \\
\hline $\begin{array}{l}\text { Parental impact } \\
\text { (time) }{ }^{1}\end{array}$ & $\begin{array}{l}2 \text { (Limits me a lot, limits } \\
\text { me some, limits me a } \\
\text { little, does not limit me) }\end{array}$ & 92.7 & 0.3 & $\begin{array}{l}\text { Parent experiences a lot of } \\
\text { limitations in time available for } \\
\text { own personal needs due to } \\
\text { child's physical health, } \\
\text { emotional wellbeing, or } \\
\text { behaviour }\end{array}$ & $\begin{array}{l}\text { Parent doesn't experience } \\
\text { a lot of limitations in time } \\
\text { available for own personal } \\
\text { needs due to child's physical } \\
\text { health, emotional wellbeing, } \\
\text { or behaviour }\end{array}$ \\
\hline Family cohesion & $\begin{array}{l}1 \text { (Excellent, very good, } \\
\text { good, fair, poor) }\end{array}$ & 76.9 & 0.4 & $\begin{array}{l}\text { Family's ability to get on is } \\
\text { rated 'poor' }\end{array}$ & $\begin{array}{l}\text { Family's ability to get on } \\
\text { is rated 'excellent' }\end{array}$ \\
\hline Family activities & $\begin{array}{l}2 \text { (Very often, fairly } \\
\text { often, sometimes, } \\
\text { almost never, never) }\end{array}$ & 84.5 & 0.4 & $\begin{array}{l}\text { The child's health very often } \\
\text { limits and interrupts family } \\
\text { activities }\end{array}$ & $\begin{array}{l}\text { The child's health never } \\
\text { limits or interrupts family } \\
\text { activities }\end{array}$ \\
\hline
\end{tabular}

Notes: Comparisons based on 5888 respondents. We did not report on the concepts 'change in health', 'general health perceptions', and 'behaviour',

1 The minimal score for these items is more than 0.

SD Standard deviation

Source: New South Wales Child Health Survey 2001 (HOIST). Centre for Epidemiology and Research, NSW Department of Health. 


\section{FIGURE 19}

HAD EMOTIONAL OR BEHAVIOURAL PROBLEMS INTHE LAST SIX MONTHS, BY AGE AND SEX, CHILDREN AGED 4-12 YEARS, NSW, 2001
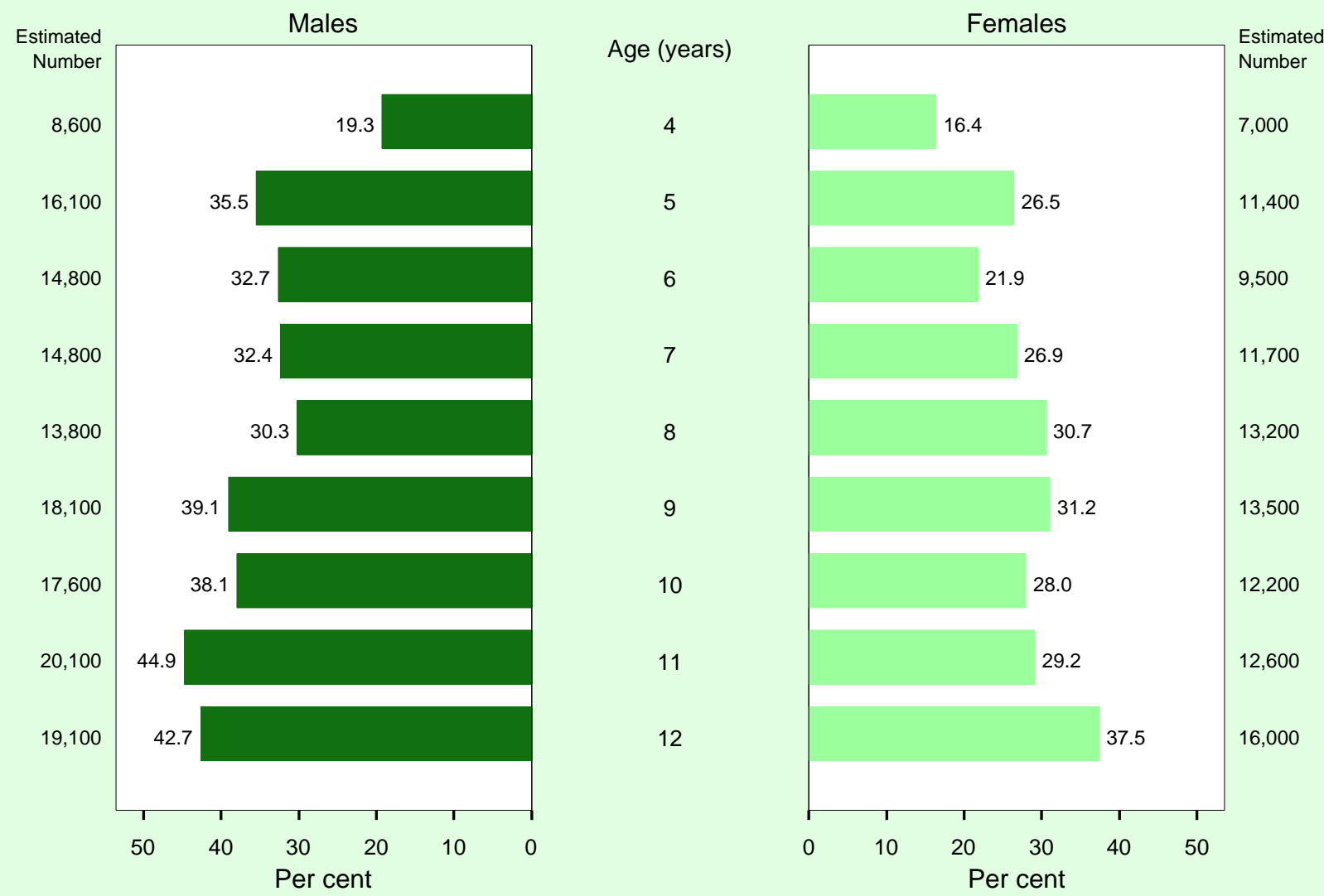

Note: Estimates based on 6503 respondents.

Source: New South Wales Child Health Survey 2001 (HOIST). Centre for Epidemiology and Research, NSW Department of Health.

with urban areas (92.5). The mean rating for 'family activities' was higher for females (86.) compared with males (83.0) and among children aged $8-12$ years (85.0) compared with children aged 5-7 years (83.7).

Similar results were reported from a self-completed parental survey in a large school-based sample in Victoria of children aged 5-18 years, using the PF50 (an expanded version of the PF28 questionnaire). ${ }^{2}$ The main differences were that the Victorian sample had lower mean scores for the concepts of 'role-social limitations (emotionalbehavioural)' (93.7) and 'self-esteem' (79.7), and slightly lower scores for 'body pain-discomfort' (82.3).

\section{References}

1. Landgraf JM, Abetz L, Ware JE. The Child Health Questionnaire (CHQ) User's Manual. First Edition. Boston, Mass: The Health Institute, New England Medical Center, 1996.

2. Waters E, Salmon L, Wake M, Hesketh K, Wright M. The Child Health Questionnaire in Australia: Reliability, validity and population norms. Aust N Z J Public Health 2000; 24: 207-210.

\section{Emotional and behavioural problems}

Childhood emotional and behavioural problems are one of the most common challenges that parents and carers face. Behaviour or school problems add stress to any family. The vast majority of childhood behavioural problems fall within the normal range and are appropriately dealt with by parents or primary care workers such as maternal and child and family health nurses, general practitioners, community health workers, and early childhood and childcare professionals. By understanding the nature of emotional or behavioural problems, and by getting the appropriate help and support, parents can better deal with these issues.

The child and adolescent component of the National Survey of Mental Health and Wellbeing 2000, ${ }^{1}$ provided the first reliable national data on the burden of mental health problems in children and adolescents in Australia. According to the results of the national survey, 15.0 per cent of boys aged 4-12 years and 14.4 per cent of girls aged 4-12 years have emotional or behavioural problems 


\section{FIGURE 20}

\section{SEVERITY OF EMOTIONAL OR BEHAVIOURAL PROBLEMS INTHE LAST SIX MONTHS, BY SEX, CHILDREN AGED}

4-12 YEARS, WHO HAD EMOTIONAL AND BEHAVIOURAL PROBLEMS, NSW, 2001
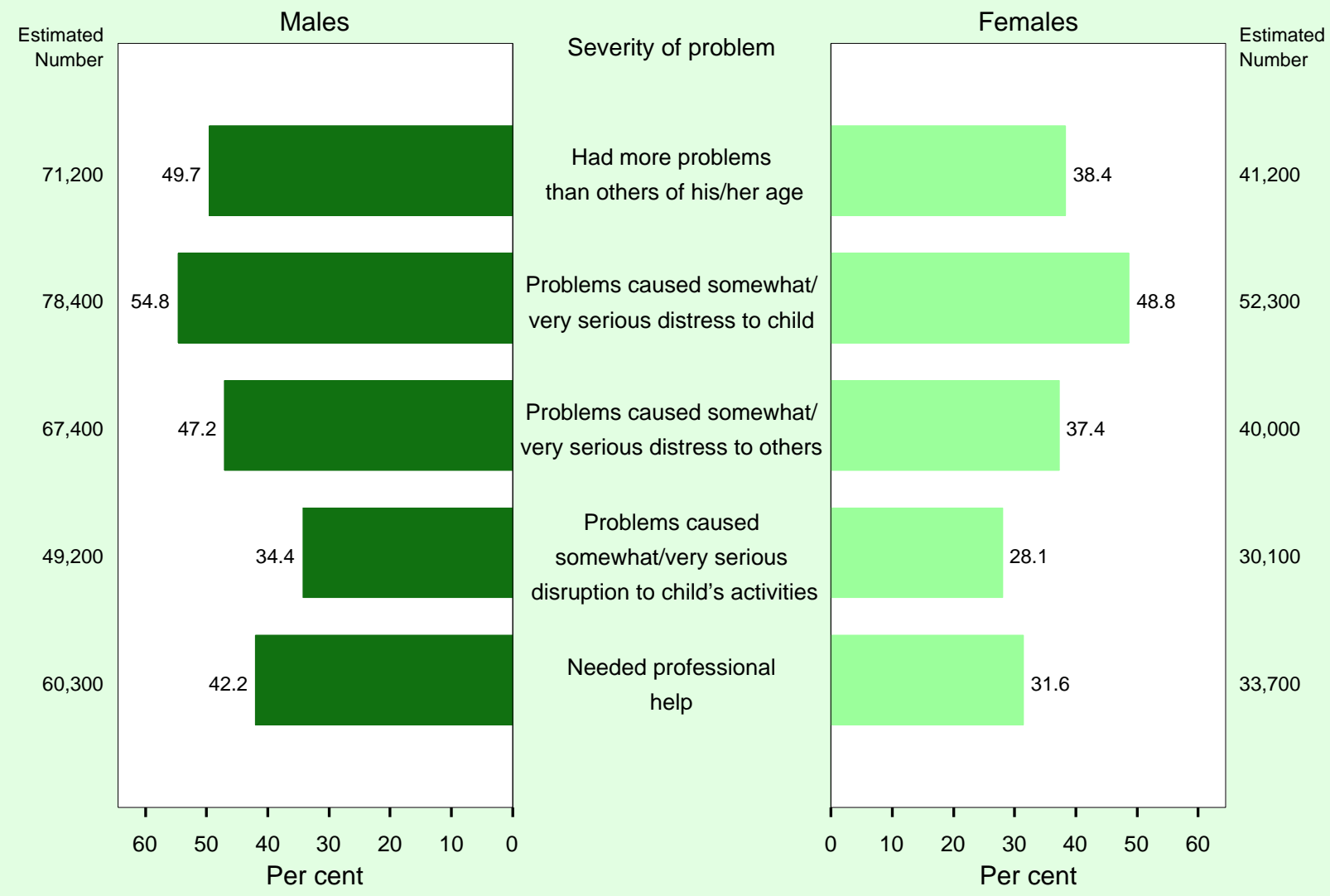

Note: Estimates based on 2082 respondents.

Source: New South Wales Child Health Survey 2001 (HOIST). Centre for Epidemiology and Research, NSW Department of Health.

in the 'clinical range' (that is, the range typically reported for those attending mental health clinics).

In addition to the CHQ items on emotional and behavioural health in the previous four weeks, parents and carers of children aged 4-12 years who participated in the New South Wales Child Health Survey 2001 were asked about emotional and behavioural problems experienced by their child over the previous six months, and about help that they needed for these problems.

Overall, almost one-third of children aged 4-12 years (31.4 per cent) were reported to have had any emotional or behavioural problems in the past six months, both clinical and non-clinical. These problems were more frequently reported among males (35.0 per cent) than among females (27.6 per cent), and their prevalence increased with age, from 17.9 per cent in children aged four years, to 40.2 per cent in children aged 12 years (Figure 19).

Among children reported to have had emotional or behavioural problems in the past six months, less than half
(44.9 per cent-49.7 per cent males; 38.4 per cent females) were reported as having had more of these problems than other children their age. In more than half of children who had emotional or behavioural problems (52.2 per cent54.8 per cent males; 48.8 per cent females), the problems were described as being somewhat or very serious in terms of causing distress to the child. Problems were less frequently described as being somewhat or very serious in terms of disrupting or causing distress to others (43.0 per cent-47.2 per cent males; 37.4 per cent females), or preventing the child from doing things usually expected of children their age (31.7 per cent-34.4 per cent males; 28.1 per cent females) (Figure 20).

More than one-third (37.6 per cent) of parents or carers of children aged 4-12 years, who were reported to have had emotional or behavioural problems in the last six months, stated that they thought their child needed professional help for these problems. Around two-thirds of these (68.3 per cent males; 61.9 per cent females) had obtained professional help. Among those who did not get help, the 


\section{FIGURE 21}

REASON FOR NOT BEING ABLE TO GET MORE HELP FOR EMOTIONAL OR BEHAVIOURAL PROBLEMS, CHILDREN AGED 4-12 YEARS, WHO NEEDED PROFESSIONAL HELP BUT DID NOT GET IT, NSW, 2001

Reasons given

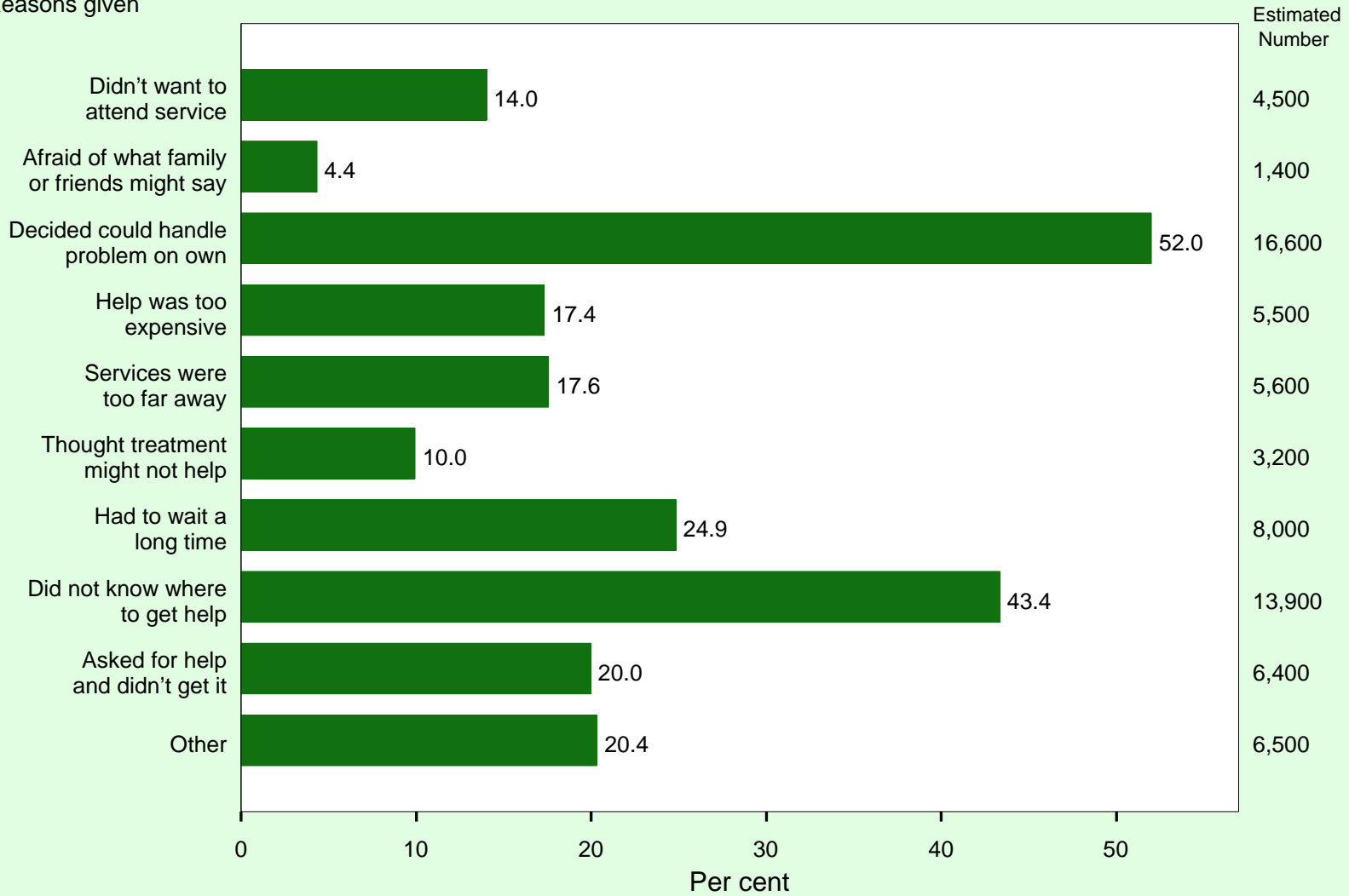

Note: Respondents could mention more than one reason. Percentages will total more than 100. Estimates based on 237 respondents.

Source: New South Wales Child Health Survey 2001 (HOIST). Centre for Epidemiology and Research, NSW Department of Health.

most common reasons cited were deciding to handle the problem on my own (52.0 per cent), not knowing where to get help (43.4 per cent), having to wait too long for an appointment (24.9 per cent), and asking for help but not getting it (20.0 per cent) (Figure 21).

\section{Reference}

1. Sawyer MG, Arney FM, Baghurst PA, et al. The Mental Health of Young People in Australia. Canberra: Mental Health and Special Programs Branch, Commonwealth Department of Health and Aged Care, 2000.

\section{Infant feeding and behavioural problems}

In the New South Wales Child Health Survey 2001, parents or carers of children aged 0-11 months were asked 17 questions regarding infant feeding and behavioural problems. For each feeding or behavioural problem, the parent or carer was asked what the most serious problem was, how serious the problem was, how difficult the problem was to manage, where they sought help, whether they still had a problem, and whether they required help to manage the problem.

Overall, 28.0 per cent of infants aged $0-1$ years were reported to have feeding problems and 35.1 per cent of infants were reported to have a behavioural problem. The main feeding problems reported were breastfeeding problems (63.0 per cent, of which 77.9 per cent were reported to be serious) and reflux (14.0 per cent, of which 90.1 per cent were reported to be serious). The main behavioural problems reported were settling difficulties (41.8 per cent, of which 51.2 per cent were reported to be serious) and colic (14.1 per cent, of which 73.1 per cent were reported to be serious).

Of the parents or carers who reported an infant feeding problem, 57.1 per cent said the problem was difficult to manage and almost all (99.0 per cent) sought help. Overall, 44.7 per cent of the parents or carers who had an infant behavioural problem said the problem was difficult to manage and, again, almost all (99.0 per cent) sought help. 
The main sources of help for infant feeding and infant behavioural problems was reported to be child and family health childhood nurses (66.7 per cent and 47.4 per cent respectively) or family and friends (30.8 per cent and 29.8 per cent respectively).

\section{Physical health of toddlers}

In the New South Wales Child Health Survey 2001, parents or carers of children aged 1-4 years were asked 17 questions regarding three main types of physical health issues relating to toddlers: eating or feeding problems, mobility problems, and other physical developmental problems. For each physical health problem, the parent or carer was asked to report the most serious problem, how serious the problem was, where they sought help, whether they still had a problem, and whether they required assistance to manage the problem.

Overall 7.5 per cent of parents or carers of children aged 1-4 years reported their child had eating or feeding problems; of these, 48.5 per cent were reported to be serious. A small proportion (1.6 per cent) of parents or carers reported their child had mobility problems (taking steps, walking or running); and, of these, 54.6 per cent were assessed by the parents to be serious. A slightly higher proportion (3.2 per cent) of parents or carers reported their child had other physical developmental problems (for example, trouble manipulating toys), of which 40.6 per cent were reported by the parents to be serious.

Of the parents or carers who reported a very serious or serious physical health problem with a toddler, 71.7 per cent had sought help for the feeding or eating problem, 82.4 per cent had sought help for the mobility problem, and 90.3 per cent had sought help for other physical developmental problems.

The main sources of help for physical health problems among toddlers were medical specialists $(31.8$ per cent for eating and feeding problems, 76.4 per cent for mobility problems, and 84.0 per cent for other physical developmental problems); and general practitioners (71.6 per cent for eating and feeding problems, 47.5 per cent for mobility problems, and 25.9 per cent for other physical developmental problems). 


\section{HEALTH SERVICES}

NSW Health provides a range of health care services to children and their families. Services specifically provided for children and their families, either through NSW Health, through other government departments, or through nongovernment or private organisations, include: child and family health services, family care centres, residential care centres, parent help telephone lines, child and family teams in community health centres, child protection services, child and adolescent mental health services, housing support services, educational support services, children's wards in general hospitals, and specialist children's hospitals. General practitioners (GPs) are key partners in the provision of primary health care services for children and their families. The New South Wales Child Health Survey 2001 focused on: use of health services, immunisation (vaccination), visits to general practitioners, use of personal health records, child and family health services, parental support services, and home visiting services.

\section{Use of health services}

It has been estimated, through ongoing data collections and previous surveys, that 7.4-20.2 per cent of children aged $0-16$ years attend emergency departments in a 12 month period and 18.0-32.0 per cent of children visit a GP in a two-week period. ${ }^{1}$

In the New South Wales Child Health Survey 2001 parents or carers of children aged 1-12 years were asked which services they had used in the last 12 months, from a list of possible services including: GPs, hospitals, community health centres, medical specialists (including paediatricians; psychiatrists; or ear, nose and throat specialists), Community services offices, services for children's behavioural and physical problems (including allied health services), parental support services (including a school counsellor or guidance officer), or other helping organisations or individuals.

\section{FIGURE 22}

HEALTH SERVICES USED IN THE LAST 12 MONTHS, BY AGE GROUP, CHILDREN AGED 1-12 YEARS, NSW, 2001
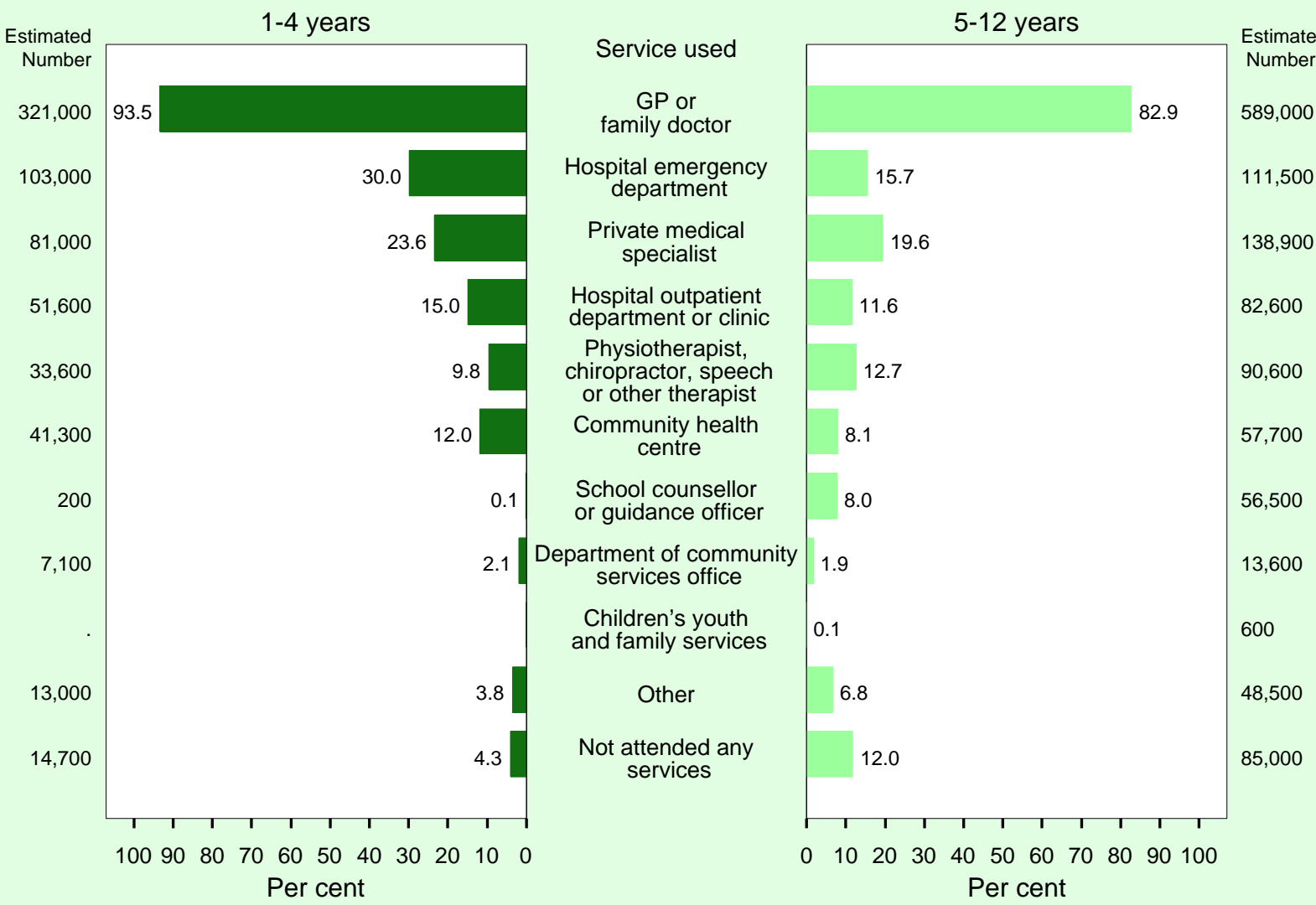

Note: Respondents could mention more than one health service. Percentages will total more than 100. Estimates based on 8689 respondents.

Source: New South Wales Child Health Survey 2001 (HOIST). Centre for Epidemiology and Research, NSW Department of Health. 


\section{FIGURE 23}

STRONGLY OR GENERALLY SUPPORT IMMUNISATION PROGRAM BY AREA HEALTH SERVICE OF RESIDENCE, PARENTS OR CARERS WITH CHILDREN AGED TWO MONTHS TO FOUR YEARS, NSW, 2001

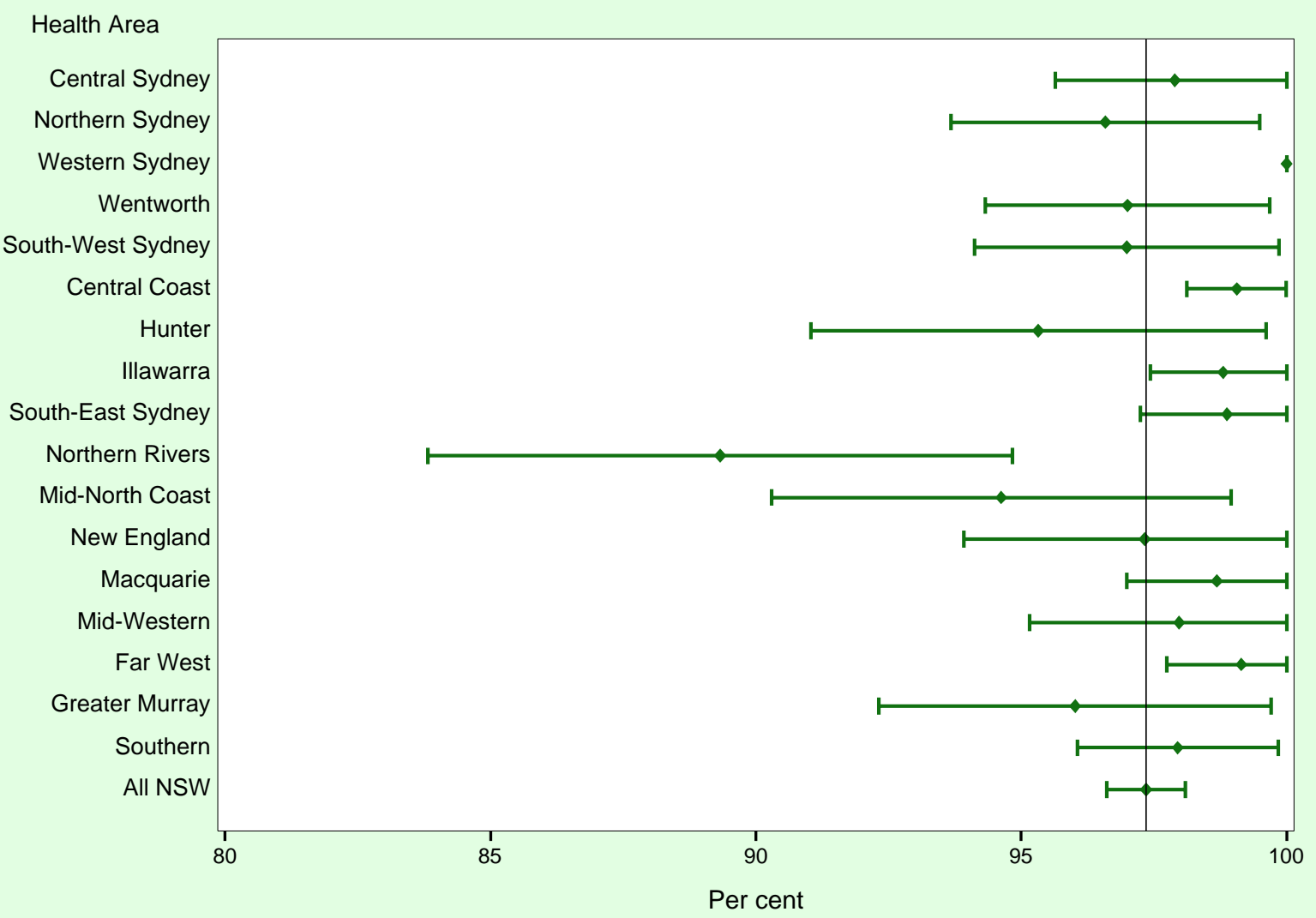

Note: Estimates are based on 3459 respondents.

Source: New South Wales Child Health Survey 2001 (HOIST). Centre for Epidemiology and Research, NSW Department of Health.

\section{TABLE 11}

STRONGLY OR GENERALLY SUPPORT IMMUNISATION PROGRAM BY AREA HEALTH SERVICE OF RESIDENCE, PARENTS OR CARERS WITH CHILDREN AGED TWO MONTHS TO FOUR YEARS, NSW, 2001

\begin{tabular}{|c|c|c|c|c|c|c|c|c|c|}
\hline Health Area & Per cent & $\begin{array}{c}\text { LL } \\
95 \% \mathrm{Cl}\end{array}$ & $\begin{array}{c}\text { UL } \\
95 \% \mathrm{Cl}\end{array}$ & $\begin{array}{l}\text { Estimated } \\
\text { Number }\end{array}$ & Health Area & Per cent & $\begin{array}{c}\text { LL } \\
95 \% \mathrm{Cl}\end{array}$ & $\begin{array}{c}\text { UL } \\
95 \% \mathrm{Cl}\end{array}$ & $\begin{array}{r}\text { Estimated } \\
\text { Number }\end{array}$ \\
\hline Central Sydney & 97.9 & 95.6 & 100.0 & 27600 & Northern Rivers & 89.3 & 83.8 & 94.8 & 13300 \\
\hline Northern Sydney & 96.6 & 93.7 & 99.5 & 41100 & Mid-North Coast & 94.6 & 90.3 & 99.0 & 14000 \\
\hline Western Sydney & 100.0 & 100.0 & 100.0 & 43200 & New England & 97.3 & 93.9 & 100.0 & 11000 \\
\hline Wentworth & 97.0 & 94.3 & 99.7 & 56900 & Macquarie & 98.7 & 97.0 & 100.0 & 7400 \\
\hline South-West Sydney & 97.0 & 94.1 & 99.9 & 49400 & Mid-Western & 98.0 & 95.2 & 100.0 & 3200 \\
\hline Central Coast & 99.1 & 98.1 & 100.0 & 23500 & Far West & 99.1 & 97.7 & 100.0 & 11300 \\
\hline Hunter & 95.3 & 91.0 & 99.6 & 18000 & Greater Murray & 96.0 & 92.3 & 99.7 & 17300 \\
\hline Illawarra & 98.8 & 97.4 & 100.0 & 34200 & Southern & 97.9 & 96.1 & 99.8 & 11500 \\
\hline South-East Sydney & 98.9 & 97.2 & 100.0 & 22200 & All NSW & 97.4 & 96.6 & 98.1 & 405200 \\
\hline
\end{tabular}

Note: Estimates are based on 3459 respondents.

Source: New South Wales Child Health Survey 2001 (HOIST). Centre for Epidemiology and Research, NSW Department of Health. 


\section{FIGURE 24}

\section{CURRENT USE OF PERSONAL HEALTH RECORD (THE 'BLUE BOOK') BY AGE GROUP, PARENTS OR CARERS OF CHILDREN AGED 0-12 YEARS, NSW, 2001}
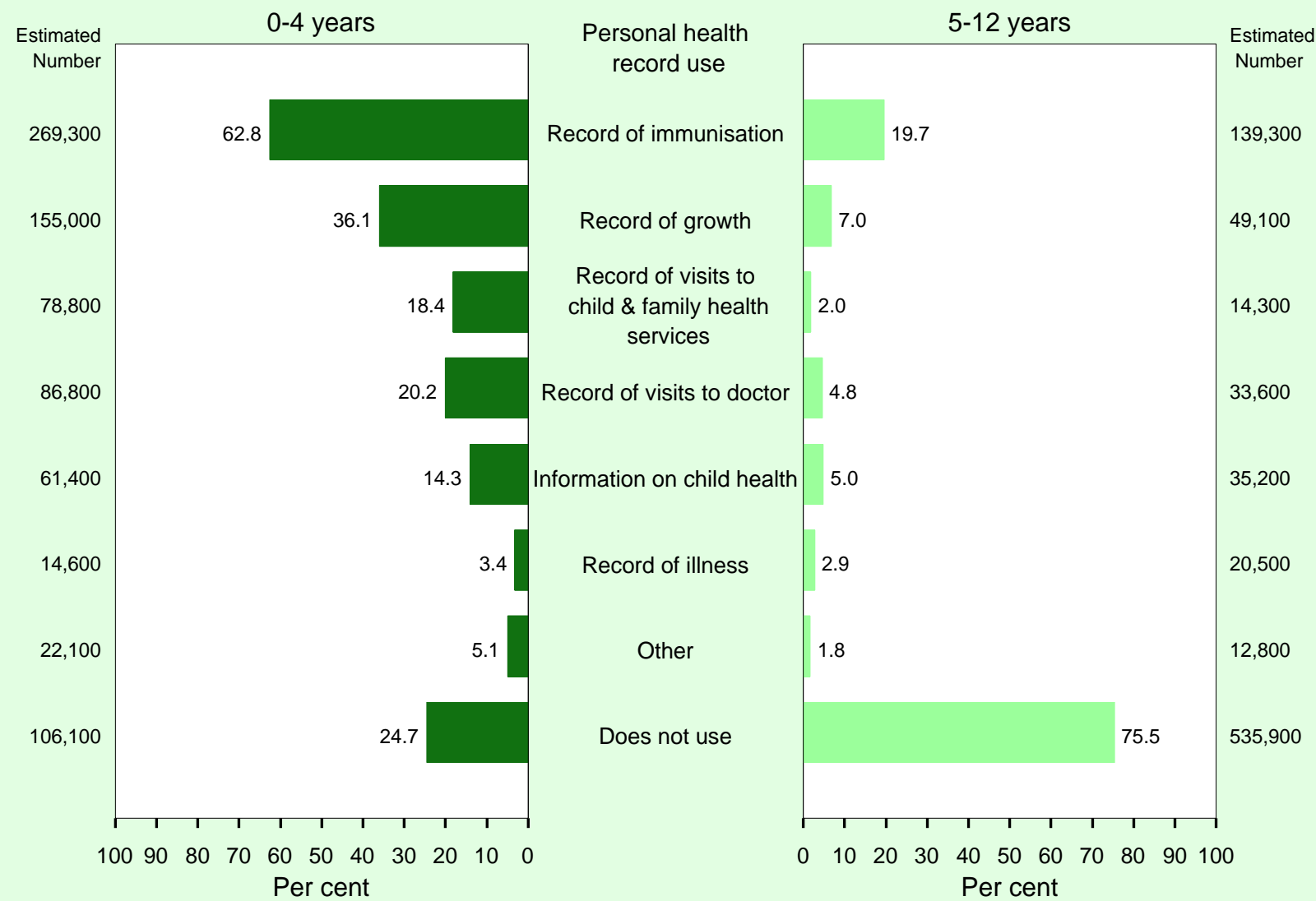

Note: Respondents could mention more than one use. Percentages will total more than 100. Estimates based on 9425 respondents.

Source: New South Wales Child Health Survey 2001 (HOIST). Centre for Epidemiology and Research, NSW Department of Health.

A majority (90.5 per cent) of parents or carers reported the child had attended at least one of the listed services in the last 12 months, with the most frequented service being a GP or family doctor ( 86.4 per cent). There was very little difference in the reported use of services by males compared with females; however, the proportion of children who had used a service was higher among children aged 0-4 years (95.7 per cent) compared with those aged 5-12 years (88.0 per cent) (Figure 22).

\section{Reference}

1. Williamson M, Jorm L, Cardona M, Chey T. Blacktown Health Survey 1993. Sydney: Western Sydney Area Health Service, 1994.

\section{Immunisation (vaccination)}

Despite a reduction in national incidence of vaccinepreventable diseases in children, since the introduction of immunisation, a range of vaccine-preventable diseases—-such as pertussis, measles, mumps, rubella, haemophilis influenza type B, hepatitis B and tetanusremain a problem in Australia. The overall aim of the NSW immunisation program for children is to reduce the incidence of vaccine-preventable diseases in children that may cause significant morbidity and mortality. Vaccination coverage in children can be monitored using information from the Australian Childhood Immunisation Register (ACIR).

Monitoring the level of support for the immunisation program, sources of information about immunisation and providers of immunisation services assist in planning efficient and effective immunisation programs that will be used by parents or carers at the appropriate time in a child's development.

In the New South Wales Child Health Survey 2001, parents or carers of children aged two months to four years were asked three questions regarding immunisation: which service providers they used for immunisation services; whether they support the immunisation program; and, for 
those who do not support the program, what sources they use to get information about immunisation. The majority (85.8 per cent) of children aged two months to four years were reported to have been immunised by a local doctor (66.0 per cent) or by a general practitioner in a medical centre (19.8 per cent).

Over 97.4 per cent of parents or carers of children aged two months to four years reported supporting the immunisation program (81.6 per cent reported that they strongly support it; 15.8 per cent reported that they generally support it). This varied by area health service, with respondents from Western Sydney reporting the strongest support for the immunisation program (100.0 per cent) and Northern Rivers reporting the lowest level of support (89.3 per cent) (Figure 23, Table 11).

Non-supporters of the immunisation program reported the main sources of information they accessed were health professionals (62.0 per cent) and the electronic and print media (52.1 per cent).

\section{Visits to general practitioners}

General practitioner (GP) consultations are a major source of health care for children. In Australia in 1995, 15.7 per cent of these consultations were for children aged less than 15 years, although this age group accounted for 21.5 per cent of the population. ${ }^{1}$ Children aged less than one year, 1-4 years, and 5-14 years, accounted for two per cent, 5.8 per cent, and 7.9 per cent, of consultations respectively.

In the New South Wales Child Health Survey 2001, parents or carers of children aged 0-12 years were asked who they normally consult about their child's general health problems (a doctor in a medical centre, a GP or local doctor, a doctor at a hospital, or someone else) and whether the child usually sees the same doctor or different doctors at the same or different centres.

More than three-quarters of parents or carers (77.7 per cent) reported that their children usually use a GP or local

\section{FIGURE 25}

EVER USED AND CURRENT USE OF CHILD AND FAMILY HEALTH SERVICES, BY AREA HEALTH SERVICE OF RESIDENCE, CHILDREN AGED 0-4 YEARS, NSW, 2001
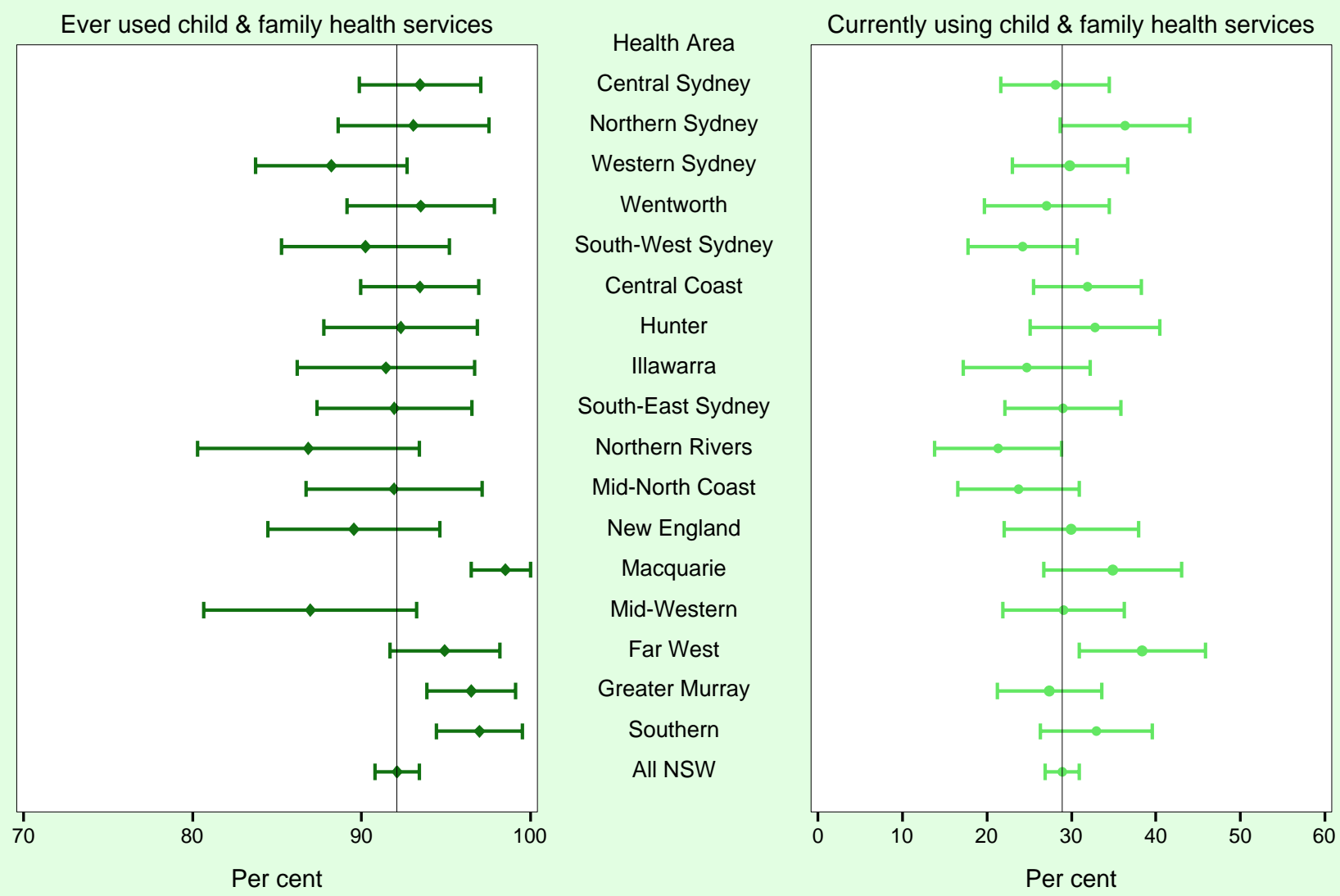

Note: $\quad$ Estimates for ever used child and family health services based on 3537 respondents. Estimates for current use of child and family health services based on 3298 respondents who had ever used child and family health services.

Source: New South Wales Child Health Survey 2001 (HOIST). Centre for Epidemiology and Research, NSW Department of Health. 


\section{TABLE 12}

EVER USED AND CURRENT USE OF CHILD AND FAMILY HEALTH SERVICES, BY AREA HEALTH SERVICE OF RESIDENCE, CHILDREN AGED 0-4 YEARS, NSW, 2001

\begin{tabular}{|c|c|c|c|c|c|c|c|c|}
\hline Health Area & Per cent & $95 \% \mathrm{CL}$ & $95 \% \mathrm{Cl}$ & $\begin{array}{l}\text { Estimated } \\
\text { Number }\end{array}$ & Per cent & $95 \% \mathrm{CL}$ & $95 \% \mathrm{Cl}$ & $\begin{array}{l}\text { Estimated } \\
\text { Number }\end{array}$ \\
\hline \multicolumn{5}{|c|}{ Ever used child \& family health services } & \multicolumn{4}{|c|}{ Currently using child \& family health services } \\
\hline Central Sydney & 93.5 & 89.9 & 97.0 & 27700 & 28.1 & 21.7 & 34.5 & 7800 \\
\hline Northern Sydney & 93.1 & 88.6 & 97.5 & 41400 & 36.3 & 28.6 & 44.0 & 15000 \\
\hline Western Sydney & 88.2 & 83.7 & 92.7 & 38200 & 29.8 & 23.0 & 36.6 & 11400 \\
\hline Wentworth & 93.5 & 89.1 & 97.9 & 57600 & 27.1 & 19.7 & 34.4 & 15600 \\
\hline South-West Sydney & 90.2 & 85.3 & 95.2 & 46800 & 24.2 & 17.7 & 30.7 & 11300 \\
\hline Central Coast & 93.4 & 89.9 & 97.0 & 22500 & 31.9 & 25.5 & 38.3 & 7200 \\
\hline Hunter & 92.3 & 87.8 & 96.9 & 18300 & 32.8 & 25.1 & 40.4 & 6000 \\
\hline Illawarra & 91.4 & 86.2 & 96.7 & 32600 & 24.7 & 17.2 & 32.2 & 8000 \\
\hline South-East Sydney & 91.9 & 87.4 & 96.5 & 21100 & 29.0 & 22.1 & 35.8 & 6100 \\
\hline Northern Rivers & 86.9 & 80.3 & 93.4 & 13800 & 21.3 & 13.8 & 28.8 & 2900 \\
\hline Mid-North Coast & 91.9 & 86.7 & 97.1 & 14000 & 23.7 & 16.6 & 30.9 & 3300 \\
\hline New England & 89.6 & 84.5 & 94.7 & 10600 & 30.0 & 22.0 & 37.9 & 3200 \\
\hline Macquarie & 98.5 & 96.5 & 100.0 & 7800 & 34.9 & 26.7 & 43.1 & 2700 \\
\hline Mid-Western & 87.0 & 80.7 & 93.3 & 2900 & 29.1 & 21.9 & 36.2 & 900 \\
\hline Far West & 94.9 & 91.7 & 98.2 & 11000 & 38.4 & 30.9 & 45.9 & 4200 \\
\hline Greater Murray & 96.5 & 93.9 & 99.1 & 17400 & 27.4 & 21.2 & 33.6 & 4800 \\
\hline Southern & 97.0 & 94.4 & 99.5 & 11500 & 32.9 & 26.3 & 39.6 & 3800 \\
\hline All NSW & 92.1 & 90.8 & 93.4 & 395100 & 28.9 & 26.9 & 31.0 & 114200 \\
\hline \multicolumn{9}{|c|}{$\begin{array}{l}\text { Note: Estimates for ever used child and family health services based on } 3537 \text { respondents. Estimates for current use of child } \\
\text { and family health services based on } 3298 \text { respondents who had ever used child and family health services. }\end{array}$} \\
\hline \multicolumn{9}{|c|}{ Source: New South Wales Child Health Survey 2001 (HOIST). Centre for Epidemiology and Research, NSW Department of Health } \\
\hline
\end{tabular}

doctor, while one in five (19.2 per cent) usually saw a doctor in a medical centre. Most children were reported to visit the same doctor ( 80.6 per cent) or the same practice (15.4 per cent), when usually seeing a doctor. The pattern of GP use was similar for children aged 0-4 years compared with children aged 5-12 years.

\section{References}

1. Australian Institute of Health and Welfare. Australia's health 1998: The sixth biennial health report of the Australian Institute of Health and Welfare. (Morbidity and Treatment Survey). Canberra: AIHW, 1998.

\section{Personal health records: The 'blue book'}

In NSW, all children born since January 1988 have been issued with a personal health record (known in NSW as the 'blue book') by a nurse at the hospital where the child was born. ${ }^{1}$ The personal health record is a booklet, usually maintained by the parent or carer of the child in association with a range of health care providers_-particularly child and family health services and general practitioners. The personal health record details a child's growth and development and contains information on immunisation, health visits, growth, teething, crying, feeding, and toilet training.

In the New South Wales Child Health Survey 2001, parents or carers of children aged 0-12 years were asked whether the child had a personal health record (the 'blue book') and the previous and current use of the personal health record.

Most parents or carers (94.0 per cent) reported their child has a personal health record. The proportion was slightly higher for children aged $0-4$ years ( 98.3 per cent) than for children aged 5-12 years ( 91.5 per cent). There were some minor variations in reported personal health record ownership among area health services; however, in all areas, reported ownership was over 91 per cent (ranging from 91.7 per cent in the South Eastern Sydney Health Area to 98.3 per cent in the Hunter Health Area).

The proportion reporting having a personal health record was similar to that reported in a previous evaluation of personal health record use in NSW in 1992 (93.0 per cent). In that study, 78.0 per cent of parents were able to produce the personal health record for the interviewer. ${ }^{2}$

\section{Past and current use of the personal health record}

Overall, 46.0 per cent of parents or carers of children aged 0-12 years reported currently using the personal health record (76.5 per cent for children aged $0-4$ years and 26.2 per cent for children aged 5-12 years). The main reported current use of the personal health record was to record immunisation (36.0 per cent), and growth (16.9 per cent). The use of the book for recording immunisation and growth was higher for children aged $0-4$ years $(62.8$ per cent) compared with children aged 5-12 years (19.7 per cent) (Figure 24). 
FIGURE 26

REASON NEVER OR NO LONGER ATTENDED CHILD AND FAMILY HEALTH SERVICES, CHILDREN AGED 0-4 YEARS, NSW, 2001

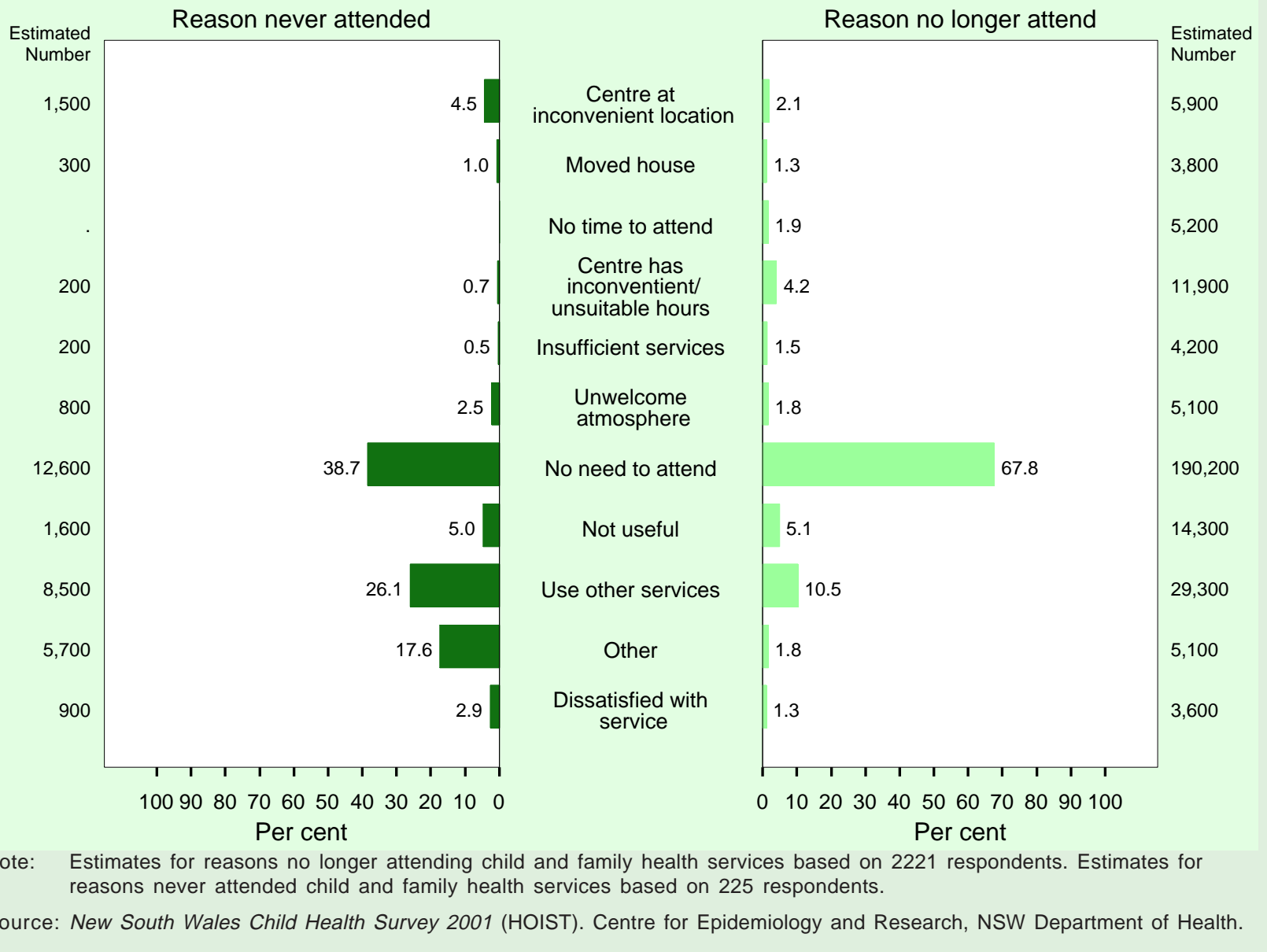

\section{Reference}

1. NSW Department of Health Public Affairs Web site at www.health.nsw.gov.au/health-public-affairs/mhcs/ publications/658.html, accessed 8 May 2002.

2. Bailey FK, Nossar V, Jeffs DA, Smith W, Chey T. An evaluation of the NSW Personal Health Record 1992. Sydney: NSW Department of Health, 1992.

\section{Child and family health services (baby health centres or early childhood health services)}

Maternity and child and family health services have a particularly important role to play in providing information and support for parents and carers of children aged $0-4$ years, in relation to health and wellbeing and family or environmental factors that affect children.

In the New South Wales Child Health Survey 2001, parents or carers of children aged 0-4 years were asked if they had ever attended a child and family health service; and, if not, why they had never attended. If they had ever used a child and family health service, they were also asked how long they had used the service; if they currently used the service; and, where applicable, why they no longer attended the service.

\section{Attendance and age at first visit}

Most (92.1 per cent) parents or carers of children aged 0 4 years reported they had attended child and family health services (with 0.3 per cent yet to attend their first visit); however, only 28.9 per cent were currently using child and family health services. The reported ever use of child and family health services varied between area health services, from 87.0 per cent in the Mid Western Health Area to 98.5 per cent in the Macquarie Health Area, while current use varied from 21.3 per cent in the Northern Rivers Health Area to 38.4 per cent in the Far West Health Area (Figure 25, Table 12).

The age of the child at first visit to the child and family health service varied from one week to 23 months; 37.2 per cent of infants attended their first visit at the age of 
FIGURE 27

TYPES OF PARENTAL SUPPORT SERVICES, PARENTS WITH CHILDREN AGED 1-12 YEARS WHO USED A SUPPORT SERVICE, NSW, 2001

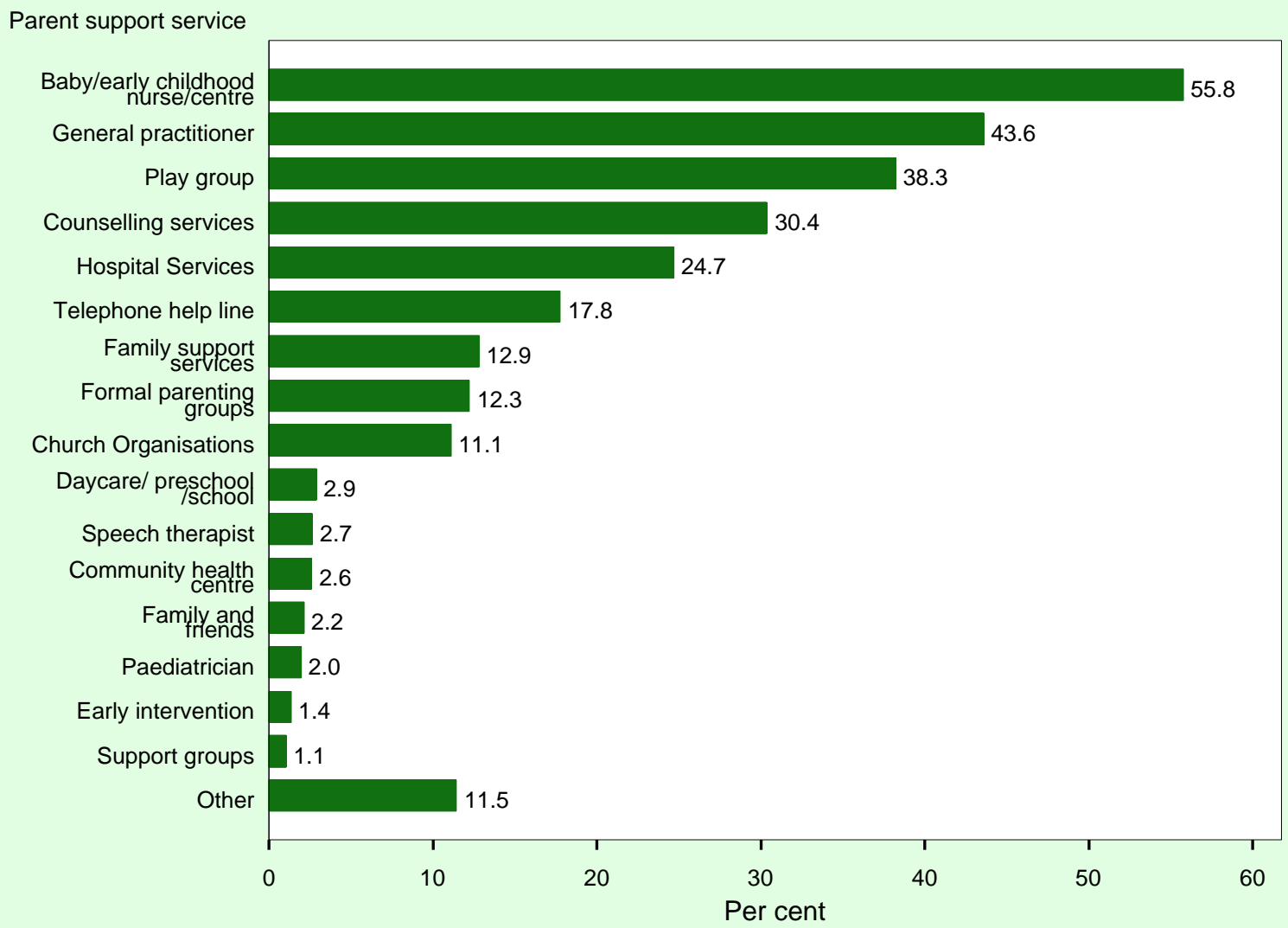

Note: More than one service could be named. Percentages will total more than 100. Estimates are based on 2224 respondents. Source: New South Wales Child Health Survey 2001 (HOIST). Centre for Epidemiology and Research, NSW Department of Health.

one week; and over 78 per cent of infants had had their first visit by four weeks of age.

\section{Reason for non-attendance or no longer attending child and family health services}

A minority (7.0 per cent) of all parents or carers reported never having attended a child and family health service. The main reasons reported by parents or carers, of children aged $0-4$ years who never attended child and family health services, was that they felt they did not need to attend (38.7 per cent) or they used other services (26.1 per cent). The main reason cited by the 71.0 per cent of parents or carers who had ceased to attend child and family health services was that they felt they no longer needed to attend (67.8 per cent) or they used other services ( 10.5 per cent) (Figure 26).

\section{Parental support services}

Parental support services include playgroups; health services such as home visiting services and child and family health services; and community, church, and school services. In the New South Wales Child Health Survey 2001 parents or carers of children aged 1-12 years were asked to report about their need for support services; whether they used such services; the types of services used; and the reasons for not accessing parental support services when they needed them.

Just over two-thirds (68.6 per cent) of parents or carers reported that they needed parental support services. Of parents or carers who reported they needed services, 81.0 per cent reported accessing the services. The services that were most likely to be used were: early childhood nurses or child and family health services (55.8 per cent), general practitioners (43.6 per cent), playgroups (38.3 per cent), and counselling services (30.4 per cent) (Figure 27). The reported reasons for not accessing parental support services when needed included: not knowing where to get help (29.3 per cent), feeling that they should be able to cope on their own (25.8 per cent), and reporting that services were either not available (14.8 per cent) or too far away (9.3 per cent) (Figure 28). 


\section{FIGURE 28}

REASON DID NOT ACCESS PARENTAL SUPPORT SERVICE, PARENTS WITH CHILDREN AGED 1-12 YEARS WHO HAD NOT USED A SUPPORT SERVICE WHEN NEEDED, NSW, 2001

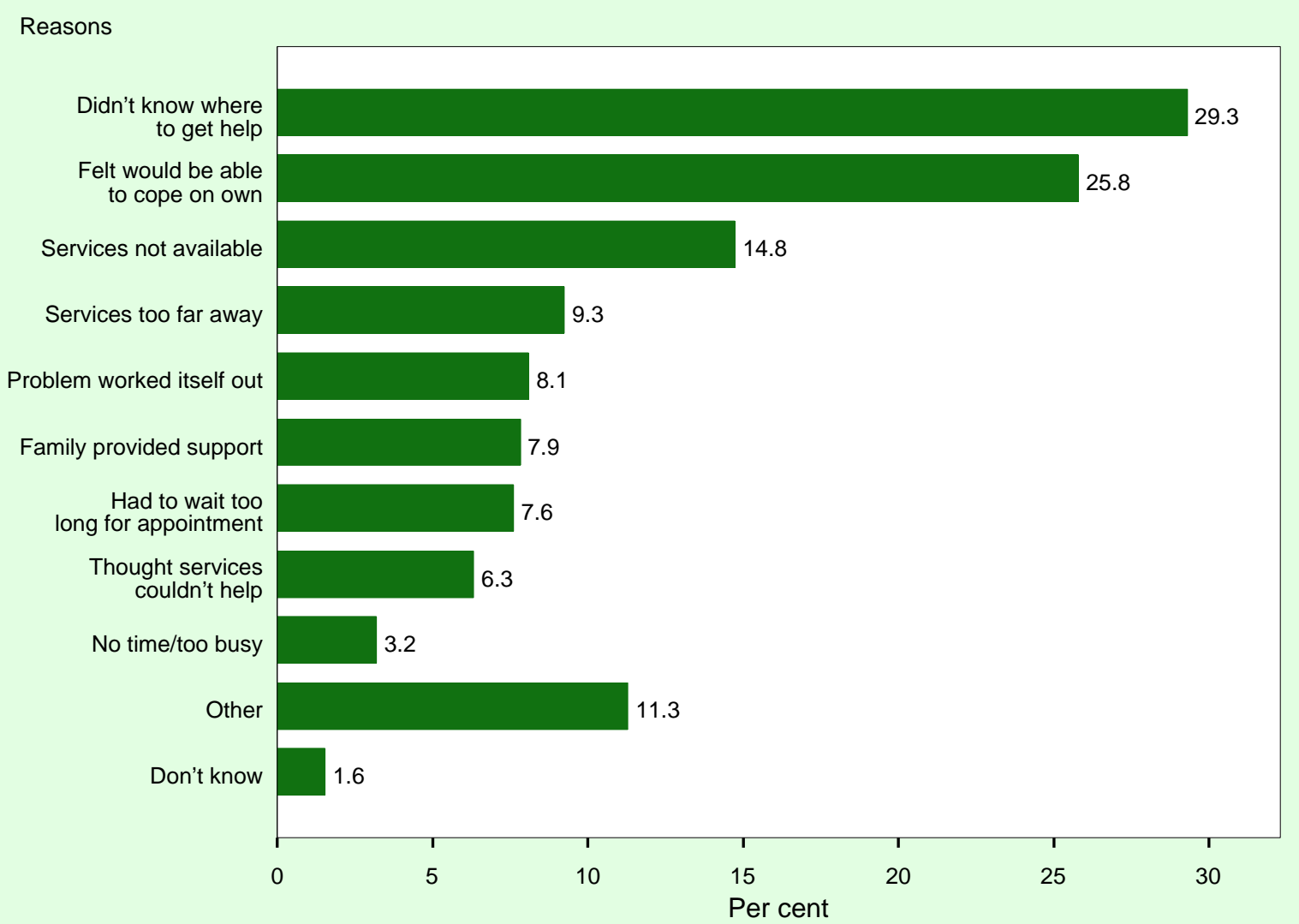

Note: Respondents could mention more than one reason. Percentages will total more than 100. Estimates are based on 510 respondents.

Source: New South Wales Child Health Survey 2001 (HOIST). Centre for Epidemiology and Research, NSW Department of Health.

\section{Home visiting (health services received in the home)}

A growing body of evidence shows that-where professionals provide services to families within their own home-improvements in socialisation, health and education outcomes, can be achieved. ${ }^{1}$ Families in the United Kingdom, who were supported at home by volunteers, had improved family functioning. ${ }^{1}$ The Cottage Care Community Project, a volunteer home visiting program in Sydney, found that families receiving visits from a volunteer recorded increased levels of family functioning, reduced numbers of subsequent pregnancies, higher immunisation levels, and accessed a greater number of other services. ${ }^{1}$

In the New South Wales Child Health Survey 2001, parents or carers of children aged 0-4 years reported on use of home visiting services. Home visiting services were defined as 'having someone, such as a nurse or a volunteer, visit you in your home to provide you with support or advice in caring for a child'. Respondents were asked about whether they had had a home visit, who had visited them, the age of their child at the first home visit, the number of home visits they had received, and the acceptability of having someone visit them in their home. Parents or carers who had not received a home visit were asked how they would feel having a health professional visit them in their home.

Overall, 36.3 per cent of parents or carers of children aged 0-4 years reported they had received a home visit. For people who received a home visit, the main person reported to attend home visits was a health professional (49.9 per cent), early childhood nurse or midwife (37.3 per cent), followed by a nurse (3.6 per cent), lactation consultant (3.3 per cent), social worker or counsellor (1.9 per cent), speech therapist or physiotherapist (1.1 per cent), and teacher ( 0.4 per cent). Most parents or carers (95.3 per cent) reported that they received their first home visit when their child was aged less than one month. Of the parents or carers who reported having a home visit, 25.1 per cent had one visit, 50.7 per cent had 2-4 visits, and 24.3 per cent had five or more visits. 
The majority (97.5 per cent) of parents or carers who reported they had received a home visit said that the home visit was acceptable. However, only three-quarters (74.8 per cent) of parents whose children did not have a home visit reported that they would be comfortable having a health professional visit them in their home.

\section{CONCLUSION}

The primary goals of the New South Wales Child Health Survey 2001 were to describe child health in NSW, and to provide baseline information to monitor the NSW Government's Families First initiative and other child health initiatives. The survey highlighted some important issues for action, to improve child health and wellbeing in NSW, and for ongoing monitoring of progress.

Information on social capital and social support suggests that families with children are reasonably well-connected through community and school networks, although parents in urban areas reported more concerns about safety in their neighbourhood, and less involvement in community activities. A high proportion of children aged 3-5 years attended pre-school, long day-care, or other formal care, as recommended in the Families First initiative for all children before they start school.

Australian guidelines recommend that all infants should be breastfed at birth and that breastfeeding should continue for up to 12 months, complimented by solid food. However, the survey showed that, although most women initially breastfeed, the majority of women cease breastfeeding between 4-6 months, and a minority continue breastfeeding past 12 months. This may be related to a range of factors including social and workrelated pressures and the degree of acceptance of breastfeeding in the wider community.

Obesity has recently been highlighted as a significant issue for Australian children, with almost one-quarter of children considered to be overweight or obese. The survey showed that children have a low intake of vegetables, and that a high proportion of fruit intake is consumed as fruit juicewhich is not ideal, due to its reduced fibre and added sugar content. The potential substitution of milk with juice and soft drink, and the relatively high intake of hot chips and french fries, are also of concern in childhood diets. The time spent playing computer games and watching television, as measures of sedentary activities, is also of concern. The survey also highlighted that a surprising proportion of families had experienced issues to do with food security, which can limit the availability of nutritionally-appropriate food, potentially influencing malnutrition, obesity, or psychological wellbeing. The NSW Minister for Health has announced a NSW Childhood Obesity Summit, to be held between 10-12 September 2002, which will bring

\section{Reference}

1. The Families First Resource Kit, NSW Cabinet Office 2000. Web site at www.parenting.nsw.gov.au, accessed 24 April 2002

together stakeholders from across government, the private sector, and the community, to develop an action plan for childhood obesity in NSW.

To prevent skin cancer, public health messages focus on protecting children from ultraviolet radiation. The survey showed that while children less than five years of age are relatively well-protected from the sun, children five years of age and over were less likely to wear a broad-brimmed cap with a flap or protective clothing, with more reliance on often or always wearing sunscreen. The use of sunscreen alone is not ideal, since it has time-limited effectiveness and can wear off with physical activity and exposure to water.

While it is recommended that all children have a dental check-up in their pre-school years, in order to identify oral health problems and issues with oral cavity development, the survey showed that a very high proportion of children under five years of age have never seen a dentist.

While most parents and carers had used child and family health services at some time, a high proportion did not currently use them, mainly because they felt they no longer needed such services. The survey showed that about half of all families had had health services provided in the home (a home visit) by a health worker. This proportion is expected to increase, with the rollout of universal home visiting as part of the Families First initiative. Encouragingly, the survey identified that most families who had infants or young children with serious physical, emotional, or behavioural problems, had accessed services. As such, these services are probably a useful place to research such issues.

Areas of child health and wellbeing that will be monitored on an ongoing basis, as part of the NSW Health Survey Program, include: family functioning; social capital; childcare, preschool, and school attendance; smoking in pregnancy; smoking in the home; infant sleeping position; folate intake during pregnancy; breastfeeding; nutrition; sun protection; injury; physical activity; asthma; oral health; disability; diabetes; health status; emotional and behavioural problems; health service use; attitudes to childhood immunisation; use of the personal health record; and parental support services. 


\section{APPENDIX : NEW SOUTH WALES CHILD HEALTH}

\section{SURVEY 2001 QUESTIONNAIRE}

\section{Introduction}

ALL 1 Good morning/afternoon/evening, my name is _. I am calling from the New South Wales Department of Health. We are conducting an important statewide study about the health of children aged between 0 and 12 years. We would like to interview the parent or carer of a child randomly selected from each participating household. May I please speak to a parent or carer of any children who live in this household?

1. Yes-that's me

2. Yes, I'll get someone

4. No children 0-12 yrs in household $\rightarrow$ THANK AND GOODBYE

5. Refusal $\rightarrow$ THANK AND GOODBYE

6. Language problem $\rightarrow$ BILINGUAL SCRIPT.

8. Household not in NSW/ACT/holiday house $\rightarrow$ THANK AND GOODBYE

12. Not a resident of NSW/ACT $\rightarrow$ THANKAND GOODBYE

13. Unavailable for duration of the study $\rightarrow$ THANK AND GOODBYE

ALL 1a Can I ask if you received the letter we sent to your household recently about this study?

[NOTE: Only asked if respondent's number is in the white pages]

Yes

No

Don't know

Refused

ALL $1 b$ Could you tell me how many children aged up to and including 12 years usually live in this household?

(NOTE: Prompt if necessary that 'live in this household' means lives there most days of the school week) number of children

Don't Know $\rightarrow$ THANK AND GOODBYE Refused $\rightarrow$ THANK AND GOODBYE

ALL 1c How many of these children are aged 0 to 4 years? number of children
Don't Know $\rightarrow$ THANK AND GOODBYE Refused $\rightarrow$ THANK AND GOODBYE

ALL 1d How many of these children are aged 5 to 12 years? number of children

Don't Know $\rightarrow$ THANK AND GOODBYE Refused $\rightarrow$ THANK AND GOODBYE

ALL 1e We are collecting information about one child from each selected household and now we would like to randomly select that child. We have done the random selection and we would like to interview the parent or carer of the [nth oldest child]. Because this study is about child health we need to speak to the parent or carer who knows most about [child's] health. Is that you?

1. Yes-I know most about [child's] health

2. Yes-I know something about [child's] health

3. No-I'll get them

4. No-not home at the moment $\rightarrow$ MAKEAPPOINTMENT

5. Refusal $\rightarrow$ THANK AND GOODBYE

6. Unavailable for duration of survey $\rightarrow$ THANKAND GOODBYE

7. Main parent/carer does not speak English $\rightarrow$ BILINGUAL SCRIPT

8. Main parent/carer unable to be interviewed due to disability $\rightarrow$ THANKAND GOODBYE

ALL if Your help with this survey is voluntary. All that is involved is answering some questions about [child's] health, wellbeing and use of health services. The survey takes around 25 to 30 minutes for most people but may take a little longer in some cases. There are no 'right' or 'wrong' answers to any of the questions. You can stop at any time or simply refuse to answer a question should you prefer. Please be assured that all the answers to questions remain completely confidential, except where you volunteer information that we are required to report by law. The information from this survey will be used to help improve health 
services for children in your area and across the state, so your help is very important to us. Do you agree to participate?

[NOTE: Prompt if necessary that all the answers that you give to the questions remain completely confidential. However if you tell us additional information about breaking the law or that suggests a child is being abused or neglected, then we are required to report this to the appropriate authority such as the Department of Community Services.]

Yes

No $\rightarrow$ THANK AND GOODBYE

\section{Preliminary demographic questions}

ALL 2. First, we need to know some information about [child], yourself and your household.

ALL 2a. Could you please tell me how old [child] is today?

1. ___ years (2-12 years only) $\rightarrow \mathrm{Q} 3$

2. $\ldots$ months (1-23 months only) $\rightarrow$ - _ weeks (1-3 weeks only) $\rightarrow$ Q3

4. Less than 1 week old $\rightarrow$ Q3

5. Don't know

6. Refused

ALL 3. Is [child] male or female?

(NOTE: ask if not obvious from name)
1. Male

2. Female

ALL 4. Could you please tell me how old you are today?

1. ____years

2. Don't know

3. Refused

\section{Respondents health}

ALL 5 The next question is about your general health

ALL 6 In general would you say your health is excellent, very good, good, fair or poor?
1. Excellent
2. Very good
3. Good
4. Fair
5. Poor
6. Don't know
7. Refused

ALL 7 Are you male or female?
(NOTE: ask if not obvious from voice)

1. Male

2. Female

ALL 8 What is your relationship to [child]?

IF FEMALE: For example are you [child]'s mother, stepmother or other relation?

IF MALE: For example are you [child]'s father, stepfather or other relation?

1. Mother

2. Father

3. Stepmother

4. Stepfather

5. Grandmother

6. Grandfather

7. Legal guardian

8. Other (Specify)

9. Don't know

10.Refused

\section{Health service use: Child and family services}

0-4Y 9 The next few questions are about use of health services.

0-4Y 9a Has [child] ever seen a baby health or early childhood health nurse? This could have been at either a baby health clinic or early childhood health centre, or in your home.

1. Yes

2. No $\rightarrow$ Q13

3. Hasn't attended first appointment yet $\rightarrow$ Q14

4. Don't know $\rightarrow$ Q14

5. Refused $\rightarrow$ Q14

0-4Y 10 What was [child]'s age when [he/she] first had contact with a baby health or early childhood health nurse?

1. ___ months (1-23 months only)

2. ___ weeks (0-12 weeks only)

3. Don't know

4. Refused

0-4Y 11 What was [child]'s age when [he/she] last had contact with a baby health or early childhood health nurse?

1. ___ years (2-4 years only)

2. ___ months (1-23 months only)

3. ___ weeks (0-12 weeks only)

4. Don't know

5. Refused

0-4Y 12 Is [child] still seeing a baby health or early childhood health nurse on a regular 
basis? (NOTE: includes regular visits to early childhood health centre or baby health centre) (NOTE: regular visits means attended last appointment and plan to take child again)
1. Yes $\rightarrow$ Q14
2. No
3. Don't know $\rightarrow$ Q14
4. Refused $\rightarrow$ Q14

0-4Y 13 What is the main reason [child] has [not seen-stopped seeing] a baby health or early childhood health nurse?

1. Centre at inconvenient location

2. Centre has inconvenient-unsuitable hours

3. Insufficient services

4. Unwelcome atmosphere

5. No need to attend-any more

6. Not useful-Not useful any more

7. Use other services instead

8. Other (Specify)

9. Don't know

10. Refused

\section{Health service use}

ALL 14 The next few questions are about visits to the doctor

ALL 15 Who do you usually consult about [child]'s general health problems? (NOTE: Medical Centres are open long hours, seven days a week and provide other services such as X-rays)

(READ OPTIONS 1-4)

1. A doctor in a medical centre

2. GP or local doctor

3. Doctor at a hospital

4. Someone else (Specify)

5. Don't know

6. Refused

ALL 16 When [child] visits the doctor does [he/ she] usually see?

\section{(READ OPTIONS 1-4)}

1. The same doctor

2. Different doctors at the same practice or Surgery

3. Different doctors at different places

4. Don't know

5. Refused

ALL 17 I'm now going to read you a list of services that you may have had contact with for [child].
ALL 18 Within the past twelve months, that is since [month] 2001, did [child] have contact with any of the following services?

(READ OUT OPTIONS 1-9 AND WAIT FOR RESPONSE; MULTIPLE RESPONSE)

1. A hospital emergency department (Specify hospital ED name)

2. A GP or family doctor

3. A community health centre, not including early childhood health centre

4. A hospital outpatient department or clinic

5. A private medical specialist eg. paediatrician, psychiatrist or ENT specialist

6. Department of Community services office-officer

7. Physiotherapist, chiropractor, or speech or other therapist,

8. A school counsellor or guidance officer

9. Other helping organisation or individual (Specify)

10. Not attended any services

11.Don't know

12. Refused

\section{Personal health records}

ALL 19 The next few questions are about any health records you may have for [child].

ALL 20 Do you have a Personal Health Record or 'blue book' for [child]?

(NOTE: A 'blue book' or personal health record is given to all babies. It contains a record of growth, health check-ups and immunisation)

1. Yes

2. No $\rightarrow$ Q24

3. Don't know $\rightarrow \mathrm{Q} 24$

4. Refused $\rightarrow$ Q24

ALL 21 Do you currently use, or have you used, the 'blue book' or 'personal health record' for [child]?

1. Yes, use it now

2. Yes, have used in past, but not now $\rightarrow$ Q23.

3. No, never used $\rightarrow \mathrm{Q} 24$

4. Don't know $\rightarrow \mathrm{Q} 24$

5. Refused $\rightarrow$ Q24

ALL 22 What do you currently use the Personal Health Record for? 


\section{(MULTIPLE RESPONSE)}

(NOTE: Prompt with 'And anything else?')

1. Record of immunisation $\rightarrow$ Q24

2. Record of growth (weight and height) $\rightarrow$ Q24

3. Record of visits to baby health or early childhood centre $\rightarrow$ Q24

4. Record of visits to doctor $\rightarrow$ Q24

5. Information on child health $\rightarrow \mathrm{Q} 24$

6. Nothing $\rightarrow$ Q24

7. Other (Specify) Q24

8. Don't know $\rightarrow \mathrm{Q} 24$

9. Refused $\rightarrow$ Q24

ALL 23 What have you used the Personal Health Record for in the past? (MULTIPLE RESPONSE)

(NOTE: Prompt with 'And anything else?')

1. Record of immunisation

2. Record of growth (weight and height)

3. Record of visits to baby health or early childhood centre

4. Record of visits to doctor

5. Information on child health

6. Nothing

7. Other (Specify)

8. Don't know

9. Refused

\section{Nutrition: Folate in pregnancy (age 0-11 months and respondent is mother)}

0-11M 24 The next questions are about nutrition in pregnancy, particularly prior to and in the early stages of pregnancy.

0-11M 25 Thinking back to before you were pregnant with [child] were you thinking about becoming pregnant?

1. Yes - trying to become pregnant

2. Not trying to become pregnant $\rightarrow$ Q27

3. Sort of - not actively trying to avoid pregnancy

4. N/A-respondent not birth mother $\rightarrow$ Q33

5. Don't know

6. Refused

0-11M 26 How long were you trying to become pregnant?

1. More than 12 months

2. ___ months (1-12 only)

3. Less than one month

4. Don't know

5. Refused
0-11M 27 Have you heard, seen or read anything about the vitamin folate or folic acid and pregnancy?

1. Yes

2. No $\rightarrow$ Q33

3. Don't know $\rightarrow \mathrm{Q} 33$

4. Refused $\rightarrow$ Q33

0-11M 28 The next few questions refer to when you were pregnant with [child]. Did you take tablets or capsules containing folate or folic acid in the month immediately before and/or in the first three months of this pregnancy?

(NOTE: In the month before includes taking folate for more than one month prior to pregnancy) (NOTE: First three months of pregnancy includes taking folate for more than the first three months of pregnancy)

1. Yes, in the month before and first 3 months of pregnancy

2. Yes, in the month before only

3. Yes, in the first 3 months of pregnancy only

4. No $\rightarrow$ Q30

5. Don't know $\rightarrow \mathrm{Q} 30$

6. Refused $\rightarrow \mathrm{Q} 30$

0-11M 29 What prompted you to take folate or folic acid tablets or capsules?

\section{(MULTIPLE RESPONSE)}

1. Saw leaflet or poster about it

2. Doctor advised me to

3. An early childhood health nurse or midwife suggested it

4. Heard about it on TV or the radio

5. Read about it in a book, newspaper or magazine

6. Pharmacist told me about it

7. Friends or relative mentioned it

8. Read about it on a food label-food package

9. Other (Specify)

\section{Don't know}

11. Refused

0-11M 30 Thinking back to when you were pregnant with [child], did you change the food you ate to increase folate or folic acid intake in the month immediately before and/or in the first three months of this pregnancy?

(PROMPT IF NO: Is that because you were already eating enough food with folate?)

1. Yes 
2. No, already eating enough foods with folate

3. No, didn't change diet

4. Don't know

5. Refused

0-11M 31 What foods do you think contain folate or folic acid?

(MULTIPLE RESPONSE)

1. Fruits

2. Vegetables

3. Fruit juice

4. Breakfast cereal with added folate

5. Bread with added folate

6. Other (Specify)

7. Don't know

8. Refused

0-11M 32 Women are advised to take additional folate or folic acid prior to and during pregnancy. Do you know the main reasons for this?

(MULTIPLE RESPONSE)

1. Makes baby healthy

2. Prevents birth defects

3. Prevents spina bifida

4. Prevents neural tube defects

5. Other (Specify)

6. Don't know

7. Refused

\section{Sleeping position}

0-11M 33 The next question is about sleeping position.

0-11M 34 What position did you put [child] to sleep in from birth?

\section{(READ OPTIONS 1-4)}

1. On [his/her] back

2. On [his/her] side

3. On [his/her] tummy

4. Any other position (Specify)

5. Don't know

6. Refused

\section{Breastfeeding (respondent is mother or father)}

0-23M 35 The next questions are about infant feeding.

0-23M 36 Has [child] ever been breastfed?
1. Yes
2. No $\rightarrow$ Q41
3. Don't know $\rightarrow \mathrm{Q} 41$
4. Refused $\rightarrow$ Q41

0-23M 37 Is [child] currently being breastfed?

1. Yes

2. No

3. Don't know

4. Refused

0-23M 38 Was [child] breastfed when [he/she] first came home from hospital?

1. Yes

2. No

3. Not born in hospital

4. Don't know

5. Refused

0-23M 39 Including times of weaning, what is the total time [child] was breastfed?

1. __ weeks (1-12 weeks only)

2. ___ months (1-23 months only)

3. Less than one week

4. Don't know

5. Refused

0-23M 40 IF MOTHER ASK: What were the main reasons you decided to breastfeed [child]? ELSE $\rightarrow$ Q41 (READ OPTIONS 1-8; MULTIPLE RESPONSE)

1. Breast milk is better for the baby

2. Breastfeeding is more convenient

3. Breastfeeding is cheaper

4. Breastfeeding prevents allergies

5. Breastfeeding helps weight loss

6. Breastfeeding is the right thing to do

7. [Child]'s father wanted you to breastfeed

8. Other people advised you to breastfeed

9. Any other reason (Specify)

10.Don't know

11. Refused

0-23M 41 Has [child] ever been given infant formula regularly?

(PROMPT IF NECESSARY: regularly means at least once a day)

1. Yes

2. No $\rightarrow$ Q43

3. Don't know $\rightarrow \mathrm{Q} 43$

4. Refused $\rightarrow \mathrm{Q} 43$

0-23M 42 At what age was [child] first given infant formula regularly?

1. ___ weeks (1-12 weeks only)

2. ___ months (1-23 months only)

3. Less than one week

4. Don't know

5. Refused 
0-23M 43 Has [child] ever been given cow's milk regularly?
1. Yes
2. No $\rightarrow$ Q45
3. Don't know $\rightarrow \mathrm{Q} 45$
4. Refused $\rightarrow$ Q45

0-23M 44 At what age was [child] first given cow's milk regularly?
1. ___weeks (1-12 weeks only)
2. ___ months (1-23 months only)
3. Less than one week
4. Don't know
5. Refused

0-23M 45 Has [child] ever been given any other type of milk substitute on a regular basis?

(PROMPT: Apart from breast milk-infant formula-cows milk)
1. Yes
2. $\mathrm{No} \rightarrow \mathrm{Q} 48$
3. Don't know $\rightarrow \mathrm{Q} 48$
4. Refused $\rightarrow$ Q48

0-23M 46 What type of milk substitutes did [child] have?

(MULTIPLE RESPONSE)
1. Soya Bean milk
2. Goat's milk
3. Evaporated milk
4. Other (Specify)

5. Don't know

6. Refused

0-23M 47 At what age was [child] first given [this/ any of these] milk substitute(s) regularly?
1. __weeks (1-12 weeks)
2. ___ months (1-23 months)
3. Less than one week
4. Don't know
5. Refused

0-6M 48 Has [child] ever been given solid food?
1. Yes
2. No $\rightarrow$ Q57
3. Don't know $\rightarrow \mathrm{Q} 57$
4. Refused $\rightarrow$ Q57

0-23M 49 At what age was [child] first given solid food regularly?

1. __ weeks (0-12 weeks only)

2. ___ months (1-23 months only)

3. Never given solids-not yet started solids

4. Don't know

5. Refused

\section{Nutrition}

2-12Y 50 The next few questions are about food. I'm going to read you a list of different food and drinks. Please tell me how much of these foods and drinks [child] usually consumes per day or per week.

2-12Y 51 How many serves of fruit does [child] usually eat in a day, including fresh, canned and dried fruit? ( 1 serve $=1-2$ piece fruit, $1 / 3$ cup canned fruit, 1 tablespoon of dried fruit.)

1. ___ serves per day

2. __ serves per week

3. Doesn't eat fruit

4. Don't know

5. Refused

2-12Y 52 How many serves of salad vegetables or raw vegetables does [child] usually eat in a day? ( 1 serve $=1 / 4$ cup salad or 4 vegetable sticks.)

1.___serves per day

2. ___ serves per week

3. Doesn't eat salads or raw vegetables

4. Don't know

5. Refused

2-12Y 53 How many serves of hot chips or french fries does [child] usually eat in a day? ( 1 serve $=1 / 2$ cup hot chips or french fries)

1. __ serves per day

2. ___ serves per week

3. Doesn't eat hot chips or french fries

4. Eats less than once a week

5. Don't know

6. Refused

2-12Y 54 How many serves of cooked vegetables (including potato) does [child] usually eat in a day?

( 1 serve $=1 / 4$ cup cooked vegetables)

1. ___ serves per day

2. ___ serves per week

3. Doesn't eat cooked vegetables

4. Don't know

5. Refused

2-12Y 55 How many cups of milk does [child] usually drink in a day?

( 1 cup $=250 \mathrm{ml}$, a household tea cup) (NOTE: milk = cow's milk. If drinks other milk such as soy milk use response option 3)

1. ___ Number of cups per day

2. ___ Number of cups per week

3. Drinks other milk such as soy milk (Specify) 
4. Doesn't drink cow's milk or other milk

5. Don't know

6. Refused

2-12Y 56 How many cups of fruit juice does [child] usually drink in a day?

( 1 cup $=250 \mathrm{ml}$, a household tea cup or 1 large 'popper')

1. ___ cups per day

2. ___ cups per week

3. Doesn't drink juice

4. Don't know

5. Refused

2-12Y 57 How many cups of soft drink, cordials or sports drink, such as lemonade or Gatorade does [child] usually drink in a day?

( 1 cup $=250 \mathrm{ml}$. One can of soft drink $=1 \frac{1}{2}$ cups. One $500 \mathrm{ml}$ bottle of Gatorade $=2$ cups)

1. ___ cups per day

2. ___ cups per week

3. Doesn't drink soft drink

4. Don't know

5. Refused

\section{Nutrition-Food security}

ALL 58 Sometimes different situations or circumstances arise which may affect family life. The next few questions are about these possible situations.

ALL 59 In the last 12 months, that is since [month] 2000, were there any times that you ran out of food and couldn't afford to buy more?
1. Yes
2. No $\rightarrow$ Q68
3. Don't know $\rightarrow$ Q68
4. Refused $\rightarrow$ Q68

ALL 60 How do you cope with feeding [child]/ your children when this happens? (MULTIPLE RESPONSE)

1 Parent or guardian skips meals or eats less

2. Children or child skip meals or eat less

3. Cut down on variety of foods family eats

4. Seek help from relatives

5. Seek help from friends

6. Seek help from Government or Social Security

7. Seek help from welfare agencies

8. Other (Specify)

9. Don't know

\section{Refusal}

ALL 61 Now I'm going to read you a series of statements that people sometimes say about their food situation. For each of these statements, can you tell me whether the statement is often true, sometimes true or never true.

ALL 62 We eat the same thing for several days in a row because we only have a few different kinds of foods on hand and don't have money to buy more. (READ OPTIONS 1-3)

1. Often true

2. Sometimes true

3. Never true

4. Don't know

5. Refused

ALL 63 I cannot feed my [child/children] a balanced meal because I can't afford that. (READ OPTIONS 1-3)

1. Often true

2. Sometimes true

3. Never true

4. Don't know

5. Refused

ALL 64 My [child/children] are not eating enough because I just can't afford enough food.

(READ OPTIONS 1-3)
1. Often true
2. Sometimes true
3. Never true
4. Don't know
5. Refused

ALL 65 I know my [child is/children are] hungry sometimes, but I just can't afford more food (READ OPTIONS 1-3)
1. Often true
2. Sometimes true
3. Never true
4. Don't know
5. Refused

IF Q59=1 + Q60=2 + Q63=1 + Q64 = 1 THEN ASK:

ALL 66 Is this still happening?
1. Yes
2. No $\rightarrow$ Q68
3. Don't know
4. Refused

2M-4Y 67 There are a number of agencies that can help with making sure your family has enough food. Would you like the phone numbers of these agencies? 
1. Yes $\rightarrow$ Refer to list of relevant agencies

2. No

3. Don't know

4. Refused

\section{Immunisation}

2M-4Y 68 The next few questions are about immunisation or vaccination

2M-4Y 69 To which health professionals or places have you ever taken [child] to be vaccinated?

\section{(MULTIPLE RESPONSE)}

1. Baby or early childhood health centre

2. Immunisation clinic

3. Local doctor or GP

4. GP at a medical centre

5. Hospital clinic

6. School or Kindergarten

7. Local council

8. Community Health Centre

9. Royal Flying Doctor Service

10. Homeopath

11. Health professional vaccinated child at home

12. Other (Specify)

13. Never vaccinated

14. Don't know

15.Refused

2M-4Y 70 Overall, how do you feel about childhood vaccination? Do you: (READ OPTIONS 1-4)

1. Strongly support it $\rightarrow \mathrm{Q72}$

2. Generally support it

3. Are you indifferent or don't care

4. Opposed to it

5. Don't know $\rightarrow \mathrm{Q} 72$

6. Refused $\rightarrow$ Q72

2M-4Y 71 From which sources have you received information about vaccination? (NOTE: Prompt with 'And anything else?')

(MULTIPLE RESPONSE)

1. Health Professional

2. Media publicity such as TV, radio, papers or magazines

3. Information from a group opposed to immunisation

4. Word of mouth

5. Personal or family experience

6. Natural therapist

7. Other (Specify)

8. Don't know

\section{Refused}

\section{Asthma}

2-12Y 72 The next few questions are about asthma.

2-12Y 73 Have you ever been told by a doctor or at a hospital that [child] has asthma?

1. Yes

2. No $\rightarrow$ Q87

3. Don't know $\rightarrow \mathrm{Q} 87$

4. Refused $\rightarrow$ Q87

2-12Y 74 How old was [child] when you were first told [he/she] had asthma?

(READ OPTIONS 1-6, depending on age)

1. Less than 12 months of age

2. 1 year to less than 3 years

3. 3 to less than 5 years of age

4. 5 to less than 7 years of age

5. 7 to less than 10 years of age

6. 10 years or older

7. Don't know

8. Refused

2-12Y 75 Has [child] had symptoms of asthma or medication for treatment or prevention of asthma in the last 12 months, that is since [month] 2000?

1. Yes

2. No $\rightarrow \mathrm{Q} 87$

3. Don't know $\rightarrow \mathrm{Q} 87$

4. Refused $\rightarrow$ Q87

2-12Y 76 How many times in the last 12 months, that is since [month] 2000, has [child] visited a GP or local doctor for an attack of asthma?

1. ___ number of times

2. Don't know

3. Refused

2-12Y 77 How many times in the last 12 months, that is since [month] 2000, has [child] visited a hospital emergency department for an attack of asthma?

1. n__ number of times

2. Don't know

3. Refused

2-12Y 78 How many days in the last 12 months, that is since [month] 2000, has asthma limited [child]'s usual activities?

1. n__ number of days

2. Don't know

3. Refused

2-12Y 79 How many nights in the last month has asthma disturbed [child]'s sleep?

1. ___ number of nights 


\section{Don't know \\ 3. Refused}

2-12Y 80 Do you have a written asthma management plan from [child]'s doctor on how to treat [his/her] asthma?
1. Yes
2. No
3. Don't know
4. Refused

2-12Y 81 Does [child] use a reliever medication with puffer, nebuliser or spacer such as Ventolin, Respolin, Asmol, Airomir or Bricanyl?

(PROMPT: A reliever medication helps to control or relieve the symptoms of asthma such as wheezing or coughing and its effect lasts about 4 hours)
1. Yes
2. $\mathrm{No} \rightarrow \mathrm{Q} 83$
3. Don't know $\rightarrow \mathrm{Q} 83$
4. Refused $\rightarrow$ Q83

2-12Y 82 In the last month, how often has [child] used reliever medication?

(READ OPTIONS 1-5)
1. Every day
2. Most days
3. About half the days
4. Less than half the days
5. Not at all
6. Don't know
7. Refused

2-12Y 83 Does [child] use Serevent or Foradile? (PROMPT: These medications are inhaled and their effects last for 12 hours)
1. Yes
2. No $\rightarrow$ Q85
3. Don't know $\rightarrow \mathrm{Q} 85$
4. Refused $\rightarrow$ Q85

2-12Y 84 In the last month, how often has [child] used Serevent or Foradile?

\section{(READ OPTIONS 1-5)}
1. Every day
2. Most days
3. About half the days
4. Less than half the days
5. Not at all
6. Don't know
7. Refused

2-12Y 85 Does [child] use preventer medication such as Becotide, Becloforte, Aldecin, Pulmicort, Flixotide, Intal, Intal forte, Cromogen or Tilade?
1. Yes

2. $\mathrm{No} \rightarrow \mathrm{Q} 87$

3. Don't know $\rightarrow \mathrm{Q} 87$

4. Refused $\rightarrow \mathrm{Q} 87$

2-12Y 86 In the last month, how often has [child] used preventer medication? (READ OPTIONS 1-5)
1. Every day
2. Most days
3. About half the days
4. Less than half the days
5. Not at all
6. Don't know
7. Refused

\section{Dental health}

1-4Y 87 The next questions are about teeth and visits to the dentist.

1-4Y 87a Has [child] ever visited a dental professional about [his/her] teeth or gums?

(NOTE: Dental professionals includes dentists, dental specialists or dental therapists)
1. Yes
2. $\mathrm{No} \rightarrow \mathrm{Q} 96$
3. Don't know $\rightarrow$ Q96
4. Refused $\rightarrow$ Q96

1-4Y 88 How long ago did [child] see a dental professional about [his/her] teeth or gums?

(READ OPTIONS 1-4 depending on age)

1. Less than 12 months ago $\rightarrow \mathrm{Q} 91$

2. One to less than two years ago $\rightarrow$ Q91

3. Two to less than four years ago $\rightarrow$ Q91

4. Never attended $\rightarrow$ Q91

5. Don't know

6. Refused $\rightarrow$ Q91

5-12Y 89 In the last 12 months, that is since [month] 2000, did [child] have a dental assessment at school as part of the SOKS (Save Our Kids Smiles) program? (PROMPT: Save our kids smiles is a school dental check done at school with the consent children's parents or carers)

1. Yes

2. No

3. Don't know

4. Refused

5-12Y 90 Apart from a dental assessment for the SOKS program how long ago did [child] see a dental professional about [his/her] teeth or gums?

(READ OPTIONS 1-6) 
1. Less than 12 months ago

2. One to less than two years ago

3. Two to less than five years ago $\rightarrow$ Q96

4. Five to less than 10 years ago $\rightarrow$ Q96

5. 10 years ago or more $\rightarrow$ Q96

6. Never attended $\rightarrow$ Q96

7. Don't know $\rightarrow$ Q96

8. Refused $\rightarrow$ Q96

1-12Y 91 Was [child]'s last dental visit made at (READ OPTIONS 1-6)

1. Private dental practice

2. School dental service $\rightarrow$ Q94

3. Other Government or public dental clinic $\rightarrow$ Q94

4. Health fund dental clinic

5. Dental hospital $\rightarrow$ Q94

6. Any other place (Specify) Q94

7. Don't know $\rightarrow$ Q94

8. Refused $\rightarrow$ Q94

1-12Y 92 Was your child listed as a dependent on a health card or pensioner concession card at that time?

(NOTE: Do not include Medicare Card)

1. Yes - eligible at that time

2. No - not eligible at that time $\rightarrow$ Q94

3. Don't know $\rightarrow$ Q94

4. Refused $\rightarrow$ Q94

1-12Y 93 If [child] was eligible for public dental treatment, what was the main reason [he/ she] went to a private practitioner, rather than a government or public clinic?

1. Access - difficult to get to

2. Quality of care better at private clinic

3. Continuity of care - had previously attended private clinic

4. Waiting times at public clinics longer

5. Getting the treatment you wanted

6. Other (Specify)

7. Don't know

8. Refused

1-12Y 94 What type of dental treatment did [child] have in the past 12 months, that is since [month] 2000? Include all dental visits in the past 12 months.

(READ OPTIONS 1-7; MULTIPLE RESPONSE)

1. Fillings

2. Tooth removed

3. Check up

4. Fluoride treatment

5. Scale and clean

6. Orthodontics
7. Any other treatment (Specify)

8. Don't know

9. Refused

5-12Y 95 Thinking back to all the times in the last 12 months [child] saw a dental professional were any of these visits for treatment of an injury?

1. Yes

2. No

3. Don't know

4. Refused

\section{Health status}

ALL 96 The next section is about [child]'s general health and wellbeing.

ALL 97 In general would you say [child]'s health is (READ OPTIONS 1-5)

1. Excellent

2. Very good

3. Good

4. Fair

5. Poor

6. Don't Know

7. Refused

5-12Y 98 The following questions ask about physical activities [child] might do during a day.

5-12Y 99 During the past 4 weeks has [child] been limited in doing things that take a lot of energy, such as playing soccer or running, due to health problems?

1. Yes

2. No $\rightarrow$ Q103

3. Don't know $\rightarrow \mathrm{Q} 103$

4. Refused $\rightarrow$ Q103

5-12Y 100 Has [he/she] been limited a lot, some or a little?

1. A lot

2. Some

3. A little

4. Don't know

5. Refused

5-12Y 101 During the past 4 weeks has [child] been limited in doing things that take some energy, such as riding a bike or skating, due to health problems?

1. Yes

2. No $\rightarrow$ Q103

3. Don't know $\rightarrow \mathrm{Q} 103$

4. Refused $\rightarrow$ Q103

5-12Y 102 Has [he/she] been limited a lot, some or a little? 

1. A lot
2. Some
3. A little
4. Don't know
5. Refused

5-12Y 103 During the past 4 weeks has [child] been limited in bending, lifting or stooping, due to health problems?
1. Yes
2. No $\rightarrow$ Q105
3. Don't know $\rightarrow \mathrm{Q} 105$
4. Refused $\rightarrow$ Q105

5-12Y 104 Has [he/she] been limited a lot, some or a little?
1. A lot
2. Some
3. A little
4. Don't know
5. Refused

5-12Y 105 The next questions are about limitations in school work or activities with friends.

5-12Y 106 During the past 4 weeks has [child] been limited in the amount of time [he/she] could spend on school work, or activities with friends because of emotional difficulties or behavioural problems?
1. Yes
2. $\mathrm{No} \rightarrow \mathrm{Q} 108$
3. Don't know $\rightarrow \mathrm{Q} 108$
4. Refused $\rightarrow$ Q108

5-12Y 107 Has [he/she] been limited a lot, some or a little?
1. A lot
2. Some
3. A little
4. Don't know
5. Refused

5-12Y 108 During the past 4 weeks has [child] been limited in the kind of school work or activities [he/she] could do with friends because of problems with [his/her] physical health?
1. Yes
2. No $\rightarrow$ Q110
3. Don't know $\rightarrow$ Q110
4. Refused $\rightarrow$ Q110

5-12Y 109 Has [he/she] been limited a lot, some or a little?
1. A lot
2. Some
3. A little
4. Don't know
5. Refused

5-12Y 110 The next question is about pain or discomfort [child] may have had in the past 4 weeks.

5-12Y 111 During the past 4 weeks, how often has [child] had bodily pain or discomfort? (READ OPTIONS 1-6)

1. None of the time

2. Once or twice

3. A few times

4. Fairly often

5. Very often

6. Every-almost every day

7. Don't know

8. Refused

5-12Y 112 Now I am going to ask some questions about children's behaviour or problems they sometimes have.

5-12Y 113 How often during the past 4 weeks did [child] argue a lot?

(READ OPTIONS 1-5)

1. Very often

2. Fairly often

3. Sometimes

4. Almost never

5. Never

6. Don't know

7. Refused

5-12Y 114 How often during the past 4 weeks did [child] have difficulty concentrating or paying attention?

\section{(READ OPTIONS 1-5)}
1. Very often
2. Fairly often
3. Sometimes
4. Almost never
5. Never
6. Don't know
7. Refused

5-12Y 115 How often in the past 4 weeks did [child] lie or cheat?

(READ OPTIONS 1-5)
1. Very often
2. Fairly often
3. Sometimes
4. Almost never
5. Never
6. Don't know
7. Refused

5-12Y 116 Compared to other children [child]'s age, in general would you say [child]'s behaviour is?

(READ OPTIONS 1-5) 

1. Excellent
2. Very good
3. Good
4. Fair
5. Poor
6. Don't know
7. Refused

5-12Y 117 The following questions are about children's moods and feelings.

5-12Y 118 During the past 4 weeks how much of the time do you think [child] felt lonely? (READ OPTIONS 1-5)
1. All of the time
2. Most of the time
3. Some of the time
4. A little of the time
5. None of the time
6. Don't know
7. Refused

5-12Y 119 During the past 4 weeks how much of the time do you think [child] acted nervous? (READ OPTIONS 1-5)
1. All of the time
2. Most of the time
3. Some of the time
4. A little of the time
5. None of the time
6. Don't know
7. Refused

5-12Y 120 During the past 4 weeks how much of the time do you think [child] acted bothered or upset?
(READ OPTIONS 1-5)
1. All of the time
2. Most of the time
3. Some of the time
4. A little of the time
5. None of the time
6. Don't know
7. Refused

5-12Y 121 The following questions ask about [child]'s satisfaction with self, school and others. It may be helpful to keep in mind how other children [child]'s age might feel about these areas.

5-12Y 122 During the past 4 weeks, how satisfied do you think [child] has felt about [his/her] school ability?

(READ OPTIONS 1-5)
1. Very satisfied
2. Somewhat satisfied
3. Neither satisfied or dissatisfied
4. Somewhat dissatisfied
5. Very dissatisfied
6. Don't know
7. Refused

5-12Y 123 During the past 4 weeks, how satisfied do you think [child] has felt about [his/her] friendships? (READ OPTIONS 1-5)

1. Very satisfied

2. Somewhat satisfied

3. Neither satisfied or dissatisfied

4. Somewhat dissatisfied

5. Very dissatisfied

6. Don't know

7. Refused

5-12Y 124 During the past 4 weeks, how satisfied do you think [child] has felt about [his/her] life overall? (READ OPTIONS 1-5)

1. Very satisfied

2. Somewhat satisfied

3. Neither satisfied or dissatisfied

4. Somewhat dissatisfied

5. Very dissatisfied

6. Don't know

7. Refused

5-12Y 125 The next questions are about you and your family.

5-12Y 126 During the past 4 weeks, how much emotional worry or concern did [child]'s physical health cause you?

(READ OPTIONS 1-5)
1. None at all
2. A little bit
3. Some
4. Quite a bit
5. A lot
6. Don't know
7. Refused

5-12Y 127 During the past 4 weeks, how much emotional worry or concern did [child]'s emotional well being or behaviour cause you?

\section{(READ OPTIONS 1-5)}

1. None at all $\rightarrow \mathrm{Q} 130$

2. A little bit $\rightarrow \mathrm{Q} 130$

3. Some $\rightarrow \mathrm{Q} 130$

4. Quite a bit $\rightarrow$ Q130

5. A lot

6. Don't know

7. Refused

5-12Y 128 Is this still worrying you a lot?

1. Yes

2. No $\rightarrow$ Q130 


\section{Don't know \\ 4. Refused}

5-12Y 129 Would you like some assistance or support with this problem?

1. Yes $\rightarrow$ refer to list of relevant agencies

2. No

3. Don't know

4. Refused

5-12Y 130 During the past 4 weeks, did [child]'s physical health limit the amount of time you have for your own personal needs?
1. Yes
2. No $\rightarrow$ Q132
3. Don't know $\rightarrow \mathrm{Q} 132$
4. Refused $\rightarrow$ Q132

5-12Y 131 Has your time been limited a lot, some or a little?
1. A lot
2. Some
3. A little
4. Don't know
5. Refused

5-12Y 132 During the past 4 weeks, did [child]'s emotional wellbeing or behaviour limit the amount of time you have for your own personal needs?
1. Yes
2. No $\rightarrow$ Q134
3. Don't know $\rightarrow \mathrm{Q} 134$
4. Refused $\rightarrow$ Q134

5-12Y 133 Has your time been limited a lot, some or a little?
1. A lot
2. Some
3. A little
4. Don't know
5. Refused

5-12Y 134 During the past 4 weeks, how often has [child]'s health or behaviour limited the types of activities you could do as a family?

\section{(READ OPTIONS 1-5)}
1. Very often
2. Fairly often
3. Sometimes
4. Almost never
5. Never
6. Don't know
7. Refused

5-12Y 135 During the past 4 weeks, how often has [child]'s health or behaviour interrupted various everyday family activities such as eating meals or watching TV?

(READ OPTIONS 1-5)

1. Very often

2. Fairly often

3. Sometimes

4. Almost never

5. Never

6. Don't know

7. Refused

5-12Y 136 Sometimes families may have difficulty getting along with one another. They do not always agree and they may get angry. In general, how would you rate your family's ability to get along with one another?

(READ OPTIONS 1-5)

1. Excellent $\rightarrow$ Q138

2. Very good $\rightarrow$ Q138

3. Good $\rightarrow$ Q138

4. Fair $\rightarrow$ Q138

5. Poor

6. Don't know $\rightarrow$ Q138

7. Refused $\rightarrow \mathrm{Q} 138$

5-12Y 137 Would you like some help or support with this problem?

1. Yes $\rightarrow$ refer to list of relevant agencies

2. No

3. Don't know

4. Refused

\section{Physical health of toddlers (aged 1-4)}

1-4Y 138 The next few questions are about [child]'s physical health.

1-4Y 139 Does [child] have any difficulties with eating or feeding?

1. Yes

2. No $\rightarrow$ Q144

3. Don't know $\rightarrow \mathrm{Q} 144$

4. Refused $\rightarrow$ Q144

1-4Y 140 How serious do these difficulties seem to you? Are they not serious, somewhat serious or very serious?

1. Not serious $\rightarrow$ Q144

2. Somewhat serious

3. Very serious

4. Don't know $\rightarrow \mathrm{Q} 144$

5. Refused $\rightarrow$ Q144

1-4Y 141 Have you sought help for this problem?

1. Yes

2. No $\rightarrow$ Q144

3. Don't know $\rightarrow \mathrm{Q} 144$

4. Refused $\rightarrow$ Q144 
1-4Y 142 Where did you seek help for that problem?

\section{(READ OPTIONS 1-8: MULTIPLE RESPONSE)}

1. Family or friends

2. General practitioner

3. Specialist

4. Baby or early childhood health nurse

5. Tresillian or Karitane

6. Telephone help line

7. Chemist

8. Any other place sought help (Specify)

9. Don't Know

10. Refused

1-4Y 143 Thinking about the help you got from $[\ldots . .$.$] how useful was that help? Was the$ help very useful, somewhat useful, a little useful, or not useful.
1. Very Useful
2. Somewhat useful
3. A little useful
4. Not useful
5. Don't Know

1-4Y 144 Does [child] have any difficulties with taking steps, walking or running?
1. Yes
2. No $\rightarrow$ Q149
3. Not walking yet $\rightarrow$ Q149
4. Don't know $\rightarrow$ Q149
5. Refused $\rightarrow$ Q149

1-4Y 145 How serious do these difficulties seem to you? Were they not serious, somewhat serious or very serious?
1. Not serious $\rightarrow$ Q149
2. Somewhat serious
3. Very serious
4. Don't know $\rightarrow$ Q149
5. Refused $\rightarrow$ Q149

1-4Y 146 Have you sought help for this problem?
1. Yes
2. No $\rightarrow$ Q149
3. Don't know $\rightarrow$ Q149
4. Refused $\rightarrow$ Q149

1-4Y 147 Where did you seek help for that problem?

(READ OPTIONS 1-8: MULTIPLE RESPONSE)

1. Family or friends

2. General practitioner

3. Specialist

4. Baby or early childhood health nurse

5. Tresillian or Karitane
6. Telephone help line

7. Chemist

8. Any other place sought help (Specify)

9. Don't know

10.Refused

1-4Y 148 Thinking about the help you got from $[\ldots . . . . .$.$] , how useful was that help? Was$ it very useful, somewhat useful, a little useful or not useful?

1. Very useful

2. Somewhat useful

3. A lttle useful

4. Not useful

5. Don't know

1-4Y 149 Considering [child]'s age, does [he/she] have any other difficulties with [his/her] physical development? (PROMPT: For example difficulties in manipulating objects such as toys)
1. Yes
2. No $\rightarrow$ Q154
3. Don't know $\rightarrow \mathrm{Q} 154$
4. Refused $\rightarrow$ Q154

1-4Y 150 How serious do these difficulties seem to you? Are they not serious, somewhat serious or very serious?

1. Not serious $\rightarrow \mathrm{Q} 154$

2. Somewhat serious

3. Very serious

4. Don't know $\rightarrow$ Q154

5. Refused $\rightarrow$ Q154

1-4Y 151 Have you sought help for this problem?

1. Yes

2. No $\rightarrow$ Q154

3. Don't know $\rightarrow \mathrm{Q} 154$

4. Refused $\rightarrow$ Q154

1-4Y 152 Where did you seek help for that problem?

(READ OPTIONS 1-8: MULTIPLE RESPONSE)

1. Family or friends

2. General practitioner

3. Specialist

4. Baby or early childhood health nurse

5. Tresillian or Karitane

6. Telephone help line

7. Chemist

8. Any other place sought help (Specify)

9. Don't know

10. Refused 
1-4Y 153 Thinking about the help you got from $[\ldots . . . .$.$] , how useful was that help? Was$ it very useful, somewhat useful, a little useful or not useful?
1. Very useful
2. Somewhat useful
3. A little useful
4. Not useful
5. Don't know

\section{Emotional-behavioural problems (4-12 yrs)}

4-12Y 154 The next section is about emotional and behavioural problems.

4-12Y 155 During the past 6 months, do you think that [child] has had any emotional or behavioural problems?
1. Yes
2. $\mathrm{No} \rightarrow \mathrm{Q} 165$
3. Don't know $\rightarrow$ Q165
4. Refused $\rightarrow$ Q165

4-12Y 156 During this time did [child] tend to have more emotional or behavioural problems than other [boys/girls] of [his/her] age?
1. Yes
2. No
3. Don't know
4. Refused

4-12Y 157 How serious do you think these behavioural and emotional problems are in terms of causing distress to [child]? Are they not serious, somewhat serious or very serious?
1. Not serious
2. Somewhat serious
3. Very serious
4. Don't know
5. Refused

4-12Y 158 How serious do you think these behavioural and emotional problems are in terms of disrupting or causing distress in others? Are they not serious, somewhat serious or very serious?
1. Not serious
2. Somewhat serious
3. Very serious
4. Don't know
5. Refused

4-12Y 159 How serious do you think these behavioural and emotional problems are in terms of preventing [child] from doing things usually expected of other [boys/ girls] of [his/her] age? Are they not serious, somewhat serious or very serious? 1. Not serious
2. Somewhat serious
3. Very serious
4. Don't know
5. Refused

4-12Y 160 Do you think that [child] needs or needed any professional help with these problems?
1. Yes
2. No $\rightarrow$ Q165
3. Don't know $\rightarrow$ Q165
4. Refused $\rightarrow$ Q165

4-12Y 161 Did [child] get help, care or treatment for these emotional and behavioural problems?
1. Yes $\rightarrow$ Q165
2. No
3. Don't know $\rightarrow$ Q165
4. Refused $\rightarrow$ Q165

4-12Y 162 During the past six months have any of the following reasons kept [child] from getting more of the help you thought [he/ she] needed for emotional or behavioural problems?

(READ OPTIONS 1-10: MULTIPLE
RESPONSE)

1. [Child] didn't want to attend service

2. You were afraid of what your family or friends might say

3. You decided you could handle [child]'s problem on your own

4. Help was too expensive

5. The services were too far away

6. You thought treatment might not help

7. You had to wait a long time for an appointment

8. You did not know where to get help

9. You asked for help and didn't get it

10. Any other reason (Specify)

\section{Don't know}

12. Refused

If $155=1$ and $157=3$ and $161=2$ ASK

4-12Y 163 Is this still a problem?

1. Yes

2. No $\rightarrow$ Q165

3. Don't know $\rightarrow$ Q 165

4. Refused $\rightarrow$ Q165

4-12Y 164 Would you like some assistance or support with this problem?

1. Yes $\rightarrow$ refer to list of relevant agencies

2. No

3. Don't know

4. Refused 


\section{Infant behavioural problems (age 0-11 months)}

0-11M 165 Parents often experience a range of difficulties with their babies such as feeding, settling and crying. The next few questions are about these difficulties that you may be currently experiencing with [child] or may have previously experienced.

0-11M 166 Do you currently, or have you had any problems with feeding [child]?
1. Yes
2. No $\rightarrow$ Q172
3. Don't know $\rightarrow \mathrm{Q} 172$
4. Refused $\rightarrow$ Q172

0-11M 167 What is, or was, the most serious feeding problem you have with [child]?

(READ OPTIONS 1-5)
1. Breastfeeding
2. Taking a bottle
3. Taking solids
4. Reflux and/or vomiting
6. Don't know $\rightarrow \mathrm{Q} 172$
7. Refused $\rightarrow \mathrm{Q} 172$

5. Any other feeding problem (Specify)

0-11M 168 How serious did this problem seem to you? Was it not serious, somewhat serious or very serious?
1. Not serious $\rightarrow \mathrm{Q} 172$
2. Somewhat serious
3. Very serious
4. Don't know $\rightarrow$ Q172
5. Refused $\rightarrow \mathrm{Q} 172$

0-11M 169 How difficult was it for you to manage this problem? (READ OPTIONS 1-3)
1. Not difficult
2. Somewhat difficult
3. Very difficult
4. Don't know
5. Refused

0-11M 170 Where did you seek help for that problem? (READ OPTIONS 1-8: MULTIPLE RESPONSE)

1. Family or friends

2. General practitioner

3. Specialist

4. Baby or early childhood health nurse

5. Tresillian or Karitane

6. Telephone help line

7. Chemist
8. Any other place sought help (Specify)

9. Did not seek help for problem $\rightarrow$ Q172 10.Don't know $\rightarrow$ Q172

11. Refused $\rightarrow$ Q172

0-11M 171 Thinking about the help you got from $[\ldots . . .$.$] how useful was that help? Was it$ very useful, somewhat useful, a little useful, not useful?

1. Very useful

2. Somewhat useful

3. A little useful

4. Not useful

5. Don't know

0-11M 172 Do you currently, or have you had any problems with [child]'s behaviour for example crying, or difficulty settling?
1. Yes
2. $\mathrm{No} \rightarrow \mathrm{Q} 178$
3. Don't know $\rightarrow$ Q178
4. Refused $\rightarrow$ Q178

$0-11 \mathrm{M} 173$ What is or was the most serious behaviour problem you have with [child]? (READ OPTIONS 1-5)

1. Controlling crying

2. Settling

3. Sleeping during day

4. Colic

5. Any other problem (Specify)

6. Don't know $\rightarrow$ Q178

7. Refused $\rightarrow$ Q178

0-11M 174 How serious did this problem seem to you? Was it not serious, somewhat serious or very serious?

1. Not serious $\rightarrow$ Q178

2. Somewhat serious

3. Very serious

4. Don't know $\rightarrow$ Q178

5. Refused $\rightarrow$ Q178

0-11M 175 How difficult was it for you to manage this problem?

(READ OPTIONS 1-3)

1. Not difficult

2. Somewhat difficult

3. Very difficult

4. Don't know

5. Refused

0-11M 176 Where did you seek help for that problem?

(READ OPTIONS 1-7: MULTIPLE RESPONSE)

1. Family or friends 
2. General practitioner

3. Specialist

4. Early childhood health nurse

5. Tresillian or Karitane

6. Telephone help line

7. Chemist

8. Any other place sought help (Specify)

9. Did not seek help for problem $\rightarrow$ Q178

10.Don't know $\rightarrow$ Q178

11. Refused $\rightarrow$ Q178

0-11M 177 Thinking about the help you got from $[\ldots]$ how useful was that help? Was it very useful, somewhat useful, a little useful, not useful?
1. Very useful
2. Somewhat useful
3. A little useful
4. Not useful
5. Don't know

\section{Home visiting (0-4 years)}

0-4Y 178 The next few questions are about visits to your home you may have had from people to assist you in caring for [child]

0-4Y 179 Have you ever had someone, such as a nurse or a volunteer, visit you in your home to provide you with support or advice in caring for [child]?
1. Yes
2. No $\rightarrow$ Q184
3. Don't know $\rightarrow \mathrm{Q} 184$
4. Refused $\rightarrow$ Q184

0-4Y 180 What was the profession of the person who visited you in your home? (READ OPTIONS 1-7: MULTIPLE RESPONSE)

1. Baby or Early childhood health nurse

2. Midwife

3. Social worker, psychologist or counsellor

4. Physiotherapist, speech or other therapist

5. Teacher

6. Volunteer

7. Other professional (Specify)

8. Don't know $\rightarrow$ Q183

9. Refused $\rightarrow$ Q183

0-4Y 181 What age was [child] when you had the first visit from the $[\ldots \ldots \ldots \ldots . . . ?$ ?

1. Age in years (2-4 years)

2. Age in months (1-23 months)
3. Age in weeks (1-3 weeks only)

4. Don't know

5. Refused

0-4Y 182 How many visits did you receive from the $[\ldots \ldots \ldots \ldots . . .$.$] to assist you in caring for$ [child]?

1. ___ number

2. Don't know

3. Refused

0-4Y 183 Which of the following best describes how you feel about having people visit you in your home to provide support and advice?

\section{(READ OPTIONS 1-3)}

1. I was happy to have someone visit me in my home

2. I found having someone visit my home uncomfortable at first but later I found it $\mathrm{OK}$

3. I was uncomfortable having someone come to my home

4. Don't know

5. Refused

ALL OPTIONS $\rightarrow$ Q185

0-4Y 184 How comfortable would you feel about having people visit you in your home to provide support and advice in caring for [child]? Would you feel:

(READ OPTIONS 1-4)

1. Very comfortable

2. Comfortable

3. Uncomfortable

4. Very uncomfortable

5. Don't know

6. Refused

\section{Parental support services (age 1-12 years)}

1-12Y 185 Parents often need support in caring for their children. They can receive support from a number of sources including family and friends and from specialised services. The next questions are about such services.

1-12Y 186 Have you ever felt the need for any type of support service to assist you in caring for [child] or dealing with problems you may have experienced with [him/her]? (PROMPT: Support services include Karitane, Tresillian, early childhood health services, family support services, counsellors)

1. Yes

2. No $\rightarrow$ Q190

3. Don't know $\rightarrow$ Q190 

4. Refused $\rightarrow$ Q190

1-12Y 187 Have you ever used any support services?
1. Yes
2. No $\rightarrow$ Q189
3. Don't know $\rightarrow$ Q189
4. Refused $\rightarrow$ Q189

1-12Y 188 What services have you used to provide you with support as a parent? (READ OPTIONS 1-11: MULTIPLE RESPONSE)

1. Play group

2. Baby or early childhood health nursecentre

3. Formal parenting groups

4. Karitane or Tresillian

5. Family support services

6. Counselling service

7. Telephone help line

8. General practitioner

9. Hospital services

10. Church organisations

11.Any other support service (Specify)

$$
\begin{aligned}
& \text { 12. Don't know } \\
& \text { 13. Refused } \\
& \text { ALL OPTIONS } \rightarrow \text { Q190 }
\end{aligned}
$$

1-12Y 189 What were the main reasons you did not access any parental support services, even though you felt you needed them?

\section{(MULTIPLE RESPONSE)}

1. Services not available

2. Services too far away

3. Felt I should be able to cope on my own

4. Stigma of using services

5. Had to wait too long wait for appointment

6. Didn't know where to get help

7. Thought services couldn't help

8. Any other reason (Specify)

9. Don't know

10. Refused

\section{Social support (age $0-12$ years)}

ALL 190 The next section is about relationships and support that you get from others. I'm going to read you a number of statements. For each of the following, please tell me whether you strongly disagree, disagree, agree or strongly agree.

ALL 191 If something went wrong, no one would help me.

(READ OPTIONS 1-4)
1. Strongly disagree

2. Disagree

3. Agree

4. Strongly agree

5. Don't know

6. Refused $\rightarrow$ Q197

ALL 192 I have family and friends who make me feel safe, secure and happy. (READ OPTIONS 1-4)

1. Strongly disagree

2. Disagree

3. Agree

4. Strongly agree

5. Don't know

6. Refused $\rightarrow$ Q197

ALL 193 There is someone I trust whom I would turn to for advice if I were having problems.

(READ OPTIONS 1-4)

1. Strongly disagree

2. Disagree

3. Agree

4. Strongly agree

5. Don't know

6. Refused $\rightarrow$ Q197

ALL 194 There is no one I feel comfortable talking about problems with. (READ OPTIONS 1-4)

1. Strongly disagree

2. Disagree

3. Agree

4. Strongly agree

5. Don't know

6. Refused $\rightarrow$ Q197

ALL 195 I lack a feeling of closeness with another person.

(READ OPTIONS 1-4)

1. Strongly disagree

2. Disagree

3. Agree

4. Strongly agree

5. Don't know

6. Refused $\rightarrow$ Q197

ALL 196 There are people I can count on in an emergency. (READ OPTIONS 1-4)

1. Strongly disagree

2. Disagree

3. Agree

4. Strongly agree

5. Don't know

6. Refused 


\section{Sun protection}

ALL 197 Next, a few questions about protecting [child]'s skin from the sun.

ALL 198 What steps could you take to reduce [child']s chance of getting skin cancer? (NOTE: probe for description of hat-cap) (NOTE: probe for anything else) (MULTIPLE RESPONSE)

1. Wear broad brimmed hat or cap with a flap

2. Wear baseball-style cap

3. Apply sun screen

4. Wear clothing to protect the skin

5. Wear sunglasses

6. Don't go outside in the middle of the day

7. Minimise time outdoors or stay indoors

8. Stay in shade or out of sun when outside

9. Teach children how to protect themselves

10. Other (Specify)

11.Don't know

12. Refused

1-12Y 199 The next few questions are about occasions last summer when you were with [child] outside in the sun for at least fifteen minutes. Please think about actions you usually took for sun protection for [child] on these occasions.

1-12Y 200 Thinking back to last summer, how often did [child] go out in the sun for more than 15 minutes between $11 \mathrm{am}$ and $3 \mathrm{pm}$ ? (READ OPTIONS 1-5)

1. Always

2. Often

3. Sometimes

4. Rarely or Never

5. Never in sun more than 15 minutes $\rightarrow$ Q204

6. Don't know

7. Refused

1-12Y 201 Thinking back to last summer, when [child] was out in the sun for more than 15 minutes, how often did [he/she] wear a broad brimmed hat or cap with a back flap?

(READ OPTIONS 1-4)
1. Always
2. Often
3. Sometimes
4. Rarely or Never
5. Don't know
6. Refused

1-12Y 202 Still thinking about last summer how often did you apply a broad-spectrum sun screen with an SPF of 15 or more to [his/ her] exposed skin?

(READ OPTIONS 1-4)
1. Always
2. Often
3. Sometimes
4. Rarely or Never
5. Don't know
6. Refused

1-12Y 203 Still thinking about last summer how often was [child] deliberately dressed in clothing to protect [him/her] from the sun?

(READ OPTIONS 1-4)
1. Always
2. Often
3. Sometimes
4. Rarely or Never
5. Don't know
6. Refused

ALL 204 Now I'm going to read out some statements people have made about sun protection and skin cancer. Please tell me how strongly you personally agree or disagree with each of them.

ALL 205 Sun screen provides adequate protection from the sun. Do you:

(READ OPTIONS 1-5)
1. Strongly agree
2. Agree
3. Neither agree nor disagree
4. Disagree
5. Strongly disagree
6. Don't know
7. Refused

ALL 206 A baseball cap is adequate to protect the face from the sun. Do you: (READ OPTIONS 1-5)
1. Strongly agree
2. Agree
3. Neither agree nor disagree
4. Disagree
5. Strongly disagree
6. Don't know
7. Refused

1-12Y 207 Still thinking of last summer, how often did [child] get sunburnt, so their skin was still sore or tender the next day?

1. Not at all 

2. Once
3. Twice
4. 3 or 4 times
5. 5 or more times
6. Don't know or don't recall
7. Refused

5-12Y 208 Imagine [child] spent short periods of time in the sun every day over the summer. How do you think [his/her] skin would look at the end of summer? (READ OPTIONS 1-4)
1. Very tanned
2. Moderately tanned
3. Lightly tanned
4. No suntan at all
5. Other (Specify)
6. Don't know
7. Refused

\section{Disability-Sight (aged 2-12 years)}

2-12Y 209 The next few questions are about sight and hearing.

2-12Y 210 As far as you know, does [child] have normal vision in both eyes?
1. Yes $\rightarrow$ Q214
2. No
3. Don't know
4. Refused

2-12Y 211 Is [child] blind or unable to see in one or both eyes?

1. Yes, unable to see with one eye only

2. Yes, unable to see with both eyes $\rightarrow$ Q214

3. No, able to see with both eyes

4. Don't know

5. Refused

2-12Y 212 Does [child] use prescribed glasses or contact lenses now?
1. Yes
2. No $\rightarrow$ Q214
3. Don't know $\rightarrow \mathrm{Q} 214$
4. Refused $\rightarrow \mathrm{Q} 214$

3-12Y 213 Even when wearing glasses or contact lenses, would [child] have any difficulty seeing the words in a [story book/ school book]?
1. Yes
2. No
3. Don't know
4. Refused

\section{Disability - hearing}

ALL 214 Has [child] ever had [his/her] hearing tested?
1. Yes
2. No
3. Don't know
4. Refused

ALL 215 As far as you know, does [child] currently have normal hearing in both ears?
1. Yes $\rightarrow$ Q219
2. No
3. Don't know
4. Refused

ALL 216 Does [child] use a hearing aid now?
1. Yes
2. No
3. Don't know
4. Refused

ALL 217 How serious is [child]'s hearing loss? Is it: (READ OPTIONS 1-4)
1. Mild
2. Moderate
3. Severe
4. Profound
5. Don't know
6. Refused

ALL 218 How old was [child] when the hearing loss was first discovered?

1. __ age in weeks (0-3 weeks only)

2 . __ age in months (1-23 months only)

3 . __ age in years (2-12 years only)

4. Not sure

5. Refused

0-4Y 219 The next few questions are about ear infections.

0-4Y 220 Has [child] ever had an ear infection diagnosed by a doctor?
1. Yes
2. $\mathrm{No} \rightarrow \mathrm{Q} 222$
3. Don't know $\rightarrow \mathrm{Q} 222$
4. Refused $\rightarrow$ Q222

0-4Y 221 Has [child] ever had a discharge from [his/ her] ear or a 'runny' ear?

1. Yes

2. No

3. Don't know

4. Refused

0-4Y 222 Has [child] ever had an operation to insert a tube or grommet into [his/her] ear?
1. Yes

2. No 


\section{Don't know \\ 4. Refused}

\section{Speech (2-12 years only)}

2-12Y 223 The next few questions are about speech.

2-12Y 224 Compared to other children of [his/her] age does [child] have any difficulty saying certain sounds?
1. Yes
2. No $\rightarrow$ Q227
3. Don't know
4. Refused

2-12Y 225 Does [child] stammer or stutter?
1. Yes
2. No
3. Don't know
4. Refused

2-12Y 226 Compared with other children [his/her] age, how well does [child] speak or use words? Would you say [he/she] is: (READ OPTIONS 1-3)

1. Better than other children $\rightarrow \mathrm{Q} 228$

2. Same as other children $\rightarrow \mathrm{Q} 228$

3. Does not speak as well as other children

4. Don't know

5. Refused

2-12Y 227 Has child ever attended speech therapy or seen a speech pathologist for problems with speech?
1. Yes
2. No
3. Don't know
4. Refused

\section{Family functioning (age $0-12$ years)}

ALL 228 The next section is about families and family relationships which can vary from family to family and influence the health of children. I'm going to read you some statements about family relationships. For each of them please tell me whether you strongly agree, agree, disagree, or strongly disagree with the statement as a description of your family.

(NOTE: 'family' refers to respondent's definition of family)

ALL 229 Planning family activities is difficult because we misunderstand each other. Do you:

(READ OPTIONS 1-4)
1. Strongly agree
2. Agree
3. Disagree
4. Strongly disagree
5. Don't know
6. Refusal $\rightarrow$ Q241

ALL 230 In times of crisis we can turn to each other for support.

(READ OPTIONS 1-4)

1. Strongly agree

2. Agree

3. Disagree

4. Strongly disagree

5. Don't know

6. Refusal $\rightarrow$ Q241

ALL 231 We cannot talk to each other about sadness we feel.

(READ OPTIONS 1-4)

1. Strongly agree

2. Agree

3. Disagree

4. Strongly disagree

5. Don't know

6. Refusal $\rightarrow$ Q241

ALL 232 Individuals, in the family, are accepted for what they are. (READ OPTIONS 1-4)

1. Strongly agree

2. Agree

3. Disagree

4. Strongly disagree

5. Don't know

6. Refusal $\rightarrow$ Q241

ALL 233 We avoid discussing our fears and concerns. (READ OPTIONS 1-4)

1. Strongly agree

2. Agree

3. Disagree

4. Strongly disagree

5. Don't know

6. Refusal $\rightarrow$ Q241

ALL 234 We express feelings to each other. (READ OPTIONS 1-4)

1. Strongly agree

2. Agree

3. Disagree

4. Strongly disagree

5. Don't know

6. Refusal $\rightarrow$ Q241

ALL 235 There are lots of bad feelings in our family.

(READ OPTIONS 1-4)

1. Strongly agree 

2. Agree
3. Disagree
4. Strongly disagree
5. Don't know
6. Refusal $\rightarrow$ Q241

ALL 236 We feel accepted for what we are. (READ OPTIONS 1-4)
1. Strongly agree
2. Agree
3. Disagree
4. Strongly disagree
5. Don't know
6. Refusal $\rightarrow$ Q241

ALL 237 Making decisions is a problem in our family.

(READ OPTIONS 1-4)
1. Strongly agree
2. Agree
3. Disagree
4. Strongly disagree
5. Don't know
6. Refusal $\rightarrow$ Q241

ALL 238 We are able to make decisions about how to solve problems.

(READ OPTIONS 1-4)
1. Strongly agree
2. Agree
3. Disagree
4. Strongly disagree
5. Don't know
6. Refusal $\rightarrow$ Q241

ALL 239 We don't get on well together.
(READ OPTIONS 1-4)
1. Strongly agree
2. Agree
3. Disagree
4. Strongly disagree
5. Don't know
6. Refusal $\rightarrow$ Q241

ALL 240 We confide in each other. (READ OPTIONS 1-4)
1. Strongly agree
2. Agree
3. Disagree
4. Strongly disagree
5. Don't know
6. Refusal $\rightarrow$ Q241

\section{Social capital (age 0-12 years)}

ALL 241 The next questions are about your involvement in your local community and neighbourhood.
ALL 242 In the past three months, how often have you helped out any local group or organisation such as a school, scouts and brownies, a sporting club, or hospital as a volunteer, or other organisation?

(READ OPTIONS 1-4)

1. About once a week

2. Once every $2-3$ weeks

3. Once a month or less

4. No, not at all

5. Don't know

6. Refused

ALL 243 In the past six months, how often have you attended a local community event such as a church or school fete, school concert, or street fair?

(READ OPTIONS 1-4)

1. Three times or more

2. Twice

3. Once

4. Never

5. Don't know

6. Refused

ALL 244 Are you an active member of a local organisation, church or club, such as a sport, craft, or social club?

(READ OPTIONS 1-4)

1. Yes, very active

2. Yes, somewhat active

3. Yes, a little active

4. No, not an active member

5. Don't know

6. Refused

ALL 245 I'm now going to read you some statements about safety in your local area. Can you tell me if you agree or disagree with these statements? I feel safe walking down my street after dark. Do you: (READ OPTIONS 1-4)

1. Strongly agree

2. Agree

3. Disagree

4. Strongly disagree

5. Don't know

6. Refused

ALL 246 Most people can be trusted. Do you: (READ OPTIONS 1-4)

1. Strongly agree

2. Agree

3. Disagree

4. Strongly disagree

5. Don't know

6. Refused 
ALL 247 My area has a reputation for being a safe place.

Do you:

$$
\text { (READ OPTIONS 1-4) }
$$
1. Strongly agree
2. Agree
3. Disagree
4. Strongly disagree
5. Don't know
6. Refused

ALL 248 The next few questions are about contact with people in your neighbourhood.

ALL 248aIf you were caring for a child and needed to go out for a while, and could not take the child with you, would you ask someone in your neighbourhood for help? (READ OPTIONS 1-4)
1. Yes, definitely
2. Yes, possibly
3. No, probably not
4. No, definitely not
5. Don't know
6. Refused

ALL 249 How often have you visited someone in your neighbourhood in the past week? (READ OPTIONS 1-4)
1. Frequently
2. A few times
3. At least once
4. Never (in the last week)
5. Don't know
6. Refused

ALL 250 When you go shopping in your local area how often are you likely to run into friends and acquaintances? (READ OPTIONS 1-4)
1. Nearly always
2. Most of the time
3. Some of the time
4. Rarely or never
5. Don't know
6. Refused

ALL 251 Would you be sad if you had to leave this neighbourhood?
1. Yes
2. No
3. Don't know
4. Refused

4-12 252 Where does [child] play when not at school or in day care? (MULTIPLE RESPONSE)
1. Inside house
2. Back yard

3. In street

4. Neighbour's house

5. In park

6. In school grounds

7. Community centre

8. Other (Specify)

9. Don't know

10.Refused

4-12 253 What is [child]'s favourite activity when not at school or in day care? (MULTIPLE RESPONSE)

1. Play with toys at home

2. Swimming at beach

3. Swimming at pool

4. Swimming at home

5. Organised sports (cricket, tennis, netball, football.)

6. Informal sports (with friends)

7. Bike riding

8. Rollerblading

9. Playing in Park

10. Visit friends or have friends over

11. Watching TV

12. Watching videos

13. Computer and video games

14.Reading

15.Listening to music

16. Attend lessons (specify: swimming, music, dance, other)

17. Go to movies

18.Dancing

19. Drawing or colouring-in

20.Playing outside or in backyard

21. Other (specify)

\section{Injury-Drowning (0-12 years)}

ALL 254 The next questions are about water safety and drowning.

ALL 255 Was there ever an occasion when [child] had to be rescued from drowning from any body of water, for example from a beach, river, bath, bucket, pond or wading pool?

1. Yes

2. No $\rightarrow \mathrm{Q} 257$

3. Don't know $\rightarrow \mathrm{Q} 257$

4. Refused $\rightarrow$ Q257

ALL 256 From which places was [child] rescued from drowning? (MULTIPLE RESPONSE)
1. Beach
2. Off a boat
3. River 

4. Lake
5. Fish pond
6. Farm dam
7. Bath
8. Swimming pool
9. Wading pool
10. Bucket
11. Any other places (Specify)

\section{Don't know \\ 13. Refused}

\section{Injury-Sports (age 5-12 years)}

5-12Y 257 The next few questions are about sports and sporting injuries

5-12Y 258 Does [child] ever play any type of sport or outdoor physical activity, including nonteam sports such as rollerblading, bike riding and skate boarding?
1. Yes
2. No $\rightarrow \mathrm{Q} 262$
3. Don't know $\rightarrow \mathrm{Q} 262$
4. Refused $\rightarrow$ Q262

5-12Y 259 In the past 12 months, that is since [month] 2000, what types of sports and outdoor activities did [child] play. Please tell me which sports [he/she] plays most often, including non team sports such as rollerblading.

\section{(MULTIPLE RESPONSE)}

1. Australian Rules football

2. Baseball or softball

3. Basketball

4. Cricket

5. Hockey

6. Netball

7. Rugby League

8. Rugby Union

9. Soccer

10.Swimming

11. Rollerblading

12. Bike riding

13. Tennis

14. Other (Specify)

\section{Don't know}

16. Refused

5-12Y 260 Have you ever prevented or discouraged [child] from playing a particular sport or physical activity because you were concerned about injury or safety?

1. Yes

2. No $\rightarrow \mathrm{Q} 262$

3. Don't know $\rightarrow \mathrm{Q} 262$
4. Refused $\rightarrow$ Q262

5-12Y 261 Which sport did you prevent your child from playing because of injury or safety concerns?

1. Australian Rules football

2. Baseball or softball

3. Basketball

4. Cricket

5. Hockey

6. Netball

7. Rugby League

8. Rugby Union

9. Soccer

10. Swimming

11.Rollerblading

12. Other (Specify)

13.Don't know

14. Refused

\section{Physical activity (5-12 years)}

5-12Y 262 The next few questions are about physical activity and watching television.

5-12Y 262a On about how many days during the school week, does [child] usually watch $\mathrm{TV}$ or videos at home?

1. days

2. None $\rightarrow$ Q264

3. No TV-video in home $\rightarrow$ Q266

4. Don't know $\rightarrow$ Q264

5. Refusal $\rightarrow$ Q264

5-12Y 263 On those days, about how many hours does [he/she] usually spend watching TV or videos?

(PROMPT: that is, how many hours on a typical weekday when TV is watched)

1. hours

2. Don't know

3. Refused

5-12Y 264 On about how many weekend days does [child] usually watch TV or videos at home?

1. ____days

2. None $\rightarrow$ Q266

3. Don't know $\rightarrow$ Q266

4. Refusal $\rightarrow$ Q266

5-12Y 265 On a typical weekend day, about how many hours does [he/she] usually spend watching TV or videos?

1. ____ hours

2. Don't know

3. Refused 
5-12Y 266 On about how many days during the school week does [child] usually play video or computer games?
1. ____days
2. None $\rightarrow$ Q268
3. No video-computer games $\rightarrow$ Q270
4. Don't know $\rightarrow$ Q270
5. Refusal $\rightarrow$ Q268

5-12Y 267 On those days, about how many hours does he/she usually spend playing video or computer games?

(PROMPT: that is, how many hours on a typical weekday when video-computer games are played)
1. H__ Hours
2. Don't know
3. Refused

5-12Y 268 On about how many weekend days does [child] usually play video or computer games?
$1 . \quad$ Days
2. None $\rightarrow$ Q270
3. Don't know $\rightarrow \mathrm{Q} 270$
4. Refusal $\rightarrow \mathrm{Q} 270$

5-12Y 269 On a typical weekend day, about how many hours does [he/she] usually spend playing video or computer games?
1. Hours
2. Don't know
3. Refused

0-4 Y 270 The next few questions are about [child's] interests and activities

0-4Y 270aDoes [he/she] currently attend any play group or other early childhood program or activity? Please do not include child care programs or time spent in preschool.
1. Yes
2. $\mathrm{No} \rightarrow \mathrm{Q} 273$
3. Don't Know $\rightarrow$ Q273
4. Refused $\rightarrow$ Q273

0-4Y 271 What type(s) of programs does [he/she] attend?
1. Play group
2. Drop-in centre
3. Toy library
4. Infant stimulation program
5. Gymbaroo
6. Story time at library
7. Other (Specify)

0-4Y 272 For about how many hours a week does [he/she] attend these in total? hours
4-12Y 273 In the past 12 months, outside of school hours, how often has [child] taken part in sports with a coach or instructor, except dance or gymnastics?

(READ OPTIONS 1-5)
1. Most days
2. A few times a week
3. About once a week
4. About once a month
5. Less than once a month

4-12Y 274 In the past 12 months, outside of school hours, how often has [child] taken lessons or instruction in other organised physical activities with a coach or instructor, such as dance, gymnastics or martial arts?

(READ OPTIONS 1-5)
1. Most days
2. A few times a week
3. About once a week
4. About once a month
5. Almost never

4-12Y 275 In the past 12 months, outside of school hours, how often has [child] taken lessons or instruction in music, art or other nonsport activities?

(READ OPTIONS 1-5)
1. Most days
2. A few times a week
3. About once a week
4. About once a month
5. Almost never

4-12Y 276 In the past 12 months, outside of school hours, has [child] taken part in any clubs, groups, or community programs with leadership, such as Girl Guides, Scouts, or church group?

(READ OPTIONS 1-4)
1. Yes
2. No
3. Don't know
4. Refused

\section{School attendance (age 4-12 years)}

4-12Y 277 The next few questions are about school attendance.

4-12Y 277aDoes [child] go to school?

1. Yes

2. $\mathrm{No} \rightarrow \mathrm{Q} 280$

3. Don't know $\rightarrow \mathrm{Q} 280$

4. Refused $\rightarrow$ Q280

4-12Y 278 What year is [child] in at school?

1. Kindergarten

2. Year 

3. Ungraded class
4. Don't know
5. Refused

4-12Y 279 What type of school does [child] currently attend?

(READ OPTIONS 1-6)

1. Public school

2. Catholic school

3. Independent school

4. Special education school

5. School of the Air

6. Any other school (Specify)

7. Don't know

8. Refusal

\section{Pre-school (age 3-6 years)-Skip this section if child attends school}

3-6Y 280 The next questions are about preschool.

3-6Y 281 Has [child] ever attended preschool? (PROMPT: preschool is usually attended between 9am and $3 \mathrm{pm}$ at least once a week before a child starts full-time school)
1. Yes
2. $\mathrm{No} \rightarrow \mathrm{Q} 285$
3. Don't know $\rightarrow \mathrm{Q} 285$
4. Refused $\rightarrow$ Q285

3-6Y 282 Is [child] currently attending preschool?
1. Yes
2. No
3. Don't know
4. Refused

3-6Y 283 How old was [child] when [he/she] first attended preschool?
1. years and months
2. Don't know
3. Refused

3-6Y 284 In total, how many hours per week does [child] usually attend preschool?
1. Hours
2. Don't know
3. Refused

\section{Child care (age 0-5)-Skip this section if child attends school}

0-5Y 285 The next few questions are about childcare. This includes formal childcare such as long day care centres or family day care and informal care such as care provided by relatives or paid babysitters or nannies.
0-5Y 286 Have you ever used any formal or informal childcare for [child] on a regular basis?

(PROMPT: formal childcare includes long day centres and family day care. Informal child care includes care by relatives or friends or paid babysitters or nannies) (PROMPT: regular basis means at least half a day a week)

1. Yes

2. No $\rightarrow$ Q291

3. Don't know $\rightarrow$ Q291

4. Refusal $\rightarrow$ Q291

0-5Y 287 Is [child] currently having any type of formal or informal childcare on a regular basis?

1. Yes

2. No

3. Don't know $\rightarrow$ Q291

4. Refused $\rightarrow$ Q291

0-5Y 288 How old was [child] when [he/she] first started formal or informal childcare for half a day or longer

1. Age in years___ and months

2. Don't know

3. Refused

If $287=2 \mathrm{ASK}$

0-5Y 289 How old was [child] when [he/she] stopped childcare?

1. Age in years____ and months

2. Don't know

3. Refused

0-5Y 290 What type of childcare [did/does] [child] have?

(READ OPTIONS 1-6: MULTIPLE RESPONSE)

1. Long day care centre

2. Family day care (usually organised through local councils)

3. Home based care

4. Occasional care centre

5. Other formal care (Specify)

6. Informal care (Specify)

7. Don't know

8. Refused

\section{Smoking (0-12 years)}

ALL 291 The following questions are about tobacco smoking. This includes cigarettes, cigars and pipes. 
ALL 292 Which of the following best describes your household?

(READ OPTIONS 1-4)

1. Myself and others in this household smoke

2. I smoke, but no one else does

3. I don't smoke, but others in the household do

4. No-one in the household smokes $\rightarrow$ Q295

5. Don't know $\rightarrow$ Q295

6. Refused $\rightarrow$ Q295

ALL 293 Do you or the other smokers living in this household ...

(READ OPTIONS 1-5)

1. Always smoke inside

2. Usually smoke inside

3. Sometimes smoke inside and sometimes smoke outside

4. Usually smoke outside

5. Always smoke outside $\rightarrow$ Q295

6. Don't know $\rightarrow$ Q295

7. Refused $\rightarrow$ Q295

ALL 294 How many cigarettes would you estimate are smoked inside your home each day? (PROMPT: Smoked by all smokers inside the home)

1. ___ number of cigarettes

2. Don't know

3. Refused

8-12Y 295 Have you ever clearly told [child] not to smoke or forbidden [him/her] from smoking?
1. Yes
2. No
3. Don't know
4. Refused

\section{Smoking in pregnancy (asked only to mother of child aged $<1$ year)}

0-11M 296 Have you ever smoked cigarettes, cigars, pipes or other tobacco products?
1. Yes
2. No $\rightarrow$ Q303
3. Don't know $\rightarrow \mathrm{Q} 303$
4. Refused $\rightarrow$ Q303

0-11M 297 Have you ever smoked more than 100 cigarettes cigars, pipes or other tobacco products?

1. Yes (more than 100)

2. Yes, (less than 100) $\rightarrow$ Q303

3. $\mathrm{No} \rightarrow \mathrm{Q} 303$

4. Don't know $\rightarrow \mathrm{Q} 303$

\section{Refused $\rightarrow$ Q303}

0-11M 298 When you were pregnant with [child], did you ever smoke cigarettes, cigars, pipes or other tobacco products?

(PROMPT: includes smoking before knowing that you were pregnant)
5. Yes
6. $\mathrm{No} \rightarrow \mathrm{Q} 303$
7. Don't know $\rightarrow$ Q303
8. Refused $\rightarrow \mathrm{Q} 303$

0-11M 299 When you were pregnant with [child],did you :

(READ OPTIONS 1-3: MULTIPLE RESPONSE)

1. Reduce the amount of tobacco you smoked

2. Try and give up smoking but were unsuccessful

3. Successfully give up smoking $\rightarrow$ Q302

4. None of the above

5. Don't Know

6. Refused

0-11M 300 How often did you smoke cigarettes, cigars, pipes or other tobacco products, while you were pregnant with [child]? (READ OPTIONS 1-4)

1. Daily

2. At least weekly, not daily

3. Less often than weekly $\rightarrow$ Q303

4. Not at all $\rightarrow \mathrm{Q} 303$

5. Don't know $\rightarrow$ Q303

6. Refused $\rightarrow$ Q303

0-11M 301 When you were pregnant with [child], how many manufactured cigarettes did you usually smoke [per day/each week]?

1. ___ Cigarettes per day $\rightarrow$ Q303

2. ___ Cigarettes per week $\rightarrow$ Q303

3. Don't Know $\rightarrow$ Q303

4. Refused $\rightarrow$ Q303

0-11M 302 At what stage during your pregnancy did you quit smoking? Was it:

(READ OPTIONS 1-4)

1. The first 3 months

2. 4-6 months

3. 7-9 months

4. Don't Know

5. Refused

\section{Demographics}

ALL 303 Now we are coming to the last section of the survey which is some routine questions about [child]'s and your family 
background.

Remember that all your answers remain confidential.

ALL 304 Besides yourself, who else does [child] live with?

(NOTE: Do not enter respondent's relationship to child)

(MULTIPLE RESPONSE)
1. Mother
2. Father
3. Respondent's partner
4. Step-mother
5. Step-father
6. Grandparents
7. Brothers and sisters
8. Step brothers-sisters
9. Other relatives
10. Non-family members
11.No-one else besides respondent
12. Other (Specify)

\section{Refused}

ALL 305 IF NO FATHER IN HOUSEHOLD: Does [child] spend any time with [his/her] father?

(NOTE: If respondent is concerned about this question advise it is to see if we need to ask demographic questions about [CHILD'S] father; for example father's education can influence child health)

1. Yes

2. No $\rightarrow$ SKIP TO 307

3. Don't know $\rightarrow$ SKIP TO 307

4. Refused $\rightarrow$ SKIP TO 307

ALL 306 How much time does [CHILD] spend with [his/her] father?
1. ___ days per week
2. ___ weeks per month
3. ___ weeks per year
4. less than one week per year
5. Don't know
6. Refused

ALL 307 IF NO MOTHER IN HOUSEHOLD: Does [child] spend any time with [his/her] mother?

(NOTE: If respondent is concerned about this question advise it is to see if we need to ask demographic questions about [CHILD'S] mother; for example mother's education can influence child health)
1. Yes
2. No $\rightarrow 309$
3. Don't know $\rightarrow 309$

\section{Refused $\rightarrow 309$}

ALL 308 How much time does [CHILD] spend with his/her mother?
1. ___ days per week
2. ___ weeks per month
3. __ weeks per year
4. less than one week per year
5. Don't know
6. Refused

ALL 309 What country was [child] born in?
1. Australia
2. Other country
3. Don't know
4. Refused

ALL 310 What country was [child's] mother or stepmother [were you] born in?

1. Australia

2. Other country

3. Don't know

4. Refused

ALL 311 What country was [child's] father or stepfather [were you] born in?
1. Australia
2. Other country
3. Don't know
4. Refused

ALL 312 Is [child] of Aboriginal or Torres Strait Islander origin?

[PROBE if yes]

1. Aboriginal but not Torres Strait Islander

2. Torres Strait Islander but not Aboriginal origin

3. Aboriginal and Torres Strait Islander origin

4. Not Aboriginal or Torres Strait Islander origin $\rightarrow$ Q315

5. Don't know $\rightarrow \mathrm{Q} 315$

6. Refused $\rightarrow$ Q315

ALL 313 Is [child's] mother or stepmother [are you] of Aboriginal or Torres Strait Islander origin?

[PROBE if yes]

1. Aboriginal but not Torres Strait Islander

2. Torres Strait Islander but not Aboriginal origin

3. Aboriginal and Torres Strait Islander origin

4. Not Aboriginal or Torres Strait Islander origin

5. Don't know

6. Refused 
ALL 314 Is [child's] father or stepfather [are you] of Aboriginal or Torres Strait Islander origin?

[NOTE: probe if yes]

1. Aboriginal but not Torres Strait Islander

2. Torres Strait Islander but not Aboriginal origin

3. Aboriginal and Torres Strait Islander origin

4. Not Aboriginal or Torres Strait Islander origin

5. Don't know

6. Refused

ALL 315 What language do you usually speak at home?

1. Language (Specify)

2. Don't know

3. Refused

ALL 316 What is the highest level of education [child's] mother or stepmother has [you have] completed?

1. Never attended school

2. Completed primary school

3. Some high school

4. Completed School CertificateIntermediate- Year 10-4th Form

5. Completed HSC-Year 12-Leaving6th Form

6. TAFE Certificate or Diploma, including trade certificate

7. University, CAE or some other tertiary institute degree or higher

8. Other (Specify)

9. Some primary school (not completed)

10.Don't know

11.Refused

ALL 317 What is the highest level of education [child's] father or stepfather has [you have] completed?

1. Never attended school

2. Completed primary school

3. Some high school

4. Completed School CertificateIntermediate- Year 10-4th Form

5. Completed HSC-Year 12-Leaving6th Form

6. TAFE Certificate or Diploma, including trade certificate

7. University, CAE or some other tertiary institute degree or higher

8. Other (Specify)

9. Some primary school (not completed)

10.Don't know

\section{Refused}

ALL 318 How would you describe [child's] mother's or stepmother's [your] current employment status?

(NOTE: If more that one code applies, code the one with the lowest number: if casually employed use code 9)

(READ OPTIONS 1-8)

1. Employed full-time (include selfemployed)

2. Employed part-time (include selfemployed)

3. Unemployed $\rightarrow 320$

4. Home Duties $\rightarrow 320$

5. Student and working

6. Student and not working

7. Retired $\rightarrow 320$

8. Unable to work due to health problems

9. Other (Specify) $\rightarrow 320$

10. Don't know $\rightarrow 320$

11. Refused $\rightarrow 320$

ALL 319 How many hours does [child's] mother or stepmother [do you] usually work or study, away from home, each week?

1.

2. Don't know

3. Refused

ALL 320 How would you describe [child's] father's -stepfather's [your] current employment status?

(NOTE: If more that one code applies, code the one with the lowest number: if casually employed use code 9)

(READ OPTIONS 1-8)

1. Employed full-time (include selfemployed)

2. Employed part-time (include selfemployed)

3. Unemployed $\rightarrow 322$

4. Home Duties $\rightarrow 322$

5. Student and working

6. Student and not working

7. Retired $\rightarrow 322$

8. Unable to work due to health problems $\rightarrow 322$

9. Other (Specify) $\rightarrow 322$

10. Don't know $\rightarrow 322$

11. Refused $\rightarrow 322$

ALL 321 How many hours do you/does [child's] father or stepfather usually work or study, away from home, each week?

1.___ hours per week

2. Don't know

3. Refused 
ALL 322 [Do you/does child's parents] receive any of the following benefits? (READ OPTIONS 1-8: MULTIPLE RESPONSE)

(NOTE: do not include back to school payment)

1. Disability Support

2. Unemployment benefits or Job Search Allowance

3. Sickness Benefits or Allowance

4. Parenting payment

5. Family allowance

6. Age pension

7. Repatriation Pension or Service Pension

8. Other type of benefit (Specify)

9. Don't know

10. Refused

ALL 323 How long have you lived in your local area?

1. ___years

2. Don't know

3. Refused

ALL 324 What locality or suburb do you live in?

1. locality or suburb

2. Don't know

3. Refused

ALL 325 Could you tell me your postcode?

1.

2. Don't know

3. Refused
ALL 326 What is the name of your local Council or Shire?

1. Council

2. Don't know

3. Refused

ALL 327 Is your telephone number listed in the White Pages?

1. Yes

2. No

3. Don't know

4. Refused

ALL 328 How many residential telephone numbers do you have? Do not include mobile phone numbers or dedicated fax numbers.

1. ___ number of residential phone numbers

2. Don't know

3. Refused

ALL 329 Finally, a percentage of respondents are contacted by our survey supervisor to ensure the survey was conducted in a professional manner. Are you willing for a supervisor to contact you at a later stage?

1. Yes

2. No

3. Refused

4. Don't know

ALLEND That ends our questionnaire. Thank you for taking the time to complete this questionnaire. The information will be used to help improve health services for children in your local area and across the state. Thanks once again. Goodbye. 